\title{
How (not) to injure the preterm lung
}

Citation for published version (APA):

Hütten, M. C. (2016). How (not) to injure the preterm lung: new ideas for improving transition in a preterm animal model. [Doctoral Thesis, Maastricht University]. Datawyse / Universitaire Pers Maastricht. https://doi.org/10.26481/dis.20161220mh

Document status and date:

Published: 01/01/2016

DOI:

10.26481/dis.20161220mh

Document Version:

Publisher's PDF, also known as Version of record

\section{Please check the document version of this publication:}

- A submitted manuscript is the version of the article upon submission and before peer-review. There can be important differences between the submitted version and the official published version of record.

People interested in the research are advised to contact the author for the final version of the publication, or visit the DOI to the publisher's website.

- The final author version and the galley proof are versions of the publication after peer review.

- The final published version features the final layout of the paper including the volume, issue and page numbers.

Link to publication

\footnotetext{
General rights rights.

- You may freely distribute the URL identifying the publication in the public portal. please follow below link for the End User Agreement:

www.umlib.nl/taverne-license

Take down policy

If you believe that this document breaches copyright please contact us at:

repository@maastrichtuniversity.nl

providing details and we will investigate your claim.
}

Copyright and moral rights for the publications made accessible in the public portal are retained by the authors and/or other copyright owners and it is a condition of accessing publications that users recognise and abide by the legal requirements associated with these

- Users may download and print one copy of any publication from the public portal for the purpose of private study or research.

- You may not further distribute the material or use it for any profit-making activity or commercial gain

If the publication is distributed under the terms of Article $25 \mathrm{fa}$ of the Dutch Copyright Act, indicated by the "Taverne" license above, 


\section{Matthias Hütten}

\section{HOW (NOT) TO INJURE THE PRETERM LUNG}

New ideas for improving transition in a preterm animal model

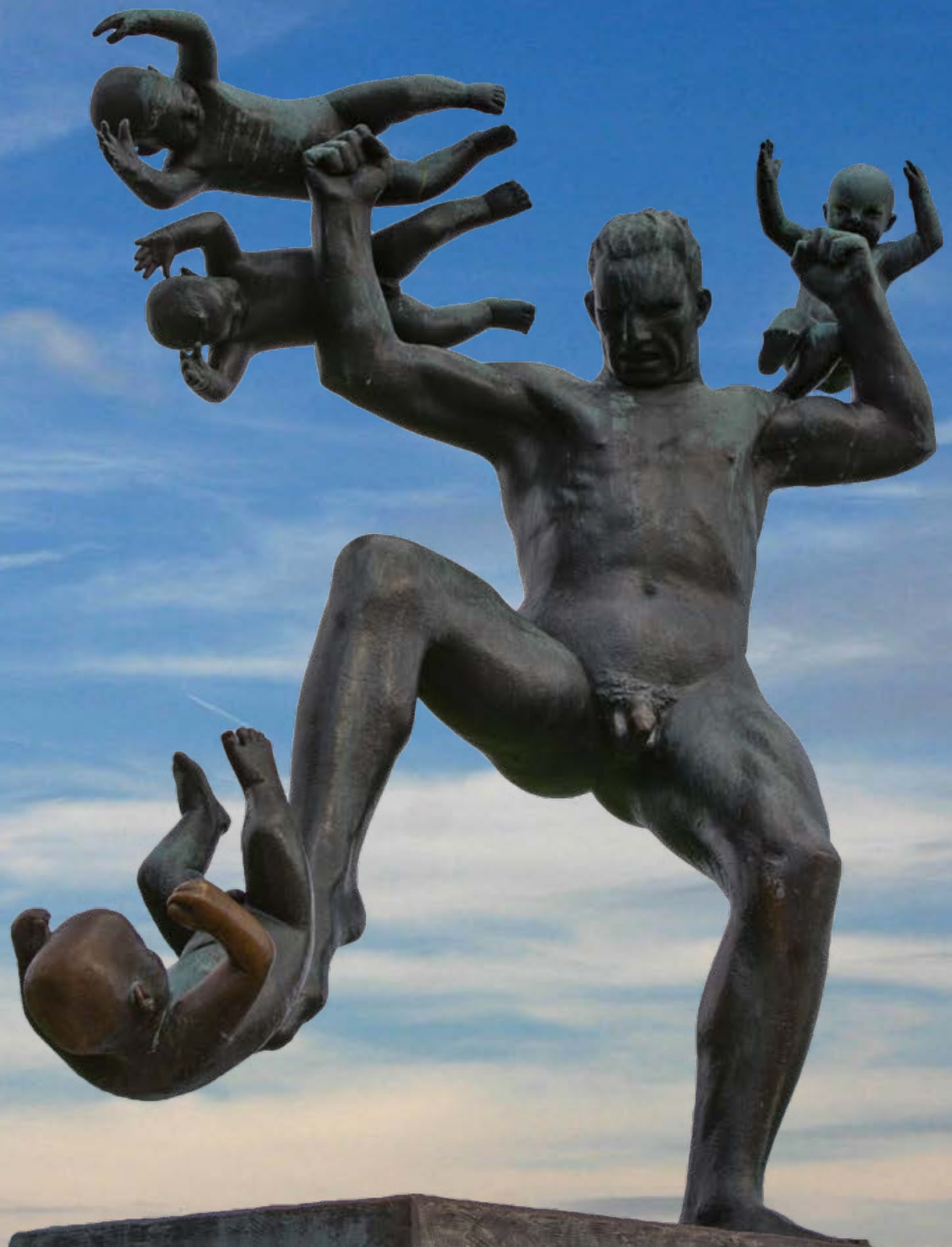


(C) Copyright Matthias Christian Hütten, 2016

ISBN 9789461596338

Production Datawyse | Universitaire Pers Maastricht

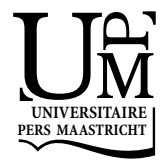

Cover photos: Ira Hütten 2016, Vigeland Parken Oslo, Norway 


\title{
HOW (NOT) TO INJURE THE PRETERM LUNG
}

- new ideas for improving transition in a preterm animal model

\author{
DISSERTATION
}

to obtain the degree of Doctor at Maastricht University, on the authority of the Rector Magnificus, Prof. dr. Rianne M. Letschert in accordance with the decision of the Board of Deans,

to be defended in public

on Tuesday $20^{\text {th }}$ December 2016, at 12.00 hours

by

Matthias Christian Hütten 


\section{Promotors}

Prof. dr. Boris W. Kramer

Univ.-Prof. Dr. med. Thorsten Orlikowsky (RWTH Aachen, Germany)

Prof. Dr. med. Steffen Kunzmann (Universität Würzburg, Germany)

\section{Copromotor}

Dr. Tim G.A.M. Wolfs

\section{Assessment commitee}

Prof. dr. Luc J.I. Zimmermann (chairman)

Prof. dr. Sidarto Bambang Oetomo (Eindhoven University of Technology)

Univ.-Prof. Dr. med. Christoph Bührer (Charité Universitätsmedizin Berlin, Germany)

Prof. dr. Edward Dompeling

Prof. dr. Marc E.A. Spaanderman 


\section{Table of contents}

Chapter 1 General introduction

Chapter 2 Nebulization of Poractant alfa via a vibrating membrane nebulizer in spontaneously breathing preterm lambs with binasal continuous positive pressure ventilation

Chapter 3 Fully automated predictive intelligent control of oxygenation (PRICO) in resuscitation and ventilation of preterm lambs

Chapter 4 Amplification of steroid-mediated SP-B expression by physiological levels of caffeine

Chapter 5 Short term effects of endotracheally vs. intravenously administered nano-encapsuled, water-soluble vitamin A in preterm lambs

Chapter 6 Discussion

Chapter 7 Summaries 103

Nederlandse samenvatting 105

English summary

Deutsche Zusammenfassung

Appendix

Valorization

Acknowledgements

Curriculum vitae

Publications

125 



\section{Chapter}

\section{General introduction}

Based in parts on Hutten, M. C. and Kramer, B. W. (2014): "Patterns and etiology of acute and chronic lung injury: insights from experimental evidence." Chinese Journal of Contemporary Pediatrics 16(5): 448-459 [1] 



\section{PRETERM BIRTH}

Preterm birth is defined as birth before 37 weeks of gestation [2]. Until today, preterm birth is the major cause of perinatal mortality, contributing to 3 out of 4 perinatal deaths in the Western world [2]. Worldwide, the overall rate of preterm birth is rising [2]. In the U.S., nearly every $8^{\text {th }}$ child is born prematurely [2], and the increase of preterm birth rate between 1981 and 2002 was 31\% [3]. In 2013, worldwide approximately 965,000 infants died because of complications related to preterm birth [4], which makes preterm birth the most important single cause for mortality in the neonatal period [4]. Survival of very preterm births increases with increasing gestational age (GA) and this effect has been shown in different geographically defined cohorts [5]. This effect is most impressive in children born very prematurely, i.e. before 28 weeks, in whom survival has dramatically increased between the 1970s and the 1990s [6]. This increase can mainly be attributed to therapeutic interventions supporting lung function of these very immature children [6], such as antenatal maternal steroids and postnatal exogenous surfactant administration.

Adequate pulmonary function is necessary for gas exchange and is a prerequisite for survival of preterm infants. However, the structural and functional immaturity of the preterm lung causes neonatal respiratory distress syndrome (RDS). In addition, the preterm lung is susceptible to injury resulting from prenatal insults, from interventions during transition at birth and from postnatal procedures and insults (Figure 1) [1]. Although postnatal therapeutic interventions are necessary to establish and maintain pulmonary function, these early alterations may also interfere with lung development, and therefore exert lasting effects on pulmonary plasticity and integrity, finally resulting in structural and functional impairment, persistent lung injury, and chronic lung disease of preterm children, bronchopulmonary dysplasia (BPD). Survivors of prematurity have per se a higher risk for long-term impairment of lung function pulmonary morbidities like asthma, and this risk is markedly pronounced in preterm infants diagnosed with BPD [7]. Lung function impairment of former very low birth weight infants with BPD can be found until adulthood [8].

\section{RESPIRATORY DISTRESS SYNDROME (RDS)}

RDS is the most common diagnosis when prematurely born infants are admitted to the neonatal intensive care (NICU) [9]. The mortality of RDS in preterm infants was historically very high. Data from an Australian level III perinatal center showed a $42.4 \%$ mortality from respiratory causes in very preterm infants born between 23-27 weeks gestational age in 1983-90, which decreased to $17.0 \%$ in 1992-96 [10]. However, in low resource settings, incidence of RDS in infants born prematurely is still reported in up to $78 \%$ of children admitted, and death from RDS is reported to be as high as $52 \%$ [11]. 


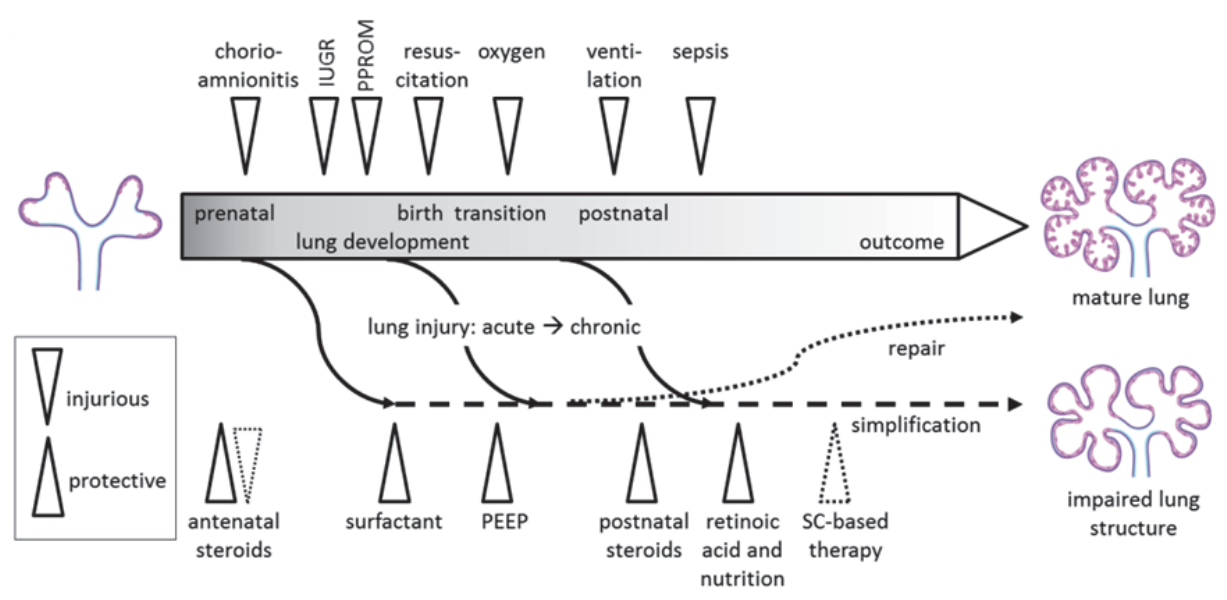

Figure 1: Mechanisms of lung injury and protection from lung injury during prenatal and postnatal development.

Dotted arrows indicate that concept of injurious or protective effect has only recently been introduced and is not yet widely accepted. IUGR: intrauterine growth restriction; PPROM: preterm prelabour rupture of membranes; SC: stem cells; PEEP: positive end expiratory pressure. From [1]

Clinically, affected infants show signs of thoracic retraction, dyspnoea, tachypnoea, and a need of supplemental oxygen. Pathophysiologically, RDS results from both morphological and functional immaturity of the lung. The lungs of infants born very immaturely are in the histologic period when lung development proceeds from the canalicular stage (16-27 weeks gestational age) to the saccular stage (24-36 weeks) [12]. At this stage, gas exchange via the lung is possible in the alveolar sacs, although the development into the final mature lung structure, the alveoli, only starts at about 36 weeks. The influence of the developmental stage can be seen clinically, with up to $93 \%$ of infants born between 22 and 28 weeks gestational age are diagnosed with RDS [9]. Functionally, at this early gestation, alveolar type 2 cells commence the production of surfactant. Surfactant is a surface active agent lining the pulmonary alveoli. Surfactant lowers surface tension mainly by its high contents of phosphatidylcholins [13]. Lower surface tension results in increased lung compliance by keeping the alveolar structures open and protecting them from collapse and atelectasis. As a result, lack of adequate endogenous surfactant production results in impaired ventilation of the lung, which has first been described in 1959 [14]. Therefore, major cornerstones in neonatology and therapy of preterm infants are linked to the treatment of RDS. Three major inventions have been introduced already in the 1970s, continuously improved since then and developed into standard treatments in the NICU. First, an important discovery was the prenatal induction of lung maturation by antenatal maternal corticosteroid treatment [15]. Antenatal maternal corticosteroid therapy accelerates fetal lung maturation [16], and supports endogenous surfactant production [17]. Maternal glucocorticosteroids are the gold standard treatment when premature delivery 
is expected [18]. However, the best preparation and dosing regime is still discussed [19]. Second, the development of animal-derived surfactant preparations allowed for widespread use of surfactant replacement therapy [20]. Postnatal replacement of surfactant by endotracheal administration of surfactant preparations [21] improves pulmonary outcome, gas exchange and survival of preterm infants [22-24]. In clinical studies, surfactant replacement therapy proved to be efficient in the prevention [25] and in the therapy of neonatal RDS [26]. In most instances surfactant is delivered to the lung of intubated and mechanically ventilated babies as a bolus via an endotracheal tube, which is common practice in neonatology [27]. Third, the possibility of postnatal mechanical ventilation and especially the improvement of ventilatory support by continuous positive pressure ventilation (CPAP) $[28,29]$ contributed impressively to the reduced mortality of preterm infants [30]. CPAP is also feasible to reduce the need for intubation and helps to avoid mechanical ventilation, which could be shown in very low birth weight infants [31].

Although these major improvements have been made in the 1970s, there still is ongoing research on improvement of RDS therapy, and on further development of these long known concepts. Until today, mortality of infants born very prematurely is constantly decreasing, as shown by data from the National Institute of Child Health and Human Development (NICHD) Neonatal Research Network (NRN) [32]. From 2009 through 2012, this effect was most pronounced in infants born very prematurely, i.e. infants born at 23 weeks (survival 27\% to 33\%), 24 weeks (63\% to 65\%) and 25 weeks (79-81\%) [32]. This might also be a result of constant improvement of neonatal therapy. New approaches are made by improving surfactant preparations which are made more resistant to inactivation [33], or by combining different beneficial therapies, e.g. surfactant replacement therapy and CPAP [34-36]. These "gentler", less invasive procedures are also developed as a result of the growing evidence for potential negative long term effects of invasive therapy on the developing lung.

\section{LUNG INJURY AND BRONCHOPULMONARY DYSPLASIA}

Bronchopulmonary dysplasia (BPD) frequently complicates preterm birth. The term BPD was first used by Northway and al in 1967 to describe a chronic lung disease of preterm infants [37]. This so called "old BPD" was associated with the exposure against mechanical ventilation and oxygen. Autoptic studies of infants who died of BPD showed prominent airway injury and parenchymal fibrosis in lung histology.

However, infants diagnosed with this form of BPD were more mature than infants diagnosed with BPD today (Table 2). In 1999, the term "new BPD" was coined by Alan Jobe [38]. Infants suffering from "new BPD" were born at a more immature gestational age, and showed a secondary increase in need for supplemental oxygen after an initial postnatal phase with little pulmonary complications [39]. In contrast, by that time BPD became infrequent in infants born at $>30$ weeks gestational age and with more than 
1200 g birth weight [39]. The "new BPD" develops in the context of multiple injurious and pro-inflammatory stimuli. It is histologically characterized by decreased septation and impaired forming of alveoli rather than fibrotic remodelling of the lung [38] (Table 2). However, oxygen toxicity and mechanical ventilation still play a role. In animal experiments, negative effects of oxygen or mechanical ventilation on the preterm lung, resulting in interference with septation of alveolar and vascular lung development, could be confirmed, and where associated with elevated pro-inflammatory cytokines and white blood cell counts [40].

In summary, structural and functional immaturity of the lung is a key factor in the development of BPD. This is supported by the findings that the risk of BPD is inversely related to GA at birth, which has been shown in the NICHD NRN cohort [9]. The reported incidence is between $16-42 \%$ in different cohorts, making BPD the major chronic morbidity in infants born very preterm $[9,41]$.

However, ranges in reported incidence partly depend on differences in definition. BPD was originally defined as need for supplemental oxygen at 28 days postnatal age, persisting clinical pulmonary impairment, and characteristic pathologies on thorax X-ray [42]. Newer definitions are based on physiological parameters. Walsh et al. defined BPD as need for supplemental oxygen at 36 weeks postmenstrual age, and added a severity score (mild, moderate, severe) based on a room air test $[43,44]$. However, different definitions make it difficult to compare studies. In the VLBW cohort of the NICHD NRN, the diagnosis of BPD was made in $42 \%$ of children born between 22-28 weeks gestational age when using the definition supplemental oxygen at 36 weeks, but in $68 \%$ when including children with need for supplemental oxygen for at least 28 days [9]. Recent data of this cohort suggests that the incidence of BPD increased from 2009 through 2012 in infants born at 26 and 27 weeks, and in all infants born $<28$ weeks of gestation in the 8 centers participating in the NRN all 20 years [32].

Table 2: Characteristics of "old" vs. "new" BPD. Modified from [45]

\begin{tabular}{lll}
\hline & "old" BPD [37] & "new" BPD [39] \\
\hline gestational age & 32 weeks & $\begin{array}{l}24-26 \text { weeks, risk inversely related to } \\
\text { gestational age }\end{array}$ \\
birth weight (average) & $1900 \mathrm{~g}$ & $600 \mathrm{~g}$ \\
major causes & long-term exposure against & $\begin{array}{l}\text { exposure against a multitude of } \\
\text { proinflammatory stimuli, inflammation, }\end{array}$ \\
& mechanical ventilation and oxygen & $\begin{array}{l}\text { ventilation and oxidative stress } \\
\text { interfering with development }\end{array}$ \\
airway injury & severe & mild to none \\
fibrosis & severe & minimal \\
alveolarization & well developed & arrested development, decreased \\
& & septation \\
follow up & $>20$ years & $<20$ years \\
\hline
\end{tabular}


Although it is unclear whether this effect results e.g. from increased survival of very preterm infants, this increase highlights the need for useful therapies which are still limited $[46,47]$. However, in the context of a multifactorial genesis, possible targets for BPD therapy can be

(1) REDUCTION of lung injury by OPTIMIZING delivery room interventions and avoiding ventilation,

(2) ACCELERATION of endogenous mechanisms of lung development in a synergistic fashion, and

(3) provision of factors necessary for pulmonary REGENERATION from lung injury.

These possible modes of action will be introduced in the following and will be further targeted in the subsequent chapters of this thesis.

\section{REDUCTION OF VENTILATION-RELATED LUNG INJURY - THE ROLE OF ANIMAL MODELS}

As explained above, various postnatal insults contribute to lung inflammation and injury, including mechanical ventilation-induced trauma from volume and pressure changes, extension of the tissue and oxygen toxicity. Awareness of these therapy-associated damages grew amongst others from animal experiments, and resulted in adjustment of ventilation strategies. One of the best established animal models for the investigation of injuries of the preterm lung related to ventilation therapy is the preterm sheep model [48]. It allows a translational approach due to its physiologic similarities of lung development to the human situation (Figure 2) $[49,50]$. Furthermore, anatomy and body size allows the use of the original equipment used in the neonatal intensive care units.

This similarity makes it an ideal model to study perinatal resuscitation and the transition from intra- to extra-uterine life. Different modes of perinatal resuscitation common in clinical management of preterm infants have already been studied in preclinical animal models. A good example is the use of manual inflation of preterm babies ("bagging") before starting mechanical ventilation, which is a common procedure in the delivery room to "open" the liquid filled lung and to facilitate gas exchange. However, a study in preterm lambs revealed that the positive effect of surfactant replacement therapy was already compromised after six manual inflations directly after birth, depicted in decreased functional measurements and histologic signs of lung injury [51]. In order to maintain lung volume, positive end expiratory pressure (PEEP) was introduced in ventilation strategies, having an impact on both lung function and lung inflammation. In surfactant-treated preterm lambs, ventilation with PEEP improved lung function [52], maintained surfactant pool size and activity [52] and modulated the expression of proinflammatory mediators [53]. When postnatally mechanical ventilation was established 
with high tidal volumes for only $15 \mathrm{~min}$, this caused bronchial epithelial disruption in both large and small airways of preterm sheep [54]. Current ventilation strategies therefore aim to avoid mechanical ventilation in preterm infants by utilizing CPAP only with [36] or without [31] surfactant replacement. Results from animal experiments support this strategy: Prematurely delivered lambs treated with CPAP alone showed decreased levels of lung injury depicted by neutrophil counts in alveolar washes and reduced hydrogen peroxide in comparison to ventilated lambs [55]. In a baboon model of BPD, up to 28 days of nasal CPAP subsequent to 24 hours of mechanical ventilation did not result in arrested alveolar development in contrast to previously ventilated baboons [56]. The "gentle-ventilation" approach is increasingly taken with the preterm infant to avoid intubation with noninvasive ventilator support [56]. Although individual trials of aggressive early continuous positive airway pressure (CPAP) therapy versus intubation and ventilation in the delivery room did not result in a reduced rate of $\operatorname{BPD}[57,58]$, a recent meta-analysis suggested that increased early CPAP with reduced intubation and subsequent ventilation had a modest effect in reducing BPD or death, calculating a relative risk of 0.91 [59]. Another meta-analysis additionally included studies of the combination of CPAP with surfactant replacement, and found an even stronger effect on the reduction of BPD or death in CPAP-treated preterm infants (odds ratio 0.83) [60].

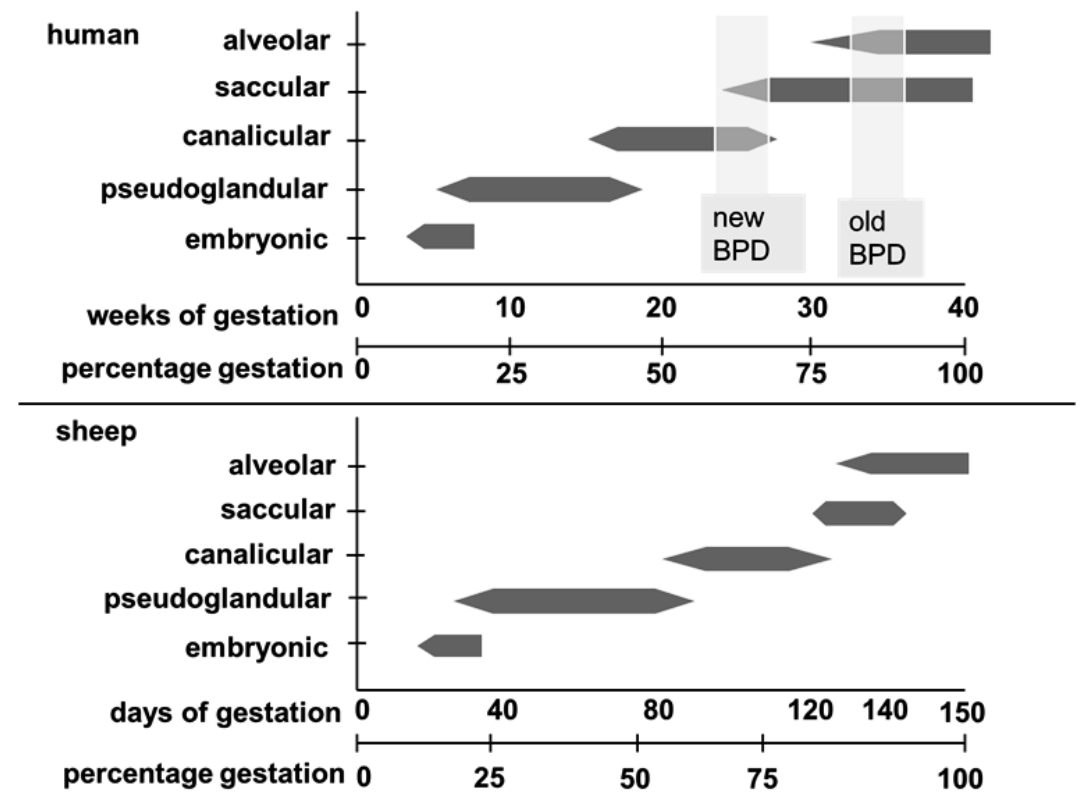

Figure 2: Lung alveolarization of different mammal species. Modified from [45].

This combined use of CPAP and surfactant replacement therapy was also tested in the preterm sheep model, proofing feasibility of the method and showing stability of 
physiological parameters during the procedure [34]. In the last years, less invasive surfactant administration (LISA) has been established as therapeutic option for RDS treatment $[35,61]$, also in extremely preterm infants $<27$ weeks gestational age [62]. LISA avoids mechanical ventilation [36], opens the lung homogenously [63], and improves pulmonary outcome of preterm infants born $<27$ weeks gestational age [64]. In an editorial regarding the cited article by van den Burg et al., Jobe stated that "in practice, the clinician simply needs to get the surfactant into the proximal airways, and the combination of the surface properties of the surfactant and a spontaneously breathing infant will finish the job" [65]. However, visualizing the vocal cords and subsequently placing a thin catheter in the trachea of a conscious child, as done during the LISA procedure, needs training and skilled personnel. An alternative way of administration, e.g. the combination of CPAP with nebulized surfactant, is therefore a promising, but not yet established approach.

\section{OPTIMIZING OXYGEN THERAPY}

Ventilation and respiratory support of the preterm infant are usually combined with oxygen supplementation. Supplemental oxygen reduces hypoxia in preterm infants. However, oxygen is a drug with large potential side effects, and a close relationship between oxygen supplementation and the development or exacerbation of BPD was noted $[66,67]$. Growing evidence suggests that reactive oxygen species interact with cell growth and development [68]. This cumulated in the hypothesis of an oxygen radical disease (ORD) of neonatology as one disease with various conditions such as BPD, necrotizing enterocolitis (NEC), retinopathy of prematurity (ROP) and periventricular leucomalacia (PVL) [68]. Although a common entity of these conditions has not been proven so far, clinical and experimental studies indicate that oxidative stress in the first days of life is involved in the development of BPD [68], partially because preterm infants have lower anti-oxidative capacity [69].

The interaction between oxygen and lung injury is complex. In a mouse model, neonatal hyperoxia resulted in histological signs of lung injury and decreased lung function [70]. Concomitantly, levels of mRNA of proinflammatory cytokines like IL-1 $\alpha$ were increased in the lung [70]. In a rabbit model, hyperoxia enhanced inflammatory cytokine response of alveolar macrophages of preterm animals in contrast to term animals [71]. In this model, hyperoxia significantly increased intracellular oxygen radical content only in premature macrophages [71].

In the NICU, oxygen saturation measured by pulse oximetry $\left(\mathrm{SpO}_{2}\right)$ is commonly used to prevent oxygen over- and underexposure. However, defining desired target ranges is difficult, and in recent studies the target range of 91-95\% was associated with significantly higher ROP rates, while a target range of $85-89 \%$ was associated with a significant increase in mortality $[72,73]$. However, even oxygen overexposure as early 
as in the delivery room directly after birth might exert lasting consequences in preterm infants. When infants born at 24 to 28 weeks' gestation were randomly assigned to resuscitation in the delivery room with either $90 \%$ or $30 \%$ oxygen, the incidence of BPD at 36 weeks' gestation was reduced from $31.7 \%$ to $15.4 \%$ in the low oxygen group [74]. Early avoidance of oxygen overexposure is therefore a key interest of current delivery room research. Current recommendations advice resuscitation of preterm infants with a mixture of room air and oxygen, to use a fraction of inspired oxygen $\left(\mathrm{FiO}_{2}\right)$ between 0.21 and 0.30 [75], and to subsequently titrate $\mathrm{FiO}_{2}$ according to the infants oxygen saturation $\left(\mathrm{SpO}_{2}\right)$, measured by pulse oximetry. However, large deviations from predefined $\mathrm{SpO}_{2}$ targets during delivery room resuscitation have been reported [76], indicating the need for optimization of oxygen therapy directly after birth.

\section{ACCELERATION OF LUNG DEVELOPMENT BY STEROIDS AND SYNERGISTIC DRUGS}

The necessity of the above mentioned therapeutic interventions strongly depends on lung maturation at birth. Postnatal pulmonary adaptation of preterm infants can already be supported antenatally by administration of corticosteroids to the mother. As described before, fetal lung maturation can be accelerated by antenatal corticosteroid therapy of the mother [16], and antenatal steroid therapy is thought to be the most effective treatment for preterm children with respect to short- and long-term outcomes [77]. A recent review showed a clear association between antenatal steroid administration to woman at risk of preterm birth and a reduced risk of neonatal death (RR 0.69, 95\% Cl 0.58-0.81) and neonatal RDS (RR 0.66, 95\% Cl 0.59-0.73) [16].

One main mechanism of how this intervention works is the support of endogenous surfactant production [78]. Corticosteroids increase biosynthesis of main surfactant components, such as phosphatidylcholine and fatty acid biosynthesis, by both transcription and post-transcription mechanisms [79, 80]. In addition, corticosteroids have differential effects on surfactant proteins (SP). Human surfactant contains four proteins, surfactant protein (SP)-A, $-B,-C$, and $-D$. SP-B and SP-C are especially important for stability of the surfactant layer [81], and SP-B is the only surfactant protein being absolutely essential [82].

The lung maturing effects of corticosteroids have also been described for postnatal systemic steroid therapy, which was shown to reduce the incidence of BPD [83]. However, this intervention has been limited in the past by data from a meta-analysis suggesting that early postnatal steroid treatment is associated with a negative impact on neurodevelopment and is related to cerebral palsy [84]. The number of alternative pharmacological interventions to prevent lung injury is very limited [47]. In the search for other pharmacological interventions supporting postnatal lung development and function, methylxanthines like caffeine are interesting candidates. 
Originally, caffeine is administered to preterm infants to enhance respiratory drive, and have been shown to be effective for the treatment of apnoea of prematurity [85]. However, a recent clinical trial investigating the effect of early administration of caffeine to preterm infants on survival without major disabilities showed a reduced incidence of BPD from $47 \%$ to $36 \%$ in the treatment group [86]. Although this effect was mainly attributed to a shorter duration of mechanical ventilation in treated infants, there are plenty of underlying mechanisms which might contribute to the proposed beneficial effects of caffeine therapy in preterm infants at risk for BPD. Caffeine is known to modulate inflammatory responses, and the influence on cytokine levels of preterm infants is dependent on blood caffeine levels [87]. At higher plasma levels, methylxanthines also act as phosphodiesterase inhibitors promoting bronchodilation [88]. Eventually, positive effects of corticosteroids on surfactant protein $B$ expression have been demonstrated in vitro [89]. In this study, evidence for a synergistic upregulation of SP-B mRNA in type II pneumocytes by a combined treatment with corticosteroids and caffeine was provided. This effect was both associated with an upregulation of glucocorticoid receptor mRNA and an intracellular enrichment of CAMP. Caffeine alone only provided a slight effect on induction of SP-B mRNA. The interplay of pharmacological interventions in the context of lung maturation therefore needs to be further studied in vivo.

\section{REGENERATION FROM LUNG INJURY - VITAMIN A}

Beside corticosteroids and caffeine, several pharmacological interventions have been proposed for the treatment of BPD, but data on these interventions are limited [47]. Despite the more preventive action of the above mentioned interventions, regeneration of the injured preterm lung is a possible target for therapy. A promising substance involved in development and repair of respiratory epithelium is vitamin A [90, 91]. Vitamin $A$ is a term summarizing chemical compounds as retinol $(R O H)$, esters like retinyl palmitate (RP) and retinoic acid (RA), the biologically active form [92]. Experimental evidence suggests that retinoids induce the formation of alveoli [90], maintain alveolar forming ability under inhibiting conditions such as hyperoxia [91], and decreases lung fibrosis as shown in rats exposed to hyperoxia [93]. In ventilated premature baboons, retinoids increased lung elastin expression [94]. However, RA did not accelerate structural and functional maturation of the lung of preterm sheep when given antenatally, possibly because antenatal treatment did not alter lung levels of RA in treated animals compared to control animals [95].

In preterm infants, serum $\mathrm{ROH}$ levels are significantly lower compared to term babies $[96,97]$. Low blood $\mathrm{ROH}$ levels have been related to BPD [98]. Vitamin A supplementation reduces BPD defined by oxygen requirement at 36 weeks postmenstrual age, although the effect on the combined outcome of death or BPD was not significant in a meta-analysis of clinical trials [99]. However, a more recent retrospective mono-center 
study confirmed a trend towards a decrease in the incidence of BPD in extreme low birthweight infants after supplementation of vitamin A was included in standard pulmonary care [100]. Today, vitamin A supplementation is not widely used in clinical practice [101], and an important reason for this is that the necessary intramuscular injection is a painful procedure [102]. In contrast, oral application of high-doses of vitamin A did not show beneficial effects in a clinical trial [103], but clinical research in enteral vitamin A supplementation in preterm infants is ongoing [104]. A promising alternative route of vitamin $A$ supplementation is endotracheal administration. Experimentally, intratracheal administration of different vitamin A preparations was sufficient to supply it to target organs in vitamin A depleted rats [105]. Vitamin A administration targeting the preterm lung directly might therefore be a step towards regeneration of the injured lung.

\section{THESIS OUTLINE}

A multitude of treatment options for pulmonary have been developed in the last 5 decades. Despite continuous advances in the therapy of the immature infant, early interventions such as ventilation can promote injury of the preterm lung. Reduction of iatrogenic lung injury, support of pre- and postnatal lung development and regeneration of the injured lung are major aims to improve pulmonary outcome of preterm infants. Therefore, in this thesis, a pre-clinical lamb model of preterm respiratory distress and early lung development is used to improve early interventions with respect to the preterm lung. Innovative therapeutic interventions are tested which might help to REDUCE lung injury during delivery room management (chapter 2 and 3); supportive effects of pharmacological therapies on lung development are investigated in vivo (chapter 4); and new ways of administration of REGENERATIVE substances are tested (chapter 5 ).

In chapter 2 the hypothesis is tested that surfactant replacement therapy for the premature lung can be done by nebulisation during CPAP. The combination of noninvasive respiratory support with a less invasive approach of surfactant therapy is a major focus of current neonatal research [106]. Recent clinical studies however focused on surfactant bolus therapy via a catheter placed in the trachea [36, 61, 62]. We hypothesize that nebulization of surfactant with a new inhalation device specifically designed for the use in infants, would result in homogenous distribution of surfactant to the preterm lung and in improved lung function. We further investigate how effects of variables such as dose and air humidity could influence these effects.

In chapter 3 we investigate if oxygen supplementation in the delivery room during transition, surfactant replacement therapy and subsequent ventilation of preterm lambs can be improved by using an innovative automated $\mathrm{FiO}_{2}$ control device. Both hyperoxia and hypoxia can have detrimental effects on the preterm organism, and 
avoidance of oxygen under- and overexposure already in the first hours of life might help to prevent negative short- and long-consequences of oxygen toxicity [107].

In chapter 4 we investigate a possible pharmacological approach to increase lung maturation by induction of surfactant protein B. SP-B expression is important for the stability of the phospholipid layer formed by surfactant, and is therefore highly important for proper lung function in preterm infants. Caffeine, a drug regularly used in the NICU to prevent and treat apnoea of prematurity, has been shown earlier to have a synergistic up-regulatory effect on SP-B in vitro when high doses of caffeine are combined with glucocorticoids (GCS) [89]. We hypothesize that physiological levels of caffeine both in vitro and in vivo would have the same synergistic effect on GC-mediated SP-B expression, which would suggest a new therapeutic indication for caffeine in RDS treatment.

Regenerative capacity of the preterm lung can be increased by vitamin A, but the ideal route of administration has not yet been established. Common route of administration is intramuscular injection, being a painful procedure for the child, which amongst others prevents widespread used [102]. Our feasibility trial described in chapter 5 addresses if application of a new vitamin A formulation via both the intravenous and the intratracheal route would result in increases in vitamin A levels in serum, in the lung as main target organ and in the liver as main storage organ for vitamin A. The results could lay a basis for optimisation of vitamin A supplementation which might help to further reduce BPD.

In chapter 6, we discuss our findings in the context of current experimental and clinical research. We also discuss how the knowledge of the combined effects of the prenatal situation and postnatal interventions might help to further optimise therapy for the preterm lung, and how progress in delivering better care based on biology and data from pre-clinical animal experiments might be achieved. 


\section{REFERENCES}

1. Hutten, M.C. and B.W. Kramer, Patterns and etiology of acute and chronic lung injury: insights from experimental evidence. Zhongguo dang dai er ke za zhi = Chinese journal of contemporary pediatrics, 2014. 16(5): p. 448-59.

2. Goldenberg, R.L., et al., Epidemiology and causes of preterm birth. Lancet, 2008. 371(9606): p. 75-84.

3. Davidoff, M.J., et al., Changes in the gestational age distribution among U.S. singleton births: impact on rates of late preterm birth, 1992 to 2002. Seminars in perinatology, 2006. 30(1): p. 8-15.

4. Liu, L., et al., Global, regional, and national causes of child mortality in 2000-13, with projections to inform post-2015 priorities: an updated systematic analysis. Lancet, 2015. 385(9966): p. 430-40.

5. Saigal, S. and L.W. Doyle, An overview of mortality and sequelae of preterm birth from infancy to adulthood. Lancet, 2008. 371(9608): p. 261-9.

6. Doyle, L.W., et al., Why do preterm infants die in the 1990s? The Medical journal of Australia, 1999. 170(11): p. 528-32.

7. Fawke, J., et al., Lung function and respiratory symptoms at 11 years in children born extremely preterm: the EPICure study. American journal of respiratory and critical care medicine, 2010. 182(2): p. 237-45.

8. Saarenpaa, H.K., et al., Lung Function in Very Low Birth Weight Adults. Pediatrics, 2015. 136(4): p. 642-50.

9. Stoll, B.J., et al., Neonatal outcomes of extremely preterm infants from the NICHD Neonatal Research Network. Pediatrics, 2010. 126(3): p. 443-56.

10. Doyle, L.W., et al., Changing mortality and causes of death in infants 23-27 weeks' gestational age. Journal of paediatrics and child health, 1999. 35(3): p. 255-9.

11. Jensen, E.A., et al., Non-invasive respiratory support for infants in low- and middle-income countries. Seminars in fetal \& neonatal medicine, 2016.

12. Burri, P.H., Structural aspects of postnatal lung development - alveolar formation and growth. Biology of the neonate, 2006. 89(4): p. 313-22.

13. Pattle, R.E. and L.C. Thomas, Lipoprotein composition of the film lining the lung. Nature, 1961. 189: p. 844.

14. Avery, M.E. and J. Mead, Surface properties in relation to atelectasis and hyaline membrane disease. A.M.A. journal of diseases of children, 1959. 97(5, Part 1): p. 517-23.

15. Liggins, G.C. and R.N. Howie, A controlled trial of antepartum glucocorticoid treatment for prevention of the respiratory distress syndrome in premature infants. Pediatrics, 1972. 50(4): p. 515-25.

16. Roberts, D. and S. Dalziel, Antenatal corticosteroids for accelerating fetal lung maturation for women at risk of preterm birth. The Cochrane database of systematic reviews, 2006(3): p. CD004454.

17. Kemp, M.W., et al., The clinical use of corticosteroids in pregnancy. Human reproduction update, 2015.

18. Gilstrap, L.C., et al., Effect of corticosteroids for fetal maturation on perinatal outcomes. NIH Consensus Development Panel on the Effect of Corticosteroids for Fetal Maturation on Perinatal Outcomes. JAMA : the journal of the American Medical Association, 1995. 273(5): p. 413-8.

19. Brownfoot, F.C., et al., Different corticosteroids and regimens for accelerating fetal lung maturation for women at risk of preterm birth. The Cochrane database of systematic reviews, 2013. 8: p. CD006764.

20. Curstedt, T., H.L. Halliday, and C.P. Speer, A unique story in neonatal research: the development of a porcine surfactant. Neonatology, 2015. 107(4): p. 321-9.

21. Fujiwara, T. and F.H. Adams, Surfactant for hyaline membrane disease. Pediatrics, 1980. 66(5): p. 795-8.

22. Jobe, A.H. and M. Ikegami, Surfactant metabolism. Clinics in perinatology, 1993. 20(4): p. 683-96.

23. Mercier, C.E. and R.F. Soll, Clinical trials of natural surfactant extract in respiratory distress syndrome. Clinics in perinatology, 1993. 20(4): p. 711-35.

24. Wirbelauer, J. and C.P. Speer, The role of surfactant treatment in preterm infants and term newborns with acute respiratory distress syndrome. Journal of perinatology : official journal of the California Perinatal Association, 2009. 29 Suppl 2: p. S18-22.

25. Soll, R.F. and C.J. Morley, Prophylactic versus selective use of surfactant in preventing morbidity and mortality in preterm infants. The Cochrane database of systematic reviews, 2001(2): p. CD000510.

26. Seger, N. and R. Soll, Animal derived surfactant extract for treatment of respiratory distress syndrome. The Cochrane database of systematic reviews, 2009(2): p. CD007836. 
27. Soll, R.F., Surfactant treatment of the very preterm infant. Biology of the neonate, 1998. 74 Suppl 1: p. 35-42.

28. Gregory, G.A., et al., Treatment of the idiopathic respiratory-distress syndrome with continuous positive airway pressure. The New England journal of medicine, 1971. 284(24): p. 1333-40.

29. Dunn, P.M., Respiratory distress syndrome. Continuous positive airway pressure (CPAP) using the Gregory box. Proceedings of the Royal Society of Medicine, 1974. 67(4): p. 245-7.

30. Jobe, A.H., What is RDS in 2012? Early human development, 2012. 88 Suppl 2: p. S42-4.

31. Gittermann, M.K., et al., Early nasal continuous positive airway pressure treatment reduces the need for intubation in very low birth weight infants. European journal of pediatrics, 1997. 156(5): p. 384-8.

32. Stoll, B.J., et al., Trends in Care Practices, Morbidity, and Mortality of Extremely Preterm Neonates, 19932012. JAMA : the journal of the American Medical Association, 2015. 314(10): p. 1039-51.

33. Seehase, M., et al., New surfactant with SP-B and $C$ analogs gives survival benefit after inactivation in preterm lambs. PloS one, 2012. 7(10): p. e47631.

34. Niemarkt, H.J., et al., Effects of less-invasive surfactant administration on oxygenation, pulmonary surfactant distribution, and lung compliance in spontaneously breathing preterm lambs. Pediatric research, 2014.

35. Kribs, A., et al., Surfactant without intubation in preterm infants with respiratory distress: first multi-center data. Klinische Padiatrie, 2010. 222(1): p. 13-7.

36. Gopel, W., et al., Avoidance of mechanical ventilation by surfactant treatment of spontaneously breathing preterm infants (AMV): an open-label, randomised, controlled trial. Lancet, 2011. 378(9803): p. 1627-34.

37. Northway, W.H., Jr., R.C. Rosan, and D.Y. Porter, Pulmonary disease following respirator therapy of hyaline-membrane disease. Bronchopulmonary dysplasia. The New England journal of medicine, 1967. 276(7): p. 357-68.

38. Jobe, A.J., The new BPD: an arrest of lung development. Pediatric research, 1999. 46(6): p. 641-3.

39. Jobe, A.H. and E. Bancalari, Bronchopulmonary dysplasia. American journal of respiratory and critical care medicine, 2001. 163(7): p. 1723-9.

40. Coalson, J.J., V. Winter, and R.A. deLemos, Decreased alveolarization in baboon survivors with bronchopulmonary dysplasia. American journal of respiratory and critical care medicine, 1995. 152(2): p. 640-6.

41. Darlow, B.A., A.E. Cust, and D.A. Donoghue, Improved outcomes for very low birthweight infants: evidence from New Zealand national population based data. Archives of disease in childhood. Fetal and neonatal edition, 2003. 88(1): p. F23-8.

42. Bancalari, E., et al., Bronchopulmonary dysplasia: clinical presentation. The Journal of pediatrics, 1979. 95(5 Pt 2): p. 819-23.

43. Walsh, M.C., et al., Safety, reliability, and validity of a physiologic definition of bronchopulmonary dysplasia. Journal of perinatology : official journal of the California Perinatal Association, 2003. 23(6): p. 451-6.

44. Walsh, M.C., et al., Impact of a physiologic definition on bronchopulmonary dysplasia rates. Pediatrics, 2004. 114(5): p. 1305-11.

45. Kramer, B.W., Antenatal inflammation and lung injury: prenatal origin of neonatal disease. Journal of perinatology : official journal of the California Perinatal Association, 2008. 28 Suppl 1: p. S21-7.

46. Wright, C.J. and H. Kirpalani, Targeting inflammation to prevent bronchopulmonary dysplasia: can new insights be translated into therapies? Pediatrics, 2011. 128(1): p. 111-26.

47. Thomas, W. and C.P. Speer, Nonventilatory strategies for prevention and treatment of bronchopulmonary dysplasia--what is the evidence? Neonatology, 2008. 94(3): p. 150-9.

48. Hilgendorff, A., et al., Chronic lung disease in the preterm infant. Lessons learned from animal models. American journal of respiratory cell and molecular biology, 2014. 50(2): p. 233-45.

49. Pringle, K.C., Human fetal lung development and related animal models. Clinical obstetrics and gynecology, 1986. 29(3): p. 502-13.

50. Wolfs, T.G., et al., Inflammation-induced immune suppression of the fetus: a potential link between chorioamnionitis and postnatal early onset sepsis. The journal of maternal-fetal \& neonatal medicine : the official journal of the European Association of Perinatal Medicine, the Federation of Asia and Oceania Perinatal Societies, the International Society of Perinatal Obstetricians, 2012. 25 Suppl 1: p. 8-11. 


\section{Chapter 1}

51. Bjorklund, L.J., et al., Manual ventilation with a few large breaths at birth compromises the therapeutic effect of subsequent surfactant replacement in immature lambs. Pediatric research, 1997. 42(3): p. 348-55.

52. Michna, J., A.H. Jobe, and M. Ikegami, Positive end-expiratory pressure preserves surfactant function in preterm lambs. American journal of respiratory and critical care medicine, 1999. 160(2): p. 634-9.

53. Naik, A.S., et al., Effects of ventilation with different positive end-expiratory pressures on cytokine expression in the preterm lamb lung. American journal of respiratory and critical care medicine, 2001. 164(3): p. 494-8.

54. Hillman, N.H., et al., Airway injury from initiating ventilation in preterm sheep. Pediatric research, 2010. 67(1): p. 60-5.

55. Jobe, A.H., et al., Decreased indicators of lung injury with continuous positive expiratory pressure in preterm lambs. Pediatric research, 2002. 52(3): p. 387-92.

56. Thomson, M.A., et al., Treatment of immature baboons for 28 days with early nasal continuous positive airway pressure. American journal of respiratory and critical care medicine, 2004. 169(9): p. 1054-62.

57. Morley, C.J., et al., Nasal CPAP or intubation at birth for very preterm infants. The New England journal of medicine, 2008. 358(7): p. 700-8.

58. Finer, N.N., et al., Early CPAP versus surfactant in extremely preterm infants. The New England journal of medicine, 2010. 362(21): p. 1970-9.

59. Schmolzer, G.M., et al., Non-invasive versus invasive respiratory support in preterm infants at birth: systematic review and meta-analysis. BMJ, 2013. 347: p. f5980.

60. Fischer, H.S. and C. Buhrer, Avoiding endotracheal ventilation to prevent bronchopulmonary dysplasia: a meta-analysis. Pediatrics, 2013. 132(5): p. e1351-60.

61. Kribs, A., et al., Early administration of surfactant in spontaneous breathing with nCPAP: feasibility and outcome in extremely premature infants (postmenstrual age $</=27$ weeks). Paediatric anaesthesia, 2007. 17(4): p. 364-9.

62. Kribs, A., et al., Nonintubated Surfactant Application vs Conventional Therapy in Extremely Preterm Infants: A Randomized Clinical Trial. JAMA pediatrics, 2015. 169(8): p. 723-30.

63. van der Burg, P.S., et al., Effect of Minimally Invasive Surfactant Therapy on Lung Volume and Ventilation in Preterm Infants. The Journal of pediatrics, 2016. 170: p. 67-72.

64. Gopel, W., et al., Less invasive surfactant administration is associated with improved pulmonary outcomes in spontaneously breathing preterm infants. Acta paediatrica, 2015. 104(3): p. 241-6.

65. Jobe, A.H., Surfactant treatments for RDS improves oxygenation. The Journal of pediatrics, 2016. 170: p. 1-4.

66. The_STOP-ROP_Multicenter_Study_Group, Supplemental Therapeutic Oxygen for Prethreshold Retinopathy Of Prematurity (STOP-ROP), a randomized, controlled trial. I: primary outcomes. Pediatrics, 2000. 105(2): p. 295-310.

67. Van Marter, L.J., et al., Do clinical markers of barotrauma and oxygen toxicity explain interhospital variation in rates of chronic lung disease? The Neonatology Committee for the Developmental Network. Pediatrics, 2000. 105(6): p. 1194-201.

68. Saugstad, O.D., Update on oxygen radical disease in neonatology. Current opinion in obstetrics \& gynecology, 2001. 13(2): p. 147-53.

69. Rogers, S., et al., Antioxidant capacity and oxygen radical diseases in the preterm newborn. Archives of pediatrics \& adolescent medicine, 2000. 154(6): p. 544-8.

70. Warner, B.B., et al., Functional and pathological effects of prolonged hyperoxia in neonatal mice. The American journal of physiology, 1998. 275(1 Pt 1): p. L110-7.

71. Rozycki, H.J., P.G. Comber, and T.F. Huff, Cytokines and oxygen radicals after hyperoxia in preterm and term alveolar macrophages. American journal of physiology. Lung cellular and molecular physiology, 2002. 282(6): p. L1222-8.

72. Carlo, W.A., et al., Target ranges of oxygen saturation in extremely preterm infants. The New England journal of medicine, 2010. 362(21): p. 1959-69.

73. Stenson, B., P. Brocklehurst, and W. Tarnow-Mordi, Increased 36-week survival with high oxygen saturation target in extremely preterm infants. The New England journal of medicine, 2011. 364(17): p. 1680-2. 
74. Vento, M., et al., Preterm resuscitation with low oxygen causes less oxidative stress, inflammation, and chronic lung disease. Pediatrics, 2009. 124(3): p. e439-49.

75. Saugstad, O.D. and D. Aune, Optimal oxygenation of extremely low birth weight infants: a meta-analysis and systematic review of the oxygen saturation target studies. Neonatology, 2014. 105(1): p. 55-63.

76. Goos, T.G., et al., Observing the resuscitation of very preterm infants: are we able to follow the oxygen saturation targets? Resuscitation, 2013. 84(8): p. 1108-13.

77. Jobe, A.H. and R.F. Soll, Choice and dose of corticosteroid for antenatal treatments. American journal of obstetrics and gynecology, 2004. 190(4): p. 878-81.

78. Kemp, M.W., et al., The clinical use of corticosteroids in pregnancy. Human reproduction update, 2016. 22(2): p. 240-59.

79. Bolt, R.J., et al., Glucocorticoids and lung development in the fetus and preterm infant. Pediatric pulmonology, 2001. 32(1): p. 76-91.

80. Garbrecht, M.R., et al., Glucocorticoid metabolism in the human fetal lung: implications for lung development and the pulmonary surfactant system. Biology of the neonate, 2006. 89(2): p. 109-19.

81. Perez-Gil, J. and T.E. Weaver, Pulmonary surfactant pathophysiology: current models and open questions. Physiology, 2010. 25(3): p. 132-41.

82. Nogee, L.M., et al., A mutation in the surfactant protein B gene responsible for fatal neonatal respiratory disease in multiple kindreds. The Journal of clinical investigation, 1994. 93(4): p. 1860-3.

83. Doyle, L.W., R.A. Ehrenkranz, and H.L. Halliday, Early (< 8 days) postnatal corticosteroids for preventing chronic lung disease in preterm infants. The Cochrane database of systematic reviews, 2014. 5: p. CD001146.

84. Barrington, K.J., Postnatal steroids and neurodevelopmental outcomes: a problem in the making. Pediatrics, 2001. 107(6): p. 1425-6.

85. Henderson-Smart, D.J. and A.G. De Paoli, Methylxanthine treatment for apnoea in preterm infants. The Cochrane database of systematic reviews, 2010(12): p. CD000140.

86. Schmidt, B., et al., Caffeine therapy for apnea of prematurity. The New England journal of medicine, 2006. 354(20): p. 2112-21.

87. Chavez Valdez, R., et al., Correlation between serum caffeine levels and changes in cytokine profile in a cohort of preterm infants. The Journal of pediatrics, 2011. 158(1): p. 57-64, 64 e1.

88. Martin, R.J. and A.A. Fanaroff, The preterm lung and airway: past, present, and future. Pediatrics and neonatology, 2013. 54(4): p. 228-34.

89. Fehrholz, M., et al., Synergistic Effect of Caffeine and Glucocorticoids on Expression of Surfactant Protein $B$ (SP-B) mRNA. PLoS One, 2012. 7(12): p. e51575.

90. Maden, M. and M. Hind, Retinoic acid in alveolar development, maintenance and regeneration. Philosophical transactions of the Royal Society of London. Series B, Biological sciences, 2004. 359(1445): p. 799-808.

91. Massaro, D. and G.D. Massaro, Retinoids, alveolus formation, and alveolar deficiency: clinical implications. American journal of respiratory cell and molecular biology, 2003. 28(3): p. 271-4.

92. Goodman, L.S., et al., Goodman \& Gilman's the pharmacological basis of therapeutics. 9th ed1996, New York: McGraw-Hill, Health Professions Division. xxi, 1905 p.

93. Ozer, E.A., et al., Effect of retinoic acid on oxygen-induced lung injury in the newborn rat. Pediatric pulmonology, 2005. 39(1): p. 35-40.

94. Pierce, R.A., et al., Retinoids increase lung elastin expression but fail to alter morphology or angiogenesis genes in premature ventilated baboons. Pediatric research, 2007. 61(6): p. 703-9.

95. Willet, K.E., et al., Antenatal retinoic acid does not alter alveolization or postnatal lung function in preterm sheep. The European respiratory journal, 2000. 16(1): p. 101-7.

96. Brandt, R.B., et al., Serum vitamin A in premature and term neonates. The Journal of pediatrics, 1978. 92(1): p. 101-4.

97. Tammela, O., M. Aitola, and S. Ikonen, Cord blood concentrations of vitamin A in preterm infants. Early human development, 1999. 56(1): p. 39-47. 


\section{Chapter 1}

98. Spears, K., C. Cheney, and J. Zerzan, Low plasma retinol concentrations increase the risk of developing bronchopulmonary dysplasia and long-term respiratory disability in very-low-birth-weight infants. The American journal of clinical nutrition, 2004. 80(6): p. 1589-94.

99. Darlow, B.A. and P.J. Graham, Vitamin A supplementation to prevent mortality and short- and long-term morbidity in very low birthweight infants. The Cochrane database of systematic reviews, 2011(10): p. CD000501.

100. Moreira, A., et al., Impact of providing vitamin A to the routine pulmonary care of extremely low birth weight infants. The journal of maternal-fetal \& neonatal medicine, 2012. 25(1): p. 84-8.

101.Ambalavanan, N., et al., Survey of vitamin A supplementation for extremely-low-birth-weight infants: is clinical practice consistent with the evidence? The Journal of pediatrics, 2004. 145(3): p. 304-7.

102. Kaplan, H.C., et al., Understanding variation in vitamin A supplementation among NICUs. Pediatrics, 2010. 126(2): p. e367-73.

103.Wardle, S.P., et al., Randomised controlled trial of oral vitamin A supplementation in preterm infants to prevent chronic lung disease. Archives of disease in childhood. Fetal and neonatal edition, 2001. 84(1): p. F9-F13.

104. Meyer, S. and L. Gortner, Early postnatal additional high-dose oral vitamin A supplementation versus placebo for 28 days for preventing bronchopulmonary dysplasia or death in extremely low birth weight infants. Neonatology, 2014. 105(3): p. 182-8.

105. Biesalski, H.K., Effects of intra-tracheal application of vitamin A on concentrations of retinol derivatives in plasma, lungs and selected tissues of rats. International journal for vitamin and nutrition research. Internationale Zeitschrift fur Vitamin- und Ernahrungsforschung. Journal international de vitaminologie et de nutrition, 1996. 66(2): p. 106-12.

106. Kribs, A., How best to administer surfactant to VLBW infants? Archives of disease in childhood. Fetal and neonatal edition, 2011. 96(4): p. F238-40.

107.Vento, M., Oxygen supplementation in the neonatal period: changing the paradigm. Neonatology, 2014. 105(4): p. 323-31. 


\title{
Chapter
}

\author{
Nebulization of Poractant alfa via a \\ vibrating membrane nebulizer in \\ spontaneously breathing preterm lambs \\ with binasal continuous positive \\ pressure ventilation
}

Hütten MC*, Kuypers E*, Ophelders DR, Nikiforou M, Jellema RK, Niemarkt HJ, Fuchs C, Tservistas M, Razetti R, Bianco F, Kramer BW.

Pediatr Res. 2015 Dec;78(6):664-9. doi: 10.1038/pr.2015.165.

*contributed equally 


\section{ABSTRACT}

Background: Surfactant replacement therapy is the gold standard treatment of neonatal respiratory distress (RDS). Nebulization is a non-invasive mode of surfactant administration. We administered Poractant alfa (Curosurf) via a vibrating perforated membrane nebulizer (eFlow Neonatal Nebulizer) to spontaneously breathing preterm lambs during binasal continuous positive pressure ventilation (CPAP).

Methods: 16 preterm lambs were operatively delivered at a gestational age of $133 \pm 1 \mathrm{~d}$ (term 150d), and connected to CPAP applied via customized nasal prongs. Nebulization was performed (i) with saline or (ii) with surfactant for 3 hours in humidified or (iii) nonhumidified air, and with surfactant (iv) for $60 \mathrm{~min}$ or (v) for $30 \mathrm{~min}$. We measured arterial oxygenation, lung gas volumes and surfactant pool size and deposition.

Results: Nebulization of surfactant in humidified air for 3 hours improved oxygenation and lung function, and surfactant was preferentially distributed to the lower lung lobes. Shorter nebulization times and $3 \mathrm{~h}$ nebulization in dry air did not show these effects. Nebulized surfactant reached all lung lobes, however the increase of surfactant pool size missed statistical significance.

Conclusion: Positive effects of surfactant nebulization to spontaneously breathing preterm lambs depend on treatment duration, surfactant dose, air humidity and surfactant distribution within the lung. 


\section{INTRODUCTION}

A major cornerstone in therapy of respiratory distress syndrome (RDS) in preterm neonates has been the introduction of surfactant replacement therapy [1]. Surfactant replacement improves gas exchange and decreases mortality [2,3], and proved to be efficient in the prevention [4] and in the therapy of neonatal RDS [5]. Surfactant is delivered to the lung of intubated and mechanically ventilated babies as a bolus via an endotracheal tube in most instances. However, endotracheal intubation is a physiologically stressful procedure [6]. Bolus administration of surfactant holds the risk of acute airway obstruction with consecutive hypoxia and bradycardia [7]. Newer techniques focus on less invasive surfactant administration (LISA), combining bolus surfactant therapy with continuous positive airway pressure (CPAP) by utilising a small tube inserted into the trachea [8-10]. However, this can only be performed by very skilled personnel, and still requires laryngoscopy and potentially a Magill forceps.

In the search for an alternative way to administer surfactant to the lung as gentle and non-invasive as possible, nebulization is a historic, but still innovative approach [11, 12]. Until now, there have been four clinical studies on nebulized surfactant as rescue therapy [13-16]. These studies confirmed the safety and feasibility of the method. However, only one showed an immediate positive effect on oxygen delivery to treated infants [16]. In addition, a clinical study recently presented by Minocchieri on the Pediatric Academic Societies Meeting 2013 reported a reduced need for intubation in preterm infants with RDS receiving CPAP plus nebulized surfactant in the first hours of life.

In order to study nebulization as a non-invasive technique, various animal models were established. Positive effects of nebulized surfactant on ventilatory parameters like lung compliance and oxygenation have been described in animal models using tracheostomized and ventilated premature lambs [17]. Furthermore, distribution of nebulized surfactant to the lung was more homogenous compared to bolus surfactant in a rabbit model [18].

In our study, we tested a customized vibrating perforated membrane nebulizer (eFlow Neonatal Nebulizer System) for delivery of a widely used animal derived surfactant (Poractant alfa) [19] in premature lambs receiving binasal CPAP. We hypothesized that the combination of binasal CPAP and nebulized surfactant would result in improvement of oxygenation and lung function. We further hypothesized that nebulization would increase surfactant pool size in a dose-dependent manner, and that surfactant nebulization would result in homogenous distribution of surfactant to different lung lobes irrespective of different technical parameters like dose, treatment duration and air humidity. 


\section{MATERIALS AND METHODS}

\section{Animals and delivery protocol}

Animal experiments were approved by the Institutional Animal Ethics Committee of Maastricht University. 16 preterm lambs were operatively delivered from time-mated Texel ewes at a gestational age of $133 \pm 1$ days (term 150 days gestational age), at which lung maturation resembles $30-32$ weeks of gestation in humans [20]. One day before the experiment, the ewe received an intra-muscular injection with $12 \mathrm{mg}$ betamethasone (Celestone Chronodose, Schering-Plough, North Ryde, New South Wales, Australia) to induce fetal lung maturation [21].

Caesarean section was performed through midline incision under spinal and local subcutaneous analgesia with $2 \%$ lidocaine. The fetus was delivered head first, and an arterial catheter was placed in the umbilical artery through a modified EXIT procedure [22], allowing monitoring of arterial blood pressure (ABP) and heart rate (HR), bloodgas analysis, and parenteral nutrition.

After cord clamping, the preterm lambs were weighed (ICI6000S balance, Sartorius, Göttingen, Germany). Each lamb was brought to an open, heated incubator (IW930 Series CosyCot Infant Warmer, Fisher \& Paykel Healthcare, Auckland, New Zealand) maintaining a body temperature of $38^{\circ} \mathrm{C}$. Body temperature was monitored by placing a rectal temperature probe.

Directly after transferring the lambs to the open incubator, custom made bi-nasal prongs were fitted and the spontaneously breathing lambs were connected to noninvasive intermittent positive pressure ventilation (NIPPV) for 15 min using an infant ventilator (Babylog 8000, Draeger, Luebeck, Germany). Initial settings were as follows: $\mathrm{FiO}_{2}=1$, PEEP $8 \mathrm{~cm} \mathrm{H} \mathrm{H}_{2} \mathrm{O}$, PIP $30 \mathrm{~cm} \mathrm{H} \mathrm{H}_{2} \mathrm{O}$, frequency 60/min, I:E 1:2. 15 minutes after birth, the ventilation was switched to CPAP with a PEEP of $8 \mathrm{~cm} \mathrm{H}_{2} \mathrm{O}$ for the remaining of the experiment. The ventilation circuit was equipped with a standard heated humidifier (MR700, Fisher \& Paykel Healthcare) to condition the inflowing gas with humidity.

Poractant alfa (Curosurf, Chiesi Pharmaceuticals, Parma, Italy) was labelled with samarium oxide $\left(\mathrm{Sm}_{2} \mathrm{O}_{3}\right)$ in a 1:1000 ratio before the experiment to track relative surfactant deposition to different lung lobes and to the stomach [22].

Nebulization was performed using a customized vibrating membrane nebulizer (eFlow Neonatal Nebulizer System, PARI Pharma, Munich, Germany), which was placed between the prongs and the connection to the ventilator circuit. It was designed to generate a particle size that was optimized to target the small airways (mass median diameter $2.6 \mu \mathrm{m}-3.3 \mu \mathrm{m}$ with saline and mass median aerodynamic diameter of nebulised Curosurf of $2.2-3.0 \mu \mathrm{m}$ according to manufacturer). Nebulization was started immediately after the connection to the ventilator. For each animal, a new nebulizer was used, and the total amount of nebulized surfactant was documented. The average 
amount of surfactant nebulized per minute was calculated by dividing the total amount of surfactant by duration of nebulization.

Lambs were randomly assigned to five treatment groups: (i) saline nebulization for 3 hours ("saline"), (ii) surfactant nebulization for 3 hours (" 3 "), (iii) surfactant nebulization for 3 hours without humidification ("3h dry"), (iv) surfactant nebulization for 60 min ("60min") and (v) 30 min ("30min") with humidified air (Table 2). Treatment duration was based on previous lamb studies on less invasive surfactant administration by our group [22].

During the experiment, blood gas analyses were performed on arterial blood at birth $(\mathrm{t}=0 \mathrm{~min}$ ) and regularly after birth at $\mathrm{t}=15 \mathrm{~min}, \mathrm{t}=45 \mathrm{~min}, \mathrm{t}=75 \mathrm{~min}, \mathrm{t}=105 \mathrm{~min}, \mathrm{t}=135$ $\min$ and $\mathrm{t}=180 \mathrm{~min}$, respectively.

\section{Autopsy}

At the end of the experiment, lambs were euthanized by an intravenous injection of 10 $\mathrm{mL}$ pentobarbital. Lambs were disconnected from ventilation and the thorax was opened. An endotracheal tube was inserted in the trachea and the lung was inflated to a maximum pressure of $40 \mathrm{~cm} \mathrm{H}_{2} \mathrm{O}$. Deflation gas volumes were recorded and adjusted for body weight as described before [23]. The lung was removed from the chest and weighed, and divided into its lobes. Again, each lung lobe was weighed. Additionally, gastric fluid was obtained for measurement of surfactant.

\section{Disaturated phospholipid (DSPL) measurements}

Lung lobes were isolated and lavaged separately with $\mathrm{NaCl} 0.9 \%$. For DSPL measurements, $2 \mathrm{ml}$ aliquots were used, while the remaining bronchoalveolar lavage fluid (BALF) was stored together with the belonging lobe. BALF samples were centrifuged for $10 \mathrm{~min}$ at $300 \times \mathrm{g}$ and $4{ }^{\circ} \mathrm{C} .1 \mathrm{~mL}$ of the supernatant BALF was evaporated overnight at $60{ }^{\circ} \mathrm{C}$ under continuous nitrogen gas flow. The dry BALF was dissolved in a mixture of carbon tetrachloride and osmium tetroxide and disaturated phospholipids were isolated by means of alumina column chromatography according to Mason et al. [24]. DSPL were dissolved in chloroform and quantified by photometry according to Stewart with some minor modifications as described by Been et al. $[25,26]$. DSPL concentration was correlated to BALF volumes and DSPL pool size of the whole lung was calculated and adjusted for body weight.

\section{Samarium oxide measurements}

The lung lobes were separately stored together with the belonging BALF fluid and deepfrozen at $-20^{\circ} \mathrm{C}$ for 24 hours, followed by storage in a $-80^{\circ} \mathrm{C}$ freezer. For analysis, the lung samples were freeze-dried and ashed. Afterwards they were dissolved in a combi- 
nation of nitric acid and hydrochloric acid, diluted in water. To allow quantification of samarium oxide, measurements were performed by inductively coupled plasma mass spectrometry (ICP-MS) [27]. Samarium oxide was measured in stomach fluid samples accordingly. For each animal treated with surfactant, Samarium oxide concentration in the individual lobes was calculated by taking into account the BAL aliquot used for lipid measurement, and was normalized to samarium oxide concentration in the whole lung.

\section{Data Analysis}

Results of arterial partial pressure of oxygen $\left(\mathrm{P}_{\mathrm{a}} \mathrm{O}_{2}\right)$ measurements and lung gas volumes were given as means \pm standard error of mean (SEM) and compared using one-way analysis of variance (ANOVA). Groups of interest were compared using t-test. DSPL and samarium oxide measurement results were given as mean \pm standard error of mean (SEM) and were compared using non-parametric testing (Mann-Whitney test). Groups of interest were compared by Kruskall-Wallis test. Statistical analysis was performed by IBM SPSS version 20; graphs were drawn with GraphPad Prism v5.0. Significance was accepted at $p<0.05$.

\section{RESULTS}

\section{Nebulization of surfactant versus saline}

3 hour nebulization of surfactant in humidified air resulted in a significantly higher arterial partial pressure of oxygen $\left(\mathrm{P}_{\mathrm{a}} \mathrm{O}_{2}\right)$ at the end of the experiment compared to saline nebulization $(p<0.05)$ (Figure 1 ). Lung gas volumes were significantly higher in the group treated with surfactant in humidified air compared to control animals $(p<0.05)$ (Figure 2). The average total amount of surfactant nebulized in this group was $861 \mathrm{mg} / \mathrm{kg}$ body weight. 


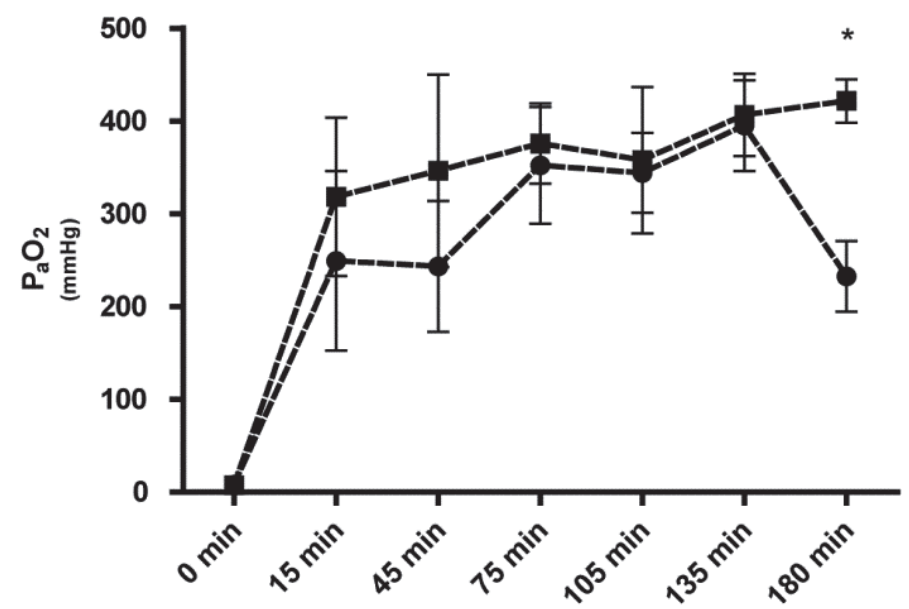

Figure 1: Arterial partial pressure of oxygen $\left(\mathrm{P}_{\mathrm{a}} \mathrm{O}_{2}\right)$ was significantly higher in animals nebulized $3 \mathrm{~h}$ with surfactant (squares) compared to saline (circles) at the end of the experiment (mean \pm SEM, $* p<0.05$ ).

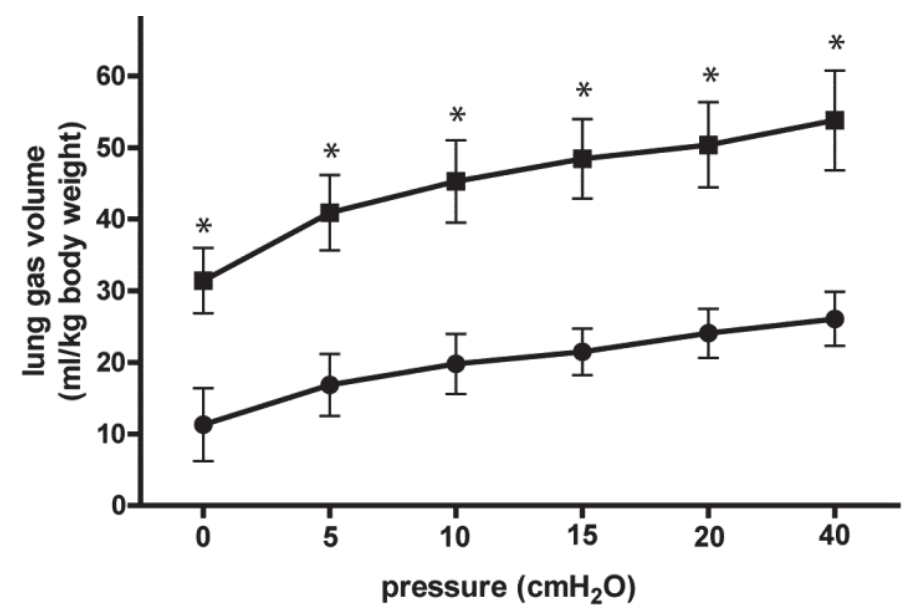

Figure 2: Lung gas volumes corrected for body weight $(\mathrm{ml} / \mathrm{kg})$ were significantly higher in animals nebulized 3 $\mathrm{h}$ with surfactant (squares) compared to saline (circles), (mean $\left.\pm \mathrm{SEM},{ }^{*} \mathrm{p}<0.05\right)$.

In animals nebulized with surfactant in non-humidified air for 3 hours, $\mathrm{P}_{2} \mathrm{O}_{2}$ at the end of the experiment was significantly lower than in the group treated with nebulized surfactant in humidified air $(p<0.05)$ (Table 1$)$, while there was no difference to control $(p=0.467)$. Lung gas volumes showed no significant improvement after $3 \mathrm{~h}$ nebulization of surfactant in non-humidified air (Table 1). The total amount of surfactant nebulized in this group was $978 \mathrm{mg} / \mathrm{kg}$ body weight, which was not different from animals nebulized with surfactant for $3 \mathrm{~h}$ and humidified air. In all experimental groups, we observed mild hypercapnia at the end of the experiment (Table 1). 
Table 1: Oxygenation, lung gas volumes and surfactant distribution to the stomach: Arterial partial pressure of oxygen $\left(\mathrm{P}_{\mathrm{a}} \mathrm{O}_{2}, \mathrm{mmHg}\right)$ at the end of experiment, and lung gas volume at pressure $0 \mathrm{~cm} \mathrm{H}_{2} \mathrm{O}$ and $40 \mathrm{~cm} \mathrm{H}_{2} \mathrm{O}$ ( $\mathrm{ml} / \mathrm{kg}$ body weight) in animals nebulized with surfactant for $3 \mathrm{~h}$ was increased compared to control, while nebulization with surfactant and dry air and for shorter times had no significant effect compared to control. Carbon dioxide $\left(\mathrm{P}_{\mathrm{a}} \mathrm{CO}_{2}, \mathrm{mmHg}\right)$ and $\mathrm{pH}$ at the end of experiment did not differ between groups. Surfactant recovered from the stomach relative to the total amount of nebulized surfactant was low in all treatment groups (Mean $\pm \mathrm{SEM},{ }^{*} \mathrm{p}<0.05$ compared to saline).

\begin{tabular}{llllll}
\hline & saline & $3 \mathrm{~h}$ & $3 \mathrm{~h}$ dry & $60 \mathrm{~min}$ & $30 \mathrm{~min}$ \\
\hline $\mathrm{P}_{\mathrm{a}} \mathrm{O}_{2}(180 \mathrm{~min})$ & $233 \pm 38$ & $422 \pm 23^{*}$ & $174 \pm 31$ & $317 \pm 107$ & $384 \pm 12$ \\
$\mathrm{pH}(180 \mathrm{~min})$ & $7.27 \pm 0.02$ & $7.25 \pm 0.05$ & $7.24 \pm 0.09$ & $7.33 \pm 0.03$ & $7.28 \pm 0.01$ \\
$\mathrm{P}_{\mathrm{a}} \mathrm{CO}_{2}(180 \mathrm{~min})$ & $58 \pm 5$ & $59 \pm 7$ & $59 \pm 23$ & $59 \pm 5$ & $57 \pm 3$ \\
$\mathrm{VO}$ & $11.3 \pm 5.1$ & $31.4 \pm 4.6^{*}$ & $16.3 \pm 8.4$ & $18.2 \pm 14.4$ & $18.8 \pm 1.7$ \\
$\mathrm{~V} 40$ & $26.8 \pm 3.8$ & $53.8 \pm 7.0^{*}$ & $41.8 \pm 17.5$ & $32.5 \pm 17.2$ & $39.9 \pm 5.9$ \\
Surfactant in stomach & n.a. & $2.1 \%$ & $1.5 \%$ & $0.1 \%$ & $1.1 \%$ \\
\hline
\end{tabular}

\section{Effect of dose and duration of surfactant treatment on deposition of nebulized surfactant}

Animals nebulized with surfactant for 60 min did not show significant improvements of $\mathrm{P}_{\mathrm{a}} \mathrm{O}_{2}$ or lung gas volumes compared to control (Table 1 ). Animals in this group were nebulized with an average of $437 \mathrm{mg} / \mathrm{kg}$ body weight surfactant in total.

Animals nebulized with surfactant for 30 min did also not show significant improvements of $\mathrm{P}_{\mathrm{a}} \mathrm{O}_{2}$ or lung gas volumes compared to control (Table 1), and was stopped at $\mathrm{n}=2$. Animals in this group were nebulized with an average of $229 \mathrm{mg} / \mathrm{kg} \mathrm{BW}$ body weight surfactant in total.

The total amount of surfactant nebulized in both groups was significantly lower compared to animals nebulized with surfactant for 3 hours, although the average amount of surfactant nebulized per minute was higher with decreasing nebulization times, i.e. $0.18 \mathrm{~mL} / \mathrm{min}, 0.26 \mathrm{~mL} / \mathrm{min}$ and $0.33 \mathrm{~mL} / \mathrm{min}$ in the " $3 \mathrm{~h}^{\prime}$," "60min" and "30min" group, respectively.

\section{Disaturated phospholipids in the lung}

Surfactant nebulization for $3 \mathrm{~h}$ and 60 min increased DSPL pool size compared to saline nebulization 2.9 fold and 3.7 fold, respectively, however this effect was not statistically significant ( $p=0.057$ and $p=0.057$ vs. control, respectively, Figure 3 ). DSPL pool size did not significantly differ between different surfactant nebulization groups (Figure 3 ). 


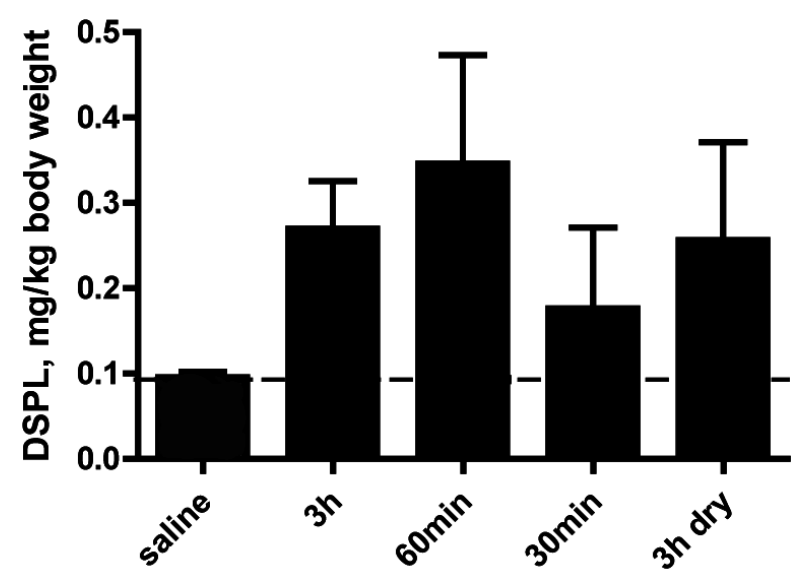

Figure 3: DSPL pool size recovered from BALF relative to body weight was increased by surfactant nebulization (mean \pm SEM), however missing statistical significance compared to saline nebulization ( $p=0.057$ " $3 h^{\prime \prime}$ vs. "saline" and p=0.057 "60min" vs. "saline", respectively).

\section{Surfactant distribution to the lung}

In all groups nebulized with surfactant, surfactant was distributed to each lung lobe (Figure 4). In the " $3 \mathrm{~h}$ " group, there was a significant difference in distribution between all lobes, with a preference of the lower lobes compared to the whole lung. Surfactant distribution to different lung lobes in the other treatment groups did not show significant differences (Figure 4). Surfactant distribution to the stomach was low in all nebulized animals (Table 1$)$.

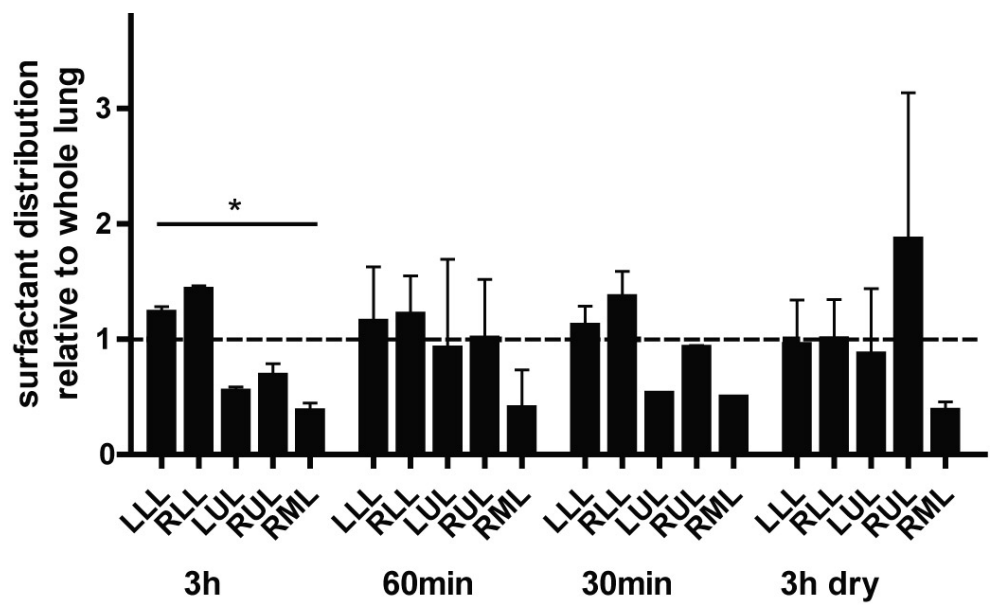

Figure 4: Surfactant distribution to different lung lobes relative to the whole lung, measured by $\mathrm{Sm}_{2} \mathrm{O}_{3}$ levels $(\mathrm{LLL}=$ left lower lobe, $\mathrm{LUL}=$ left upper lobe, $\mathrm{RLL}=$ right lower lobe, $\mathrm{RML}=$ right middle lobe, $\mathrm{RUL}=$ right upper lobe; $\left.{ }^{*} \mathrm{p}<0.05\right)$. 


\section{DISCUSSION}

In our study, nebulization of natural surfactant in humidified air for 3 hours improved physiological parameters like oxygenation and lung function in spontaneously breathing preterm lambs. This is in line with previous experimental findings, showing that nebulization of synthetic surfactant using CPAP increased lung compliance in anaesthetized lambs receiving CPAP [28] and both lung compliance and oxygenation in lavaged rabbits [29], and a clinical study on nebulized surfactant which reported an improvement of the (A/a) $\mathrm{O}_{2}$ gradient compared to control [16].

We used a preterm sheep model, which included two major advantages: First, the similarity in anatomy and size allowed the use of equipment which is originally used in humans. Secondly, maturation of the lung closely resembles to that of humans [20]. Preterm lambs at this age have a sufficient respiratory drive, allowing the use of CPAP. We found positive physiological effects of surfactant nebulization using binasal CPAP provided by prongs. In contrary, previous animal studies which showed positive effects of nebulized natural surfactant on lung function have mainly focused on tracheostomized, intubated and ventilated sheep $[17,30]$ or rabbits $[18,31]$. Our data indicates that nebulized surfactant reached the lung and was deposited in all lung lobes. Positive treatment effects of $3 \mathrm{~h}$ surfactant nebulization may arise from both increased surfactant pool size and the pattern of surfactant distribution to different lung lobes. According to previous data, we would have expected that the upper lobes of both sides were preferred. In tracheostomized animals, the greatest recovery of surfactant both after nebulization and bolus application of surfactant was observed in the right upper lobe $[17,32]$. The upper lobes develop faster than the remaining lobes [20], and are therefore supposed to show advanced surfactant production compared to the lower lobes. In our study, the preferred distribution to the lower, less developed lung lobes might therefore have contribute to the positive effect of surfactant nebulization. This preference might also result from spontaneous breathing during CPAP support, as surfactant bolus administration during CPAP resulted in preferential distribution to lower lobes compared to intubation in a previous study from our group [22].

However, we observed that the nebulized amount of surfactant by the device had to be very high for a clinical effect. In order to reduce the amount of surfactant nebulized and to compare the effects of lower doses in our setting, we shortened nebulization times. However, lower doses of nebulized surfactant did not result in significant improvements of oxygenation and lung function, despite an increase in surfactant pool size comparable to the $3 \mathrm{~h}$ group. Furthermore, we observed a non-linear rate of surfactant nebulization over time. We hypothesize that this non-linear surfactant delivery resulted from the fact that all animals underwent NIPPV in the first 15 min, which meant a higher percentage of NIPPV during nebulization in the $60 \mathrm{~min}$ and $30 \mathrm{~min}$ group. We also could not reproduce the preferential distribution to the lower lung lobes in the shorter experiments. These findings indicate that in addition to surfactant pool 
size, the distribution pattern of surfactant within the lung influences treatment benefits from surfactant nebulization.

Surprisingly, we also found that nebulization with dry air instead of humidified air, which is a common situation when CPAP is applied during transition in the delivery room, did not result in significant improvement of physiological parameters, although the amount of surfactant used for treatment did not differ from animals nebulized with surfactant in humidified air. This was unexpected because non-conditioning of inspired gas did not result in abnormal gas exchange or lung function in a previous study in intubated preterm lambs ventilated for $3 \mathrm{~h}$ [33]. However, in our study animals nebulized with dry air showed highest surfactant pools in the right upper lobe, a finding which has been previously described in tracheostomized animals [17, 32]. These findings support the importance of the surfactant distribution pattern within the lung for therapeutic benefit. However, the interactions between surfactant dosing, treatment duration and air humidity remain complex. Further studies are needed to elucidate the influence of air humidity on surfactant distribution, surfactant clearance and surfactant droplet formation in spontaneously breathing animals.

Beside these parameters, pharmacological and technical aspects influence effects of surfactant nebulization. Different surfactants might vary in their suitability for nebulization, which is reflected by the great quantity of different preparations of surfactant that have been tested in both animal and clinical studies [12]. In our study, we used Poractant alfa, an animal derived surfactant which proved to be advantageous compared to different surfactant preparations regarding rapid onset of action, less need for redosing and higher survival free of BPD in preterm infants [34], and regarding mortality [35] after bolus administration. Recently, an artificial surfactant aerosolized in a piglet model of acute lung injury resulted in improved gas exchange [36]. We have previously shown that artificial surfactant with two protein analogs was more resistant to inactivation when given as bolus [37]. However, physiological differences between the acute lung injury model and our preterm RDS model have to be taken into account when comparing different surfactant preparations. In addition, different nebulization techniques showed differences in their suitability for surfactant nebulization [38], and different surface active substances affected nebulization depending on the nebulizer [39]. The nebulizer we used has been reported to be suitable for nebulization of Poractant alfa, and surfactant characteristics were similar before and after nebulization [40].

Our study is limited by the fact that we found endogenous surfactant also in control animals. We believe that endogenous surfactant production was induced by maternal steroid treatment given prenatally for maturation of the animals [21]. However, in our opinion this setting best reflects the clinical situation, as prenatal corticosteroid treatment for women at risk of preterm birth is the gold standard [41]. In addition, we refrained from using animals of younger gestational age to maintain a sufficient intrinsic drive for breathing without additional drugs like caffeine, which might have had additive effects on endogenous surfactant production [42]. 
Our study might also be limited by the use of binasal prongs for CPAP, which reached about $2 \mathrm{~cm}$ into the nostrils. Although the amount of surfactant measured in the stomach was surprisingly low, we might underestimate surfactant losses into the mouth, within the nose and in the esophageal groove, as well as additional dilution by saliva and gastric secretion. However, in our opinion binasal CPAP using prongs best reflects the clinical situation and has proven to be beneficial in a clinical setting [43]. Furthermore, the combination of CPAP and nebulization resulted in blood gas values acceptable within the limits of permissive hypercapnia, and are comparable to values of lambs receiving CPAP alone [44]. Additionally, we did not observe complications such as pneumothorax during CPAP and nebulization, further indicating the safety of the method.

In conclusion, our model allowed surfactant nebulization in a near-clinical setup using binasal CPAP in spontaneously breathing premature lambs. In combination with a customized nebulizer, surfactant was distributed to the lung of the animals and improved physiological parameters. However, the interaction between surfactant dose, treatment duration, air humidity and local surfactant distribution remains complex. By using translational models to identify pharmacological and technical factors influencing surfactant distribution and treatment effects, nebulization might allow surfactant therapy in the least invasive and most sophisticated way.

\section{ACKNOWLEDGMENTS}

The authors would like to thank Nico Kloosterboer for excellent technical assistance and Dennis Kruk, Jennifer Collins and Monique Willems for their valuable support in the experimental handling of the animals. 


\section{REFERENCES}

1. Wirbelauer, J. and C.P. Speer, The role of surfactant treatment in preterm infants and term newborns with acute respiratory distress syndrome. Journal of perinatology : official journal of the California Perinatal Association, 2009. 29 Suppl 2: p. S18-22.

2. Jobe, A.H. and M. Ikegami, Surfactant metabolism. Clinics in perinatology, 1993. 20(4): p. 683-96.

3. Mercier, C.E. and R.F. Soll, Clinical trials of natural surfactant extract in respiratory distress syndrome. Clinics in perinatology, 1993. 20(4): p. 711-35.

4. Soll, R.F. and C.J. Morley, Prophylactic versus selective use of surfactant in preventing morbidity and mortality in preterm infants. The Cochrane database of systematic reviews, 2001(2): p. CD000510.

5. Seger, N. and R. Soll, Animal derived surfactant extract for treatment of respiratory distress syndrome. The Cochrane database of systematic reviews, 2009(2): p. CD007836.

6. Marshall, T.A., et al., Physiologic changes associated with endotracheal intubation in preterm infants. Critical care medicine, 1984. 12(6): p. 501-3.

7. Tarawneh, A., et al., Severe airway obstruction during surfactant administration using a standardized protocol: a prospective, observational study. Journal of perinatology : official journal of the California Perinatal Association, 2012. 32(4): p. 270-5.

8. Dargaville, P.A., et al., Preliminary evaluation of a new technique of minimally invasive surfactant therapy. Archives of disease in childhood. Fetal and neonatal edition, 2011. 96(4): p. F243-8.

9. Gopel, W., et al., Avoidance of mechanical ventilation by surfactant treatment of spontaneously breathing preterm infants (AMV): an open-label, randomised, controlled trial. Lancet, 2011. 378(9803): p. 1627-34.

10. Kribs, A., et al., Early administration of surfactant in spontaneous breathing with nCPAP: feasibility and outcome in extremely premature infants (postmenstrual age </=27 weeks). Paediatric anaesthesia, 2007. 17(4): p. 364-9.

11. Robillard, E., et al., Microaerosol Administration of Synthetic Beta-Gamma-Dipalmitoyl-L-Alpha-Lecithin in the Respiratory Distress Syndome: A Preliminary Report. Canadian Medical Association journal, 1964. 90: p. 55-7.

12. Abdel-Latif, M.E. and D.A. Osborn, Nebulised surfactant in preterm infants with or at risk of respiratory distress syndrome. The Cochrane database of systematic reviews, 2012. 10: p. CD008310.

13. Berggren, E., et al., Pilot study of nebulized surfactant therapy for neonatal respiratory distress syndrome. Acta paediatrica, 2000. 89(4): p. 460-4.

14. Arroe, M., et al., Inhalation of aerosolized surfactant (Exosurf (R)) to neonates treated with nasal continuous positive airway pressure. Prenatal and Neonatal Medicine, 1998. 3(3): p. 346-352.

15. Finer, N.N., et al., An open label, pilot study of Aerosurf(R) combined with nCPAP to prevent RDS in preterm neonates. Journal of aerosol medicine and pulmonary drug delivery, 2010. 23(5): p. 303-9.

16. Jorch, G., et al., Surfactant aerosol treatment of respiratory distress syndrome in spontaneously breathing premature infants. Pediatric pulmonology, 1997. 24(3): p. 222-4.

17. Lewis, J.F., et al., Aerosolized surfactant treatment of preterm lambs. Journal of applied physiology, 1991. 70(2): p. 869-76.

18. Dijk, P.H., A. Heikamp, and S. Bambang Oetomo, Surfactant nebulisation: lung function, surfactant distribution and pulmonary blood flow distribution in lung lavaged rabbits. Intensive care medicine, 1997. 23(10): p. 1070-6.

19. van Kaam, A.H., et al., Surfactant replacement therapy in preterm infants: a European survey. Neonatology, 2011. 100(1): p. 71-7.

20. Pringle, K.C., Human fetal lung development and related animal models. Clinical obstetrics and gynecology, 1986. 29(3): p. 502-13.

21. Jobe, A.H., et al., Betamethasone for lung maturation: testing dose and formulation in fetal sheep. American journal of obstetrics and gynecology, 2007. 197(5): p. 523 e1-6.

22. Niemarkt, H.J., et al., Effects of less-invasive surfactant administration on oxygenation, pulmonary surfactant distribution, and lung compliance in spontaneously breathing preterm lambs. Pediatric research, 2014. 


\section{Chapter 2}

23. Jobe, A.H., et al., Endotoxin-induced lung maturation in preterm lambs is not mediated by cortisol. American journal of respiratory and critical care medicine, 2000. 162(5): p. 1656-61.

24. Mason, R.J., J. Nellenbogen, and J.A. Clements, Isolation of disaturated phosphatidylcholine with osmium tetroxide. Journal of lipid research, 1976. 17(3): p. 281-4.

25. Been, J.V., et al., Pulmonary vascular endothelial growth factor expression and disaturated phospholipid content in a chicken model of hypoxia-induced fetal growth restriction. Neonatology, 2010. 97(3): p. 1839.

26. Stewart, J.C., Colorimetric determination of phospholipids with ammonium ferrothiocyanate. Analytical biochemistry, 1980. 104(1): p. 10-4.

27. Rahmel, D.K., et al., The non-intubated, spontaneously breathing, continuous positive airway pressure (CPAP) ventilated pre-term lamb: a unique animal model. Reproductive toxicology, 2012. 34(2): p. 204-15.

28. Wolfson, M.R., et al., Dose-Response to Aerosolized KL4 Surfactant in the Spontaneously Breathing CPAPSupported Preterm Lamb. Pediatric research, 2011. 70(S5): p. 751-751.

29. Walther, F.J., J.M. Hernandez-Juviel, and A.J. Waring, Aerosol delivery of synthetic lung surfactant. PeerJ, 2014. 2: p. e403.

30. Rey-Santano, C., et al., Acute and sustained effects of aerosolized vs. bolus surfactant therapy in premature lambs with respiratory distress syndrome. Pediatric research, 2013. 73(5): p. 639-46.

31. Wagner, M.H., et al., Endotracheal surfactant atomization: an alternative to bolus instillation? Critical care medicine, 2000. 28(7): p. 2540-4.

32. Brain, J.D., et al., Pulmonary distribution of particles given by intratracheal instillation or by aerosol inhalation. Environmental research, 1976. 11(1): p. 13-33.

33. Pillow, J.J., et al., Oxygen, temperature and humidity of inspired gases and their influences on airway and lung tissue in near-term lambs. Intensive care medicine, 2009. 35(12): p. 2157-63.

34. Dizdar, E.A., et al., A randomized, controlled trial of poractant alfa versus beractant in the treatment of preterm infants with respiratory distress syndrome. American journal of perinatology, 2012. 29(2): p. 95100.

35. Ramanathan, R., et al., Mortality in preterm infants with respiratory distress syndrome treated with poractant alfa, calfactant or beractant: a retrospective study. Journal of perinatology : official journal of the California Perinatal Association, 2013. 33(2): p. 119-25.

36. Lampland, A.L., et al., Aerosolized KL4 surfactant improves short-term survival and gas exchange in spontaneously breathing newborn pigs with hydrochloric acid-induced acute lung injury. Pediatric pulmonology, 2014. 49(5): p. 482-9.

37. Seehase, M., et al., New surfactant with SP-B and $C$ analogs gives survival benefit after inactivation in preterm lambs. PloS one, 2012. 7(10): p. e47631.

38. Pillow, J.J. and S. Minocchieri, Innovation in Surfactant Therapy II: Surfactant Administration by Aerosolization. Neonatology, 2012. 101(4): p. 337-344.

39. Arzhavitina, A. and H. Steckel, Surface active drugs significantly alter the drug output rate from medical nebulizers. International journal of pharmaceutics, 2010. 384(1-2): p. 128-36.

40. Minocchieri, S., et al., Nebulizing poractant alfa versus conventional instillation: Ultrastructural appearance and preservation of surface activity. Pediatric pulmonology, 2014. 49(4): p. 348-56.

41. Roberts, D. and S. Dalziel, Antenatal corticosteroids for accelerating fetal lung maturation for women at risk of preterm birth. The Cochrane database of systematic reviews, 2006(3): p. CD004454.

42. Fehrholz, M., et al., Amplification of steroid-mediated SP-B expression by physiological levels of caffeine. American journal of physiology. Lung cellular and molecular physiology, 2014. 306(1): p. L101-9.

43. Pillow, J.J., Which Continuous Positive Airway Pressure System is Best for the Preterm Infant with Respiratory Distress Syndrome? Clinics in perinatology, 2012. 39(3): p. 483-+.

44. Mulrooney, N., et al., Surfactant and physiologic responses of preterm lambs to continuous positive airway pressure. American journal of respiratory and critical care medicine, 2005. 171(5): p. 488-93. 


\section{Chapter}

\section{Fully automated predictive intelligent control of oxygenation (PRICO) in resuscitation and ventilation of preterm lambs}

Hütten MC*, Goos TG*, Ophelders D, Nikiforou M, Kuypers E, Willems M, Niemarkt HJ, Dankelman J, Andriessen P, Mohns T, Reiss IK, Kramer BW.

Pediatr Res. 2015 Dec;78(6):657-63. doi: 10.1038/pr.2015.158. Epub 2015 Aug 31.

*contributed equally 


\section{ABSTRACT}

Background: Hyperoxia and hypoxia influence morbidity and mortality of preterm infants. Automated closed-loop control of the fraction of inspired oxygen $\left(\mathrm{FiO}_{2}\right)$ has been shown to facilitate oxygen supplementation in the NICU, but has not yet been tested during preterm resuscitation. We hypothesized that fully automated $\mathrm{FiO}_{2}$ control based on predefined oxygen saturation $\left(\mathrm{SpO}_{2}\right)$ targets was applicable in both preterm resuscitation and ventilation.

Methods: 22 preterm lambs were operatively delivered and intubated in a modified EXIT procedure. They were randomized to receive standardized resuscitation with either automated or manual $\mathrm{FiO}_{2}$ control, targeting $\mathrm{SpO}_{2}$ according to the Dawson curve in the first 10 minutes and $\mathrm{SpO}_{2}$ 90-95\% hereafter. Automated $\mathrm{FiO}_{2}$ control also was applied during surfactant replacement therapy and subsequent ventilation.

Results: Time within target range did not differ significantly between manual and automated $\mathrm{FiO}_{2}$ control during resuscitation, however automated $\mathrm{FiO}_{2}$ control significantly avoided hyperoxia. Automated $\mathrm{FiO}_{2}$ control was feasible during surfactant replacement and kept $\mathrm{SpO}_{2}$ within target range significantly better than manual control during subsequent ventilation.

Conclusion: In our model, fully automated $\mathrm{FiO}_{2}$ control was feasible in rapidly changing physiologic conditions during postnatal resuscitation and prevented hyperoxia. We conclude that closed loop $\mathrm{FiO}_{2}$ control is a promising tool for the delivery room. 


\section{INTRODUCTION}

Oxygen supplementation is one of the most common therapeutic interventions in resuscitation and neonatal intensive care of term and preterm infants [1]. However, both hypoxia and hyperoxia must be avoided because of their detrimental effects on morbidity and mortality in these children. While hypoxia may lead to direct and indirect cellular damage, hyperoxia has been associated with oxygen toxicity, oxidative stress [2], and chronic diseases of preterm infants such as bronchopulmonary dysplasia (BPD) [3] and retinopathy of prematurity (ROP) [4].

Increase in oxygenation after birth is a gradual process [5]. Measurement of oxygen saturation $\left(\mathrm{SpO}_{2}\right)$ by pulse oximetry in the delivery room is feasible in newborn resuscitation [6] and preterm infants within the first minutes of life [7]. $\mathrm{SpO}_{2}$ reference values of preterm infants increase within the first 10 minutes of life [5]. This has led to $\mathrm{SpO}_{2}$ target values incorporated in the current European Resuscitation Council (ERC) guidelines on resuscitation of newborns [8]. In order to avoid hyperoxia, current recommendations advice resuscitation of preterm infants with a mixture of air and oxygen, and to use fraction of inspired oxygen $\left(\mathrm{FiO}_{2}\right)$ between 0.21 and 0.30 [9]. $\mathrm{FiO}_{2}$ should subsequently be titrated according to $\mathrm{SpO}_{2}[10,11]$. General use of pulse oximetry has been shown to extensively reduce $\mathrm{O}_{2}$-derived toxicity in preterm infants [12]. However, keeping $\mathrm{SpO}_{2}$ manually within changing saturation limits during a hectic period of resuscitation is a difficult task. Large deviations from $\mathrm{SpO}_{2}$ targets during resuscitation of preterm infants have been observed in clinical studies [13].

These deviations have also been described during routine NICU care, where $\mathrm{SpO}_{2}$ target ranges are met during $50 \%$ of the time $[14,15]$. Meeting $\mathrm{SpO}_{2}$ targets affects morbidity and mortality, depending on the target range chosen [16-18]. Beside overall $\mathrm{SpO}_{2}$ targets, variability of oxygenation influences outcome of preterm infants [4, 19, 20]. A promising solution to optimize oxygen therapy is the employment of an automatic "closed loop" system for regulation of $\mathrm{FiO}_{2}$ based on $\mathrm{SpO}_{2}$. Several clinical trials with different devices have proven feasibility of automated closed loop $\mathrm{FiO}_{2}$ control in the $\mathrm{NICU}$ for various modes of ventilation, mixed populations, and by using different algorithms [14, 21-26]. In addition, an overall reduction of manual interventions during automated control was found in these studies, indicating facilitation of caretakers and nursing staff in clinical routine $[27,28]$. However, at least one study raised concerns about safety, as time within target range was accompanied by an increase in time spent below saturation target range [25].

The delivery of oxygen is also crucial in the delivery room setting where automated $\mathrm{FiO}_{2}$ control has not yet been tested [28]. We therefore hypothesized that an algorithm developed for automated $\mathrm{FiO}_{2}$ control during mechanical ventilation is feasible in the delivery room setting with rapidly changing physiology of fetal transition to extrauterine life and during surfactant replacement therapy. We further hypothesized that fully automated $\mathrm{FiO}_{2}$ control conducted by this algorithm would keep $\mathrm{SpO}_{2}$ within a 
predefined target range as good as a dedicated caretaker during stable ventilation conditions. We tested our hypotheses in an established lamb model of preterm respiratory distress syndrome (RDS).

\section{MATERIALS AND METHODS}

\section{Experimental setup}

An infant ventilator (Fabian HFO, Acutronic, Hirzel, Switzerland) was prepared for digital control of the $\mathrm{FiO}_{2}$. $\mathrm{SpO}_{2}$ measurement was obtained via a Masimo pulse oximeter (Radical 7, Masimo Inc., Irvine, CA). Both devices were linked to a laptop computer (ThinkPad T500, Lenovo Pte., Singapore, with Windows 7, Microsoft Corp., Redmond, WA), containing control software with a user interface showing $\mathrm{SpO}_{2}, \mathrm{FiO}_{2}$, pulse and $\mathrm{SpO}_{2}$ target ranges over time (as presented by Goos et al. on the 4th Congress of the European Academy of Pediatric Societies 2012). The algorithm used was a rule based control scheme that used both the current $\mathrm{SpO}_{2}$ together with the trend in the $\mathrm{SpO}_{2}$ measurement (Figure 1). The trend was used to fine tune the $\mathrm{FiO}_{2}$ step size by recognizing larger and quicker changes. A prediction based on the trend was used to limit under- and overshoot. A number of safety checks were performed before an automated $\mathrm{FiO}_{2}$ adjustment could be made, including checks for proper ventilation (TVe and percentage of leak within acceptable limits), reliable connections between all devices and an assessment on the correctness of all measured parameters. After each adjustment a $30 \mathrm{~s} \mathrm{time}$ out followed to allow the effect of the adjustment to be observed. 


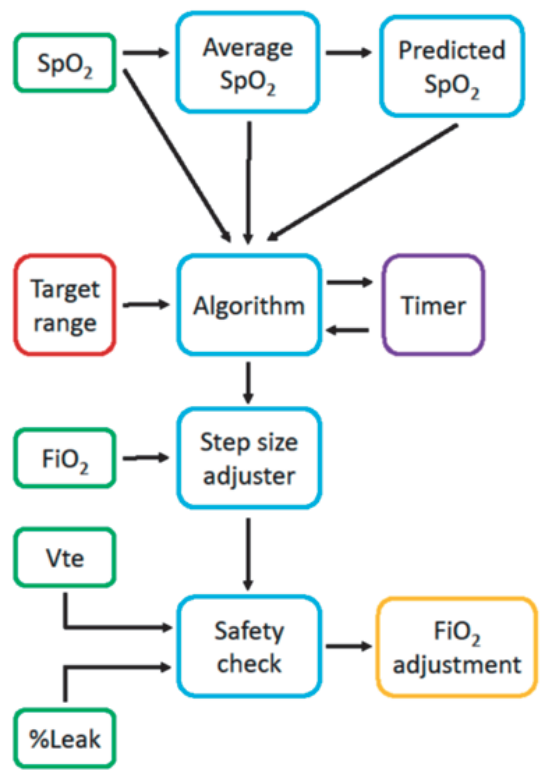

Figure 1: Flow scheme of algorithm

\section{Animal study}

The lamb model of neonatal RDS allowed us a translational approach due to its physiologic similarities of lung development in humans [29,30]. Furthermore, anatomy and body size allowed us the use of the original equipment used in the neonatal intensive care units. The study design and the experimental protocol were in line with the institutional guidelines for animal experiments and were approved by the institutional Animal Ethics Research Committee, Maastricht University, The Netherlands.

One day before caesarean section, 22 date-mated ewes received an intra-muscular injection with betamethasone (12 mg, Celestone Chronodose, Schering-Plough, North Ryde, New South Wales, Australia) to induce fetal lung maturation [31]. Before delivery, lambs were randomly assigned to four different treatment groups for resuscitation and independently for two different treatment groups for subsequent stable ventilation. This setup allowed us to separately analyse the algorithm during rapidly changing and stable conditions.

\section{Resuscitation}

Lambs were operatively delivered prematurely at a gestational age of 128-132 days (term 150 d) via a modified EXIT procedure, equipped with umbilical artery and vein catheters and intubated orally with a cuffed tube [32]. The arterial catheter was used to monitor heart rate and blood pressure, and to frequently obtain blood for blood gas 
analysis. After cord clamping, lambs were weighed, sedated and transferred to an infant radiator bed (IW930 Series CosyCot Infant Warmer, Fisher \& Paykel Healthcare, Auckland, New Zealand). An adhesive pulse oximeter sensor (M-LNCS Neo, MasimoSET, Masimo Inc., Irvine, CA) was placed around the tongue and subsequently connected to the pulse oximeter. Resuscitation in the first 15 minutes was standardized to the greatest possible extend. This was achieved by connecting lambs to an infant ventilator set to volume-controlled mechanical ventilation (volume guarantee $6-7 \mathrm{ml} / \mathrm{kg}$, max. PIP 45 $\mathrm{cmH}_{2} \mathrm{O}$, frequency $50 / \mathrm{min}$ ). $\mathrm{FiO}_{2}$ at start of resuscitation was randomized to either 0.3 or 0.6. $\mathrm{FiO}_{2}$ was adjusted to keep the lamb within the $25^{\text {th }}$ and $75^{\text {th }}$ percentile of saturation in preterm infants according to Dawson [5] for the first ten minutes and subsequently between $90 \%$ and $95 \%$. In all experiments, $\mathrm{FiO}_{2}$ was either controlled by the algorithm alone, without manual interventions allowed, or by a caretaker. This person was solely dedicated to adjusting $\mathrm{FiO}_{2}$, while resuscitation was performed by others. $\mathrm{FiO}_{2}$ adjustment was performed by experienced animal researchers and medical doctors or last year students with experience in neonatology, who were not limited regarding frequency and size of $\mathrm{FiO}_{2}$ changes. Outcome parameters for the resuscitation part were time within, above and below target range, number of events outside the target range, and total number of $\mathrm{FiO}_{2}$ adjustments.

\section{Stabilization and surfactant replacement therapy}

Resuscitation was followed by a short stabilization period. Animals which needed a fraction of inspired oxygen $\left(\mathrm{FiO}_{2}\right)$ above 0.8 at any time during resuscitation or stabilization were eligible to receive surfactant replacement therapy with Poractant alfa (Curosurf, $100 \mathrm{mg} / \mathrm{kg}$ body weight, Chiesi Pharmaceuticals, Pari, Italy). Lambs were considered to be stabilized after 30 minutes, or if they received surfactant, 15 minutes after surfactant replacement therapy. We recorded $\mathrm{SpO}_{2}$ and $\mathrm{FiO}_{2}$ before and after surfactant replacement therapy.

\section{Stable ventilation}

After stabilization, stabilized lambs were mechanically ventilated with either automated or manual $\mathrm{FiO}_{2}$ control for three hours. Automated $\mathrm{FiO}_{2}$ control was performed without additional manual interventions. In the manual group, caretaker-lamb ratio was 1:1. Arterial blood gas analysis was obtained every 30 minutes and respiratory settings were adjusted to keep $\mathrm{P}_{\mathrm{a}} \mathrm{CO}_{2}$ between 45 and $65 \mathrm{mmHg}$. Saturation target range was $90-95 \%$ according to current consensus guidelines from European neonatologists [33], and the alarm range was set accordingly. Outcome parameters were time within and outside $\mathrm{SpO}_{2}$ target range (90-95\%), number and duration of episodes of hyperoxia $\left(\mathrm{SpO}_{2}>\right.$ $95 \%)$, hypoxia $(<85 \%)$ and severe hypoxia $(<75 \%)$, average variation from median target saturation and total number of $\mathrm{FiO}_{2}$ adjustments. For analysis, we excluded times 
when (i) animals showed saturation above the high target without a need for supplemental oxygen or when (ii) $\mathrm{SpO}_{2}$ was below the low target despite a $\mathrm{FiO}_{2}$ of 1.0. This was done because during these episodes, $\mathrm{FiO}_{2}$ control alone was not capable of keeping oxygen targets within the predefined limits.

\section{Statistics}

Normally distributed data are expressed as mean and standard deviation (SD), nonnormally-distributed data are expressed as median and interquartile range (IQR). Statistical analysis was performed using Student's t-test for normally distributed data and Mann- Whitney test for non-normally distributed data, using IBM SPSS version 20 (IBM, Armink, NY). Graphs were drawn with Microsoft Excel 2010 and GraphPad Prism v5.0 (GraphPad Software, San Diego, CA). Significance was accepted at $p<0.05$.

\section{RESULTS}

\section{Animal characteristics}

Preterm lambs did not vary significantly in baseline characteristics and ventilation parameters in both the resuscitation part and the stable ventilation part of the study (Table 1). From 22 animals, 19 animals could be included for analysis of the resuscitation period. 2 animals were excluded because the control software was unintentionally activated other than intended in the protocol, and one animal was excluded because of sensor malfunction. In all animals included, time until first $\mathrm{SpO}_{2}$ measurement was about 2 minutes (median $106 \mathrm{~s}$, IQR (80-148 s)) and time until pulse readout of the pulse oximeter correlated to the heart rate was 3 minutes on average (median $181 \mathrm{~s}$, IQR (129-271s)). Fifteen animals underwent automated $\mathrm{FiO}_{2}$ control during resuscitation, from which 9 started with a $\mathrm{FiO}_{2}$ of 0.3 and 6 started with a $\mathrm{FiO}_{2}$ of 0.6. In 4 animals $\mathrm{FiO}_{2}$ was controlled manually (starting from $\mathrm{FiO}_{2} 0.3$ in 3 and from $\mathrm{FiO}_{2} 0.6$ in 1 animal). 


\section{Chapter 3}

Table 1: Animal characteristics

\begin{tabular}{|c|c|c|c|c|c|c|}
\hline & & \multicolumn{2}{|c|}{ automated } & \multicolumn{2}{|l|}{ manual } & $\mathrm{p}$ \\
\hline \multicolumn{7}{|l|}{ Resuscitation } \\
\hline number of animals & & 15 & & 4 & & \\
\hline male : female $(n)$ & & $5: 10$ & & $1: 3$ & & \\
\hline surfactant replacement & & 9 & & 1 & & \\
\hline gestational age $(d)$ & median (IQR) & 130 & $(128-132)$ & 130 & $(129-131)$ & 0.589 \\
\hline birth weight (kg) & mean (SD) & 3.5 & $(0.8)$ & 3.1 & $(0.8)$ & 0.375 \\
\hline \multicolumn{7}{|l|}{ First blood gas analysis } \\
\hline $\mathrm{pH}$ & mean (SD) & 7.14 & $(0.10)$ & 7.15 & $(0.08)$ & 0.912 \\
\hline $\mathrm{P}_{\mathrm{a}} \mathrm{CO}_{2}(\mathrm{mmHg})$ & median (IQR) & 62.2 & $(55.0-70.7)$ & 50.1 & $(49.1-50.1)$ & 0.115 \\
\hline $\mathrm{P}_{\mathrm{a}} \mathrm{O}_{2}(\mathrm{mmHg})$ & median (IQR) & 43 & $(39-45)$ & 39 & $(30-39)$ & 0.411 \\
\hline \multicolumn{7}{|c|}{ Blood gas analysis after resuscitation } \\
\hline $\mathrm{pH}$ & mean (SD) & 7.18 & $(0.15)$ & 7.19 & $(0.11)$ & 0.899 \\
\hline $\mathrm{P}_{\mathrm{a}} \mathrm{CO}_{2}(\mathrm{mmHg})$ & median (IQR) & 56.0 & $(44.2-85.3)$ & 52.6 & $(47.8-58.3)$ & 0.368 \\
\hline $\mathrm{P}_{\mathrm{a}} \mathrm{O}_{2}(\mathrm{mmHg})$ & median (IQR) & 51 & $(41-57)$ & 44 & $(35-54)$ & 0.342 \\
\hline \multicolumn{7}{|l|}{ Stable ventilation } \\
\hline number of animals & & 11 & & 11 & & \\
\hline male : female $(n)$ & & $4: 7$ & & $4: 7$ & & \\
\hline gestational age (d) & median (IQR) & 130 & $(129-132)$ & 130 & $(129-131)$ & 0.401 \\
\hline birth weight (kg) & mean (SD) & 3.7 & $(0.8)$ & 3.2 & $(0.7)$ & 0.545 \\
\hline average $\mathrm{FiO}_{2}$ & median (IQR) & 0.60 & $(0.25-0.66)$ & 0.35 & $(0.25-0.49)$ & 0.243 \\
\hline PIP (mbar) & median (IQR) & 24 & $(23-30)$ & 25 & $(23-34)$ & 1.000 \\
\hline PEEP (mbar) & median (IQR) & 6.1 & $(5.7-7.3)$ & 6.1 & $(5.6-7.2)$ & 0.438 \\
\hline TVe (ml) & mean (SD) & 21.9 & $(5.2)$ & 20.6 & $(4.7)$ & 0.519 \\
\hline
\end{tabular}

IQR interquartile range; SD standard deviation; PIP: positive inspiratory pressure; PEEP: positive end expiratory pressure; TVe: expiratory tidal volume

\section{Resuscitation}

$\mathrm{SpO}_{2}$ target during resuscitation was defined as $25^{\text {th }}$ and $75^{\text {th }}$ percentile over time for both groups (Figure $2 \mathrm{~A}$ ). Relative time within target range did not differ significantly within groups (Table 2). However, we observed significantly less time spent above the target range in the automated group, while time below the target range was similar (Table 2). Average time until first $\mathrm{FiO}_{2}$ adjustment was below 3 minutes in both the automated and the manual group (median $160 \mathrm{~s}$, IQR (134-208 s) vs. $149 \mathrm{~s}$ (81-1698 s), $\mathrm{p}=0.317)$. The average number of adjustments during resuscitation was similar in both groups (median 27, IQR (17-35) vs. 28 (20-36); $p=0.796)$. 

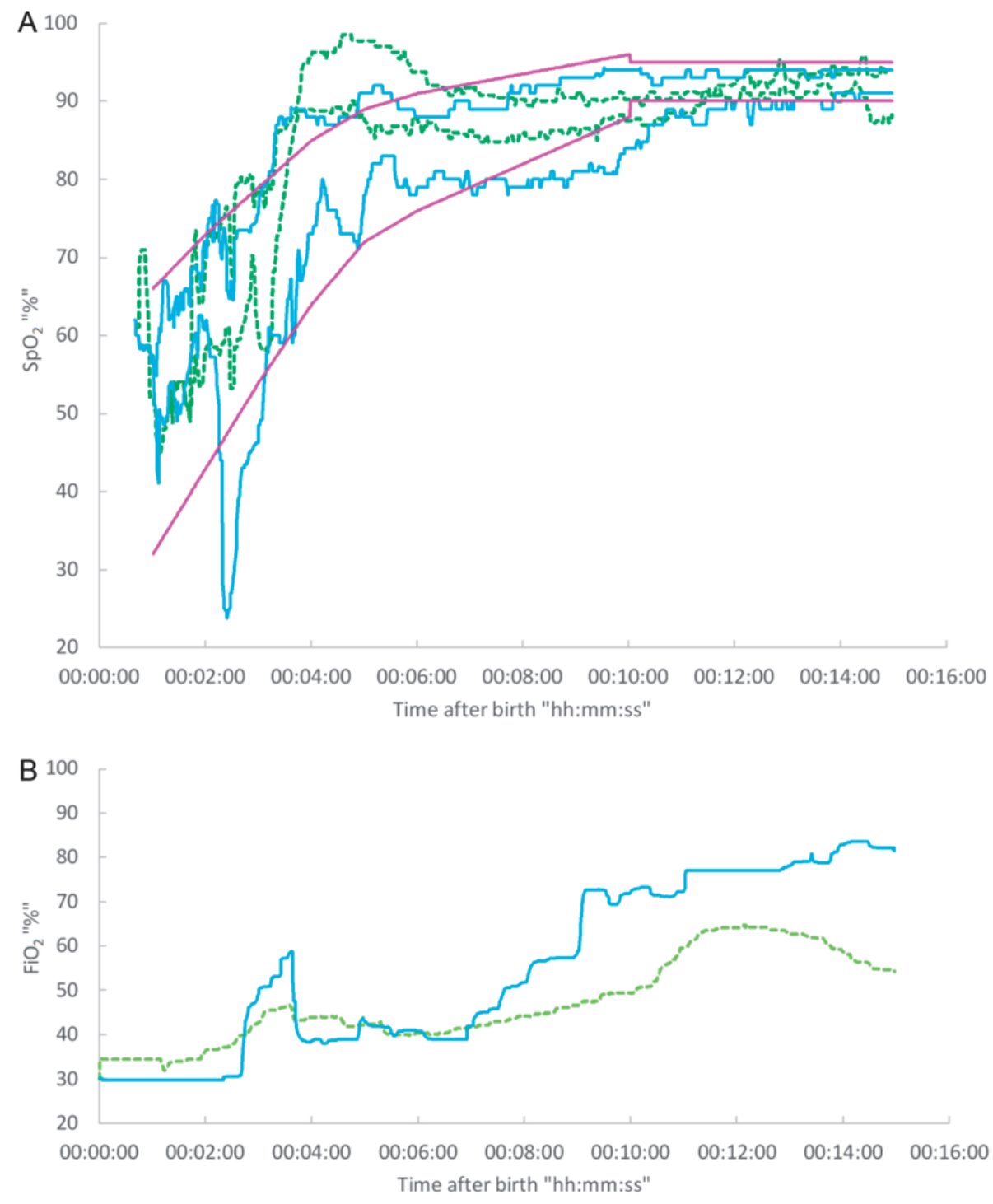

Figure 2: Resuscitation $\mathrm{SpO}_{2}$ and $\mathrm{FiO}_{2}:(\mathrm{A}) \mathrm{SpO}_{2}(\%)$ during resuscitation is depicted as $25^{\text {th }}$ and $75^{\text {th }}$ percentile over time for automated (solid blue line) and manual (dotted green line) $\mathrm{FiO}_{2}$ control. (B) depicts the $\mathrm{FiO}_{2}$ (median) during resuscitation for the automated (solid blue lines) and manual (dotted green lines) control. 
Table 2: Time within and outside saturation targets during resuscitation

\begin{tabular}{llllll}
\hline \multicolumn{2}{c}{ automated } & & manual & & $\mathrm{p}$ \\
\hline Relative time & & & & & \\
within target range & $44.3 \%$ & $(30.7-48.1 \%)$ & $41.4 \%$ & $(28.6-66.8 \%)$ & 0.456 \\
outside target range & $34.6 \%$ & $(25.3-36.7 \%)$ & $42.2 \%$ & $(24.7-58.6 \%)$ & 0.212 \\
above target range & $6.8 \% *$ & $(3.4-16.7 \%)$ & $18.9 \%$ & $(10.5-32.4 \%)$ & 0.035 \\
below target range & $20.3 \%$ & $(15.4-31.8 \%)$ & $13.3 \%$ & $(7.0-43.3 \%)$ & 0.908 \\
Number of times & & & & & 0.480 \\
outside target range & 5 & $(4-9)$ & 8.5 & $(6-10)$ & $(2-7)$ \\
above target range & 2 & $(1-4)$ & 3.5 & $(3-5)$ & 0.354 \\
below target range & 3 & $(2-5)$ & 4.5 & & 0.826 \\
\hline
\end{tabular}

Data is given as Median and (IQR). ${ }^{*} \mathrm{p}<0.05$ compared to manual.

\section{Automated resuscitation with $\mathrm{FiO}_{2} 0.3$ vs. 0.6}

Time within target range did not differ between animals receiving automated $\mathrm{FiO}_{2}$ control with an initial $\mathrm{FiO}_{2}$ of 0.3 compared to $\mathrm{FiO}_{2} 0.6$ (median 44.9\%, IQR (24.2-48.5\%) vs. $40.6 \%$ (30.5-45.9\%), p=0.814). However, animals resuscitated with an initial $\mathrm{FiO}_{2}$ of 0.3 showed significant less time above target range than animals resuscitated with $\mathrm{FiO}_{2} 0.6$ (3.7\% (1.6-8.0\%) vs. $14.9 \%$ (9.2-23.3\%), $\mathrm{p}=0.008)$, while time below target range did not differ significantly (23.5\% (18.9-32.1\%) vs. 19.9\% (6.4-34.5\%), $p=0.587$ ).

Median applied $\mathrm{FiO}_{2}$ at the end of the resuscitation period was higher in the automated group (Figure $2 \mathrm{~B}$ ), however the oxygen need was highly variable in both the automated (IQR (0.52-0.98)) and the manual group (IQR (0.37-0.72)).

\section{Automated $\mathrm{FiO}_{2}$ control during stabilization and surfactant replacement therapy}

Nine animals received surfactant replacement therapy in the stabilization period during automated $\mathrm{FiO}_{2}$ control. After surfactant replacement, $\mathrm{FiO}_{2}$ was decreased from 0.97 (IQR (0.86-0.99)) to $0.46(0.35-0.56)$ in $14(10-16)$ steps (Figure $3 \mathrm{~B})$. The maximum number of steps the algorithm could make due to timeout restrictions of $30 \mathrm{~s}$ between steps was 20. Average time until the last $\mathrm{FiO}_{2}$ step down after surfactant replacement was $623 \mathrm{~s}$ (IQR 421-807 s).

In the 10 minutes after surfactant administration $\mathrm{SpO}_{2}$ was subsequently kept close to target ranges, but was within the target range $44 \%$ of the time and above the range $54 \%$ (Figure $3 \mathrm{~A}$ ). Average time until $\mathrm{SpO}_{2}$ was again within target range after surfactant replacement was 576 s (387 -650 s). SpO $\mathrm{Sp}_{2}$, however, reached $100 \%$ in only $9 \%$ of the time. 

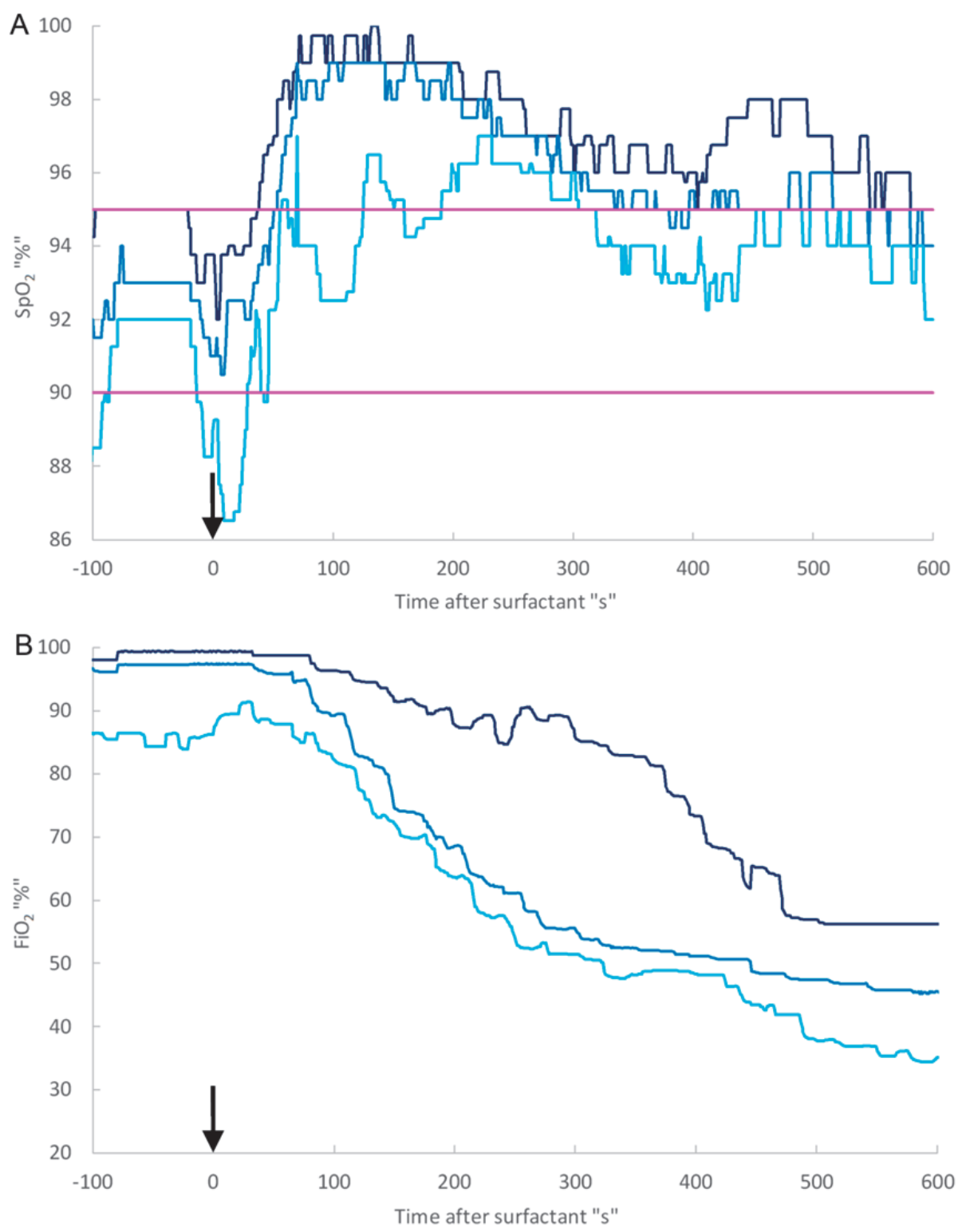

Figure 3: $\mathrm{FiO}_{2}$ and $\mathrm{SpO}_{2}$ after surfactant administration during automated $\mathrm{FiO}_{2}$ control: After surfactant application (arrow), $\mathrm{SpO}_{2}(\mathrm{~A})$ reached target range on average within less than 10 minutes. $\mathrm{FiO}_{2}(\mathrm{~B})$ was automatically adjusted according to changed oxygen needs (depicted are median (medium blue), $25^{\text {th }}$ (light blue) and $75^{\text {th }}$ percentile (dark blue line)). 


\section{Stable ventilation}

Animals were stabilized within the first half hour of life (median 33:11 min:sec, IQR (30:01-39:47 min:sec)). During the subsequent stable ventilation phase, time spend within the target range was significantly higher when the automated controller was used (93.2\% (80.6-98.9\%) vs. 84.0\% (63.8-89.4\%), p<0.05, Figure 4 A), and time outside the target range, depicted as area under the curve $\left(\mathrm{SpO}_{2}{ }^{*} \mathrm{sec}\right.$ per hour) was significantly lower (Figure $4 \mathrm{~A}$ ). The number of episodes outside the target range per hour was also significantly lower in the automated group (Table 3).
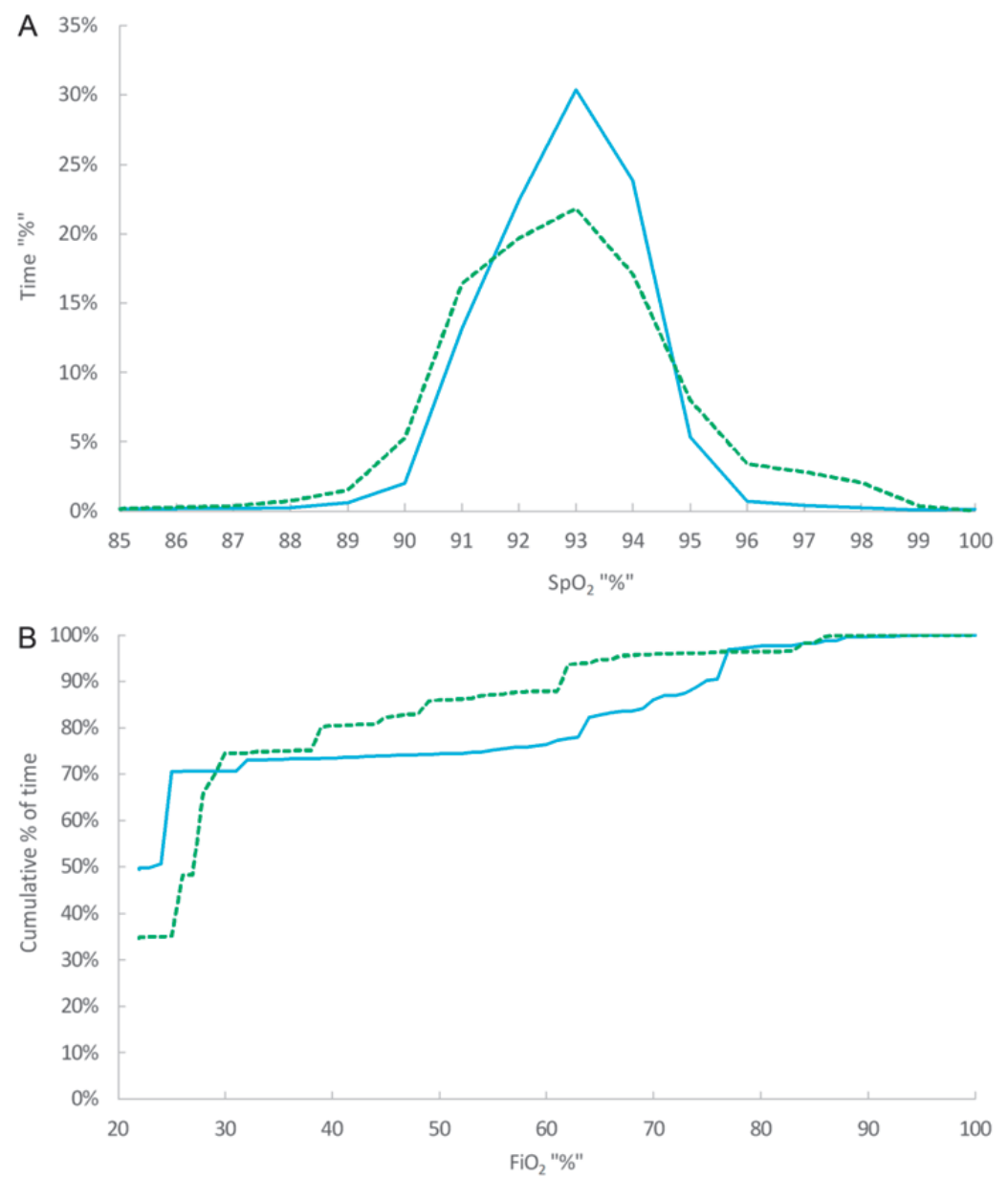

Figure 4: Stable ventilation $\mathrm{SpO}_{2}$ and $\mathrm{FiO}_{2}$ : Distribution of oxygen saturation during stable ventilation in percentage of time (A) was significantly more within predefined limits in the automated (solid blue line) compared to the manual (dotted green line) group. Need for supplemental oxygen highly varied between animals in both experimental groups, as depicted (B) by the cumulative percentage of time spent at different levels of $\mathrm{FiO}_{2}$ during stable ventilation in the automated (solid blue line) and manual group (dotted green line). 
When comparing hypoxic and hyperoxic episodes, animals ventilated with automated control had significantly less episodes below the lower target saturation of $90 \%$ and showed a trend towards less hyperoxic episodes per hour ( $p=0.065$, Table 3 ). We observed only a small number of short hypoxic $(<85 \%)$ and severe hypoxic $(<75 \%)$ episodes in our model, and number of these episodes did not differ between groups. This was also reflected in the low average deviation of saturation from the median target saturation in both groups (Table 3). The duration of hyperoxic, hypoxic and severe hypoxic episodes did no differ significantly between groups.

Compared to manual control, the number of $\mathrm{FiO}_{2}$ adjustments per hour was 2.3 times higher in the automated group, although this difference was not significant (median 13.0, IQR (3.0-16.4) vs. 5.7 (2.3-9.8), p=0.243). Applied $\mathrm{FiO}_{2}$ did not differ significantly between groups, and we observed a heterogeneous need for oxygen within the groups (Figure $3 \mathrm{~B}$ ). Animals in the manual group were outside target range longer with higher oxygen need, however correlation between time outside target range and average $\mathrm{FiO}_{2}$ was not significant $\left(\mathrm{R}^{2}\right.$ linear $\left.=0.614, \mathrm{p}=0.889\right)$. In the automated group, average $\mathrm{FiO}_{2}$ and time outside target range did not correlate $\left(R^{2}\right.$ linear $\left.=0.229, p=0.136\right)$.

Table 3: Number and duration of hyperoxic, hypoxic and severe hypoxic episodes during stable ventilation

\begin{tabular}{|c|c|c|c|c|c|}
\hline \multirow[b]{2}{*}{ No of episodes above $95 \%$ per hour } & \multirow[b]{2}{*}{0.0} & \multirow{2}{*}{$\frac{\text { automated }}{(0.0-1.4)}$} & \multicolumn{2}{|c|}{ manual } & \multirow{2}{*}{$\frac{p}{0.065}$} \\
\hline & & & 3.3 & $(0.6-10.3)$ & \\
\hline average duration of episodes $>95 \%$ (sec) & 18.5 & $(7.5-51.1)$ & 16.5 & $(13.1-57.7)$ & 0.797 \\
\hline No of episodes below $90 \%$ per hour & $1.4^{*}$ & $(0.9-2.2)$ & 4.0 & $(1.7-6.4)$ & 0.010 \\
\hline average duration of episodes $<90 \%$ (sec) & 4.7 & $(1.0-27.5)$ & 14.6 & $(6.3-49.4)$ & 0.088 \\
\hline No of episodes below $85 \%$ per hour & 0.0 & $(0.0-0.3)$ & 0.0 & $(0.0-0.7)$ & 0.748 \\
\hline average duration of episodes $<85 \%$ (sec) & 16.5 & $(6.0-29.3)$ & 36.3 & $(6.6-157.5)$ & 0.686 \\
\hline No of episodes below $75 \%$ per hour & 0.0 & $(0.0-0.0)$ & 0.0 & $0.0-0.3$ & 0,438 \\
\hline average duration of episodes $<75 \%$ (sec) & 5.0 & & 47.8 & $(1.0-75.0)$ & 1.000 \\
\hline Average deviation from target saturation $\left(\mathrm{SpO}_{2} \%\right)$ & 1.0 & $(0.0-1.9)$ & 1.7 & $(1.1-2.4)$ & 0.171 \\
\hline
\end{tabular}

Data is given as Median and (IQR). ${ }^{*} \mathrm{p}<0.05$ compared to manual.

\section{DISCUSSION}

We tested in our study if fully automated $\mathrm{FiO}_{2}$ control without manual interventions was feasible to keep preterm lambs within a predefined $\mathrm{SpO}_{2}$ target range under both rapidly changing conditions in a delivery room setting and under stable volume guarantee ventilation. Tailoring oxygen supplementation to the needs of preterm infants in the first minutes of life is difficult because of the gradual increase of oxygenation [5]. In our study, time within target range with both manual and automated $\mathrm{FiO}_{2}$ control resembled clinical data obtained in the delivery room [13]. 
Our data indicated that automated $\mathrm{FiO}_{2}$ control avoided hyperoxia during resuscitation. This might have resulted from the algorithm following the target ranges in a stricter way than the human controller, although the number of adjustments and time until first $\mathrm{FiO}_{2}$ adjustment did not differ between groups. However, we did not see significantly more time within target range in automated $\mathrm{FiO}_{2}$ control during resuscitation. A possible explanation is that the caretaker providing manual $\mathrm{FiO}_{2}$ adjustments was able to see the changing $\mathrm{SpO}_{2}$ target ranges depicted as Dawson's curve during resuscitation and therefore had more information about saturation trends than in a standard delivery room. This could have facilitated the decision for which $\mathrm{FiO}_{2}$ to provide, and made it easier to achieve saturations within the limits than during routine clinical resuscitation where $\mathrm{SpO}_{2}$ is presented only by pulse oximeter readout. However, we cannot rule out that the manual adjustments were based on additional clinical parameters such as heart rate, although heart rate increased adequately in both groups. Automated $\mathrm{FiO}_{2}$ control might be further improved by choosing a narrowed target range. By basing the target range on Dawson's curve, the predefined range was broader during resuscitation than during subsequent ventilation. Closed loop $\mathrm{FiO}_{2}$ control has already been shown to maintain functionality in a setting of narrowed target ranges in the NICU [34]. Furthermore, automated $\mathrm{FiO}_{2}$ control might be improved by allowing the algorithm to change $\mathrm{FiO}_{2}$ more frequently, although the limitation of at least 30 seconds between two steps resembled clinical recommendations [10].

Avoidance of oxygen overexposure is a major concern for implementing automated control in the delivery room [28]. In our study, animals resuscitated with an initial $\mathrm{FiO}_{2}$ of 0.3 showed less $\mathrm{SpO}_{2}$ above target range than animals initially resuscitated with $\mathrm{FiO}_{2}$ 0.6 , although $\mathrm{FiO}_{2}$ had to be increased during resuscitation in the first group. The starting $\mathrm{FiO}_{2}$ had an effect until about 5 minutes after birth. This observation is in accordance to a previous study where initial $\mathrm{FiO}_{2}$ of 0.3 or 0.65 had a significant effect on the $\mathrm{FiO}_{2}$ during the first 6 minutes of life [35]. This data supports previous findings that resuscitation with initially low $\mathrm{FiO}_{2}$ might be beneficial for preterm infants [9].

Automated $\mathrm{FiO}_{2}$ control was also feasible directly after surfactant replacement therapy. The automated controller showed immediate and adequate reaction on the altered needs for supplemental oxygen. In this scenario, a caretaker might have the advantage from knowing what to expect from the applied treatment. However, the small number of animals receiving surfactant during the study did not allow us a direct comparison between automated and manual control after surfactant replacement therapy.

During stable ventilation, animals receiving automated $\mathrm{FiO}_{2}$ control spent significantly more time within the predefined target range. This advanced performance of the controller was striking, as manual control was performed in a 1-on-1 setting by a person without other tasks than ventilation control during the experiment. This dedicated $\mathrm{FiO}_{2}$ control, which is different from the clinical situation, improved time within target range compared to routine control in a previous study [23]. In a clinical setting, meeting $\mathrm{SpO}_{2}$ target ranges depends -amongst others - on patient-caretaker ratio [36]. Most closed loop studies compared automated to routine clinical care [14, 21, 24-26], only one 
study could show a significant improvement comparing closed loop to dedicated manual control [22]. In addition, in our study alarm range was equal to target range, which created an ideal setting for dedicated manual control as caregivers are more effective in keeping $\mathrm{SpO}_{2}$ within alarm limits then within target limits in preterm infants [37]. Interestingly, our data suggests that keeping animals manually within the limits was more difficult with high oxygen need, while individual oxygen need did not influence the performance of the automated control.

We therefore conclude that automated $\mathrm{FiO}_{2}$ control is applicable both during rapidly changing physiologic conditions and during stable ventilation. Automated $\mathrm{FiO}_{2}$ control has therefore the potential to facilitate delivery room management during resuscitation. On the NICU, automated $\mathrm{FiO}_{2}$ control reduced the need for manual interventions during automated control by $33 \%$ to $90 \%$ [23-25]. Only one study reported no manual interventions during automated control [22], however the overall time within target range for both manual and automated control was lower and the target range was wider compared to our study. The potential of acting autonomously for at least a certain time is a prerequisite of safe use of automated $\mathrm{FiO}_{2}$ control in this vulnerable patient population.

Nevertheless, automated control cannot outrun clinical experience, as therapeutic interventions in the delivery room have to be adapted to a multitude of parameters [38]. Early $\mathrm{SpO}_{2}$ is related not only to $\mathrm{FiO}_{2}$, but also to factors like adequate functional residual capacity (FRC) [39] and perinatal procedures like delayed cord clamping [40]. In addition, rising need for oxygen can be a symptom of a pathological condition such as pneumothorax or ventilation related complication, e.g. tube dislocation. Automated control may mask these changes, at least for a short period of time. Therefore, adequate feedback about automated intervention to the caretaker must be ensured. Additional alarms for parameters like tidal volume (TVe) should be routinely implemented.

Our model is limited by the fact that animals were mildly sedated for mechanical ventilation, partially preventing spontaneous breathing. Hypoventilation after episodes of active breathing during mechanical ventilation has been previously described as important contributor to desaturations in ventilated preterm children [41]. Automated $\mathrm{FiO}_{2}$ control might be ineffective in prevention of hypoxic spells [27]. However, our data suggests that automated control prevented episodes below target and might therefore have an effect on these episodes, as hypoxic spells have been associated with lower average $\mathrm{SpO}_{2}$ levels [42]. This highlights the need for additional studies investigating the influence of parameters defining the automated controller.

In summary, to the best of our knowledge this is the first study where we demonstrate that fully automated $\mathrm{FiO}_{2}$ control is feasible during neonatal resuscitation in a near-clinical preterm delivery room setting, and that automated control prevents hyperoxia. We speculate that in a clinical scenario where not only $\mathrm{SpO}_{2}$ but also clinical evaluation of the patient influence oxygen therapy, the combination of automated and manual control might even imply better results. However, this question may best be addressed in a clinical trial. In parallel, translational trials will help to improve closed-loop equipment. 


\section{REFERENCES}

1. Finer, N. and W. Rich, Neonatal resuscitation for the preterm infant: evidence versus practice. Journal of perinatology : official journal of the California Perinatal Association, 2010. 30 Suppl: p. S57-66.

2. Saugstad, O.D., Update on oxygen radical disease in neonatology. Current opinion in obstetrics \& gynecology, 2001. 13(2): p. 147-53.

3. Laughon, M., et al., Patterns of respiratory disease during the first 2 postnatal weeks in extremely premature infants. Pediatrics, 2009. 123(4): p. 1124-31.

4. Cunningham, S., et al., Transcutaneous oxygen levels in retinopathy of prematurity. Lancet, 1995. 346(8988): p. 1464-5.

5. Dawson, J.A., et al., Defining the reference range for oxygen saturation for infants after birth. Pediatrics, 2010. 125(6): p. e1340-7.

6. Sendak, M.J., A.P. Harris, and R.T. Donham, Use of pulse oximetry to assess arterial oxygen saturation during newborn resuscitation. Critical care medicine, 1986. 14(8): p. 739-40.

7. Maxwell, L.G., et al., Monitoring the resuscitation of preterm infants in the delivery room using pulse oximetry. Clinical pediatrics, 1987. 26(1): p. 18-20.

8. Richmond, S. and J. Wyllie, European Resuscitation Council Guidelines for Resuscitation 2010 Section 7. Resuscitation of babies at birth. Resuscitation, 2010. 81(10): p. 1389-99.

9. Saugstad, O.D., et al., Systematic review and meta-analysis of optimal initial fraction of oxygen levels in the delivery room at </=32 weeks. Acta paediatrica, 2014. 103(7): p. 744-51.

10. Vento, M., et al., Oxygen saturation targets for preterm infants in the delivery room. The journal of maternal-fetal \& neonatal medicine : the official journal of the European Association of Perinatal Medicine, the Federation of Asia and Oceania Perinatal Societies, the International Society of Perinatal Obstetricians, 2012. 25 Suppl 1: p. 45-6.

11. Vento, M., Oxygen supplementation in the neonatal period: changing the paradigm. Neonatology, 2014. 105(4): p. 323-31.

12. Finer, N. and T. Leone, Oxygen saturation monitoring for the preterm infant: the evidence basis for current practice. Pediatric research, 2009. 65(4): p. 375-80.

13. Goos, T.G., et al., Observing the resuscitation of very preterm infants: are we able to follow the oxygen saturation targets? Resuscitation, 2013. 84(8): p. 1108-13.

14. Bhutani, V.K., et al., Adaptive control of inspired oxygen delivery to the neonate. Pediatric pulmonology, 1992. 14(2): p. 110-7.

15. van der Eijk, A.C., et al., An observational study to quantify manual adjustments of the inspired oxygen fraction in extremely low birth weight infants. Acta paediatrica, 2012. 101(3): p. e97-104.

16. Carlo, W.A., et al., Target ranges of oxygen saturation in extremely preterm infants. The New England journal of medicine, 2010. 362(21): p. 1959-69.

17. Askie, L.M., et al., NeOProM: Neonatal Oxygenation Prospective Meta-analysis Collaboration study protocol. BMC pediatrics, 2011. 11: p. 6.

18. Schmidt, B., et al., Effects of targeting higher vs lower arterial oxygen saturations on death or disability in extremely preterm infants: a randomized clinical trial. JAMA : the journal of the American Medical Association, 2013. 309(20): p. 2111-20.

19. Di Fiore, J.M., et al., A higher incidence of intermittent hypoxemic episodes is associated with severe retinopathy of prematurity. The Journal of pediatrics, 2010. 157(1): p. 69-73.

20. Martin, R.J., et al., Intermittent hypoxic episodes in preterm infants: do they matter? Neonatology, 2011. 100(3): p. 303-10.

21. Morozoff, P.E. and R.W. Evans, Closed-loop control of SaO2 in the neonate. Biomedical instrumentation \& technology / Association for the Advancement of Medical Instrumentation, 1992. 26(2): p. 117-23.

22. Claure, N., et al., Closed-loop controlled inspired oxygen concentration for mechanically ventilated very low birth weight infants with frequent episodes of hypoxemia. Pediatrics, 2001. 107(5): p. 1120-4.

23. Urschitz, M.S., et al., Automatic control of the inspired oxygen fraction in preterm infants: a randomized crossover trial. American journal of respiratory and critical care medicine, 2004. 170(10): p. 1095-100. 
24. Morozoff, E.P. and J.A. Smyth, Evaluation of three automatic oxygen therapy control algorithms on ventilated low birth weight neonates. Conference proceedings : ... Annual International Conference of the IEEE Engineering in Medicine and Biology Society. IEEE Engineering in Medicine and Biology Society. Conference, 2009. 2009: p. 3079-82.

25. Claure, N., et al., Multicenter crossover study of automated control of inspired oxygen in ventilated preterm infants. Pediatrics, 2011. 127(1): p. e76-83.

26. Hallenberger, A., et al., Closed-loop automatic oxygen control (CLAC) in preterm infants: a randomized controlled trial. Pediatrics, 2014. 133(2): p. e379-85.

27. Claure, N. and E. Bancalari, Automated closed loop control of inspired oxygen concentration. Respiratory care, 2013. 58(1): p. 151-61.

28. Hummler, H., H. Fuchs, and M. Schmid, Automated Adjustments of Inspired Fraction of Oxygen to Avoid Hypoxemia and Hyperoxemia in Neonates - A Systematic Review on Clinical Studies. Klinische Padiatrie, 2014. 226(4): p. 204-210.

29. Pringle, K.C., Human fetal lung development and related animal models. Clinical obstetrics and gynecology, 1986. 29(3): p. 502-13.

30. Wolfs, T.G., et al., Inflammation-induced immune suppression of the fetus: a potential link between chorioamnionitis and postnatal early onset sepsis. The journal of maternal-fetal \& neonatal medicine : the official journal of the European Association of Perinatal Medicine, the Federation of Asia and Oceania Perinatal Societies, the International Society of Perinatal Obstetricians, 2012. 25 Suppl 1: p. 8-11.

31. Jobe, A.H., et al., Betamethasone for lung maturation: testing dose and formulation in fetal sheep. American journal of obstetrics and gynecology, 2007. 197(5): p. 523 e1-6.

32. Seehase, M., et al., New surfactant with SP-B and $C$ analogs gives survival benefit after inactivation in preterm lambs. PloS one, 2012. 7(10): p. e47631.

33. Sweet, D.G., et al., European consensus guidelines on the management of neonatal respiratory distress syndrome in preterm infants--2013 update. Neonatology, 2013. 103(4): p. 353-68.

34. Wilinska, M., et al., Automated FiO2-SpO2 control system in Neonates requiring respiratory support: a comparison of a standard to a narrow SpO2 control range. BMC pediatrics, 2014. 14: p. 130.

35. Rook, D., et al., Resuscitation of Preterm Infants with Different Inspired Oxygen Fractions. The Journal of pediatrics, 2014. 164(6): p. 1322-1326. e3.

36. Sink, D.W., S.A. Hope, and J.I. Hagadorn, Nurse:patient ratio and achievement of oxygen saturation goals in premature infants. Archives of disease in childhood. Fetal and neonatal edition, 2011. 96(2): p. F93-8.

37. Hagadorn, J.I., et al., Achieved versus intended pulse oximeter saturation in infants born less than 28 weeks' gestation: the AVIOx study. Pediatrics, 2006. 118(4): p. 1574-82.

38. Rich, W.D., T. Leone, and N.N. Finer, Delivery room intervention: improving the outcome. Clinics in perinatology, 2010. 37(1): p. 189-202.

39. Hooper, S.B. and R. Harding, Role of aeration in the physiological adaptation of the lung to air-breathing at birth. Curr. Resp. Med. Rev. , 2005(1): p. 185-195.

40. Valero, J., et al., Effect of delayed umbilical cord clamping on blood gas analysis. European journal of obstetrics, gynecology, and reproductive biology, 2012. 162(1): p. 21-3.

41. Bolivar, J.M., et al., Mechanisms for episodes of hypoxemia in preterm infants undergoing mechanical ventilation. The Journal of pediatrics, 1995. 127(5): p. 767-73.

42. Di Fiore, J.M., et al., Low oxygen saturation target range is associated with increased incidence of intermittent hypoxemia. The Journal of pediatrics, 2012. 161(6): p. 1047-52. 



\section{Chapter}

\section{Amplification of steroid-mediated SP-B expression by physiological levels of caffeine}

Fehrholz $M$, Hütten $M$, Kramer BW, Speer CP, Kunzmann S.

Am J Physiol Lung Cell Mol Physiol. 2014 Jan 1;306(1):L101-9. doi:

10.1152/ajplung.00257.2013. 


\section{ABSTRACT}

Factors positively influencing surfactant homeostasis in general and SP-B expression in particular are considered of clinical importance regarding an improvement of lung function in preterm infants. The objective of the study was to identify effects of physiological levels of caffeine on glucocorticoid-mediated SP-B expression in vitro and in vivo.

Levels of SP-B and pepsinogen $C$ were quantified by qPCR or immunoblotting in $\mathrm{NCl}$ H441 cells daily exposed to caffeine and/or DEX. In vivo, SP-B expression was analyzed in BAL of preterm sheep exposed to antenatal DEX and/or postnatal caffeine.

If DEX and caffeine were continuously present, SP-B mRNA and protein levels were increased for up to 6 days after induction $(p<0.05)$. Additionally, caffeine enhanced SP-B mRNA expression in DEX-pretreated cells $(p<0.05)$. Moreover, caffeine amplified DEXinduced pepsinogen $C$ mRNA expression $(p<0.05)$. After short-term treatment with caffeine in vivo, only slightly higher SP-B levels could be detected in BAL of preterm sheep following antenatal DEX, combined with an increase of arterial oxygen partial pressure $(p<0.01)$.

Our data demonstrated that the continuous presence of caffeine in vitro is able to amplify DEX-mediated SP-B expression. In contrast, short-term improvement of lung function in vivo is likely to be independent of altered SP-B transcription and translation. An impact of caffeine on release of surfactant reservoirs from lamellar bodies could however quickly affect SP-B content in BAL, which has to be further investigated. Our findings indicate that caffeine is able to amplify main effects of glucocorticoids which result from changes in surfactant production, maturation, and release. 


\section{INTRODUCTION}

To ensure and improve proper gas exchange in alveoli of mammalian lungs, surface tension of the alveolar epithelium is reduced significantly by pulmonary surfactant, a mixture of lipids and four different proteins, namely surfactant protein (SP)-A, -B, -C, and -D (8). Beside a postulated role of SP-B in immunity (31), a more essential function of the hydrophobic SP-B and $-C$ molecules is to stabilize the thin surfactant film and couple it to the aqueous phase lining the inner alveolar epithelium (19). SP-B is mainly synthesized in alveolar type II and club cells (Clara cells) and interacts with dipalmitoyl phosphatidylcholine, the major constituent of pulmonary surfactant (28). Survival rates of preterm infants with respiratory distress syndrome (RDS) have been substantially increased in the last decades by administering exogenous surfactant of animal origin containing SP-B (25). Since SP-B is the only SP being absolute essential for survival (18), different factors controlling or influencing its expression are considered of major importance regarding an improvement of proper lung function.

Beside SP-B mRNA transcription and stability (30), also post-translational events in $\mathrm{SP}-\mathrm{B}$ processing and trafficking are main regulators of SP-B expression (13). In this context, three proteases involved in maturation of the SP-B-proprotein (pro-SP-B) have been described: the cysteine protease cathepsin $\mathrm{H}(\mathrm{Cts} H)$ and the two aspartyl proteases napsin A (NpsA) and pepsinogen C (PGC) (13).

On the transcriptional level, glucocorticoids (GCS) are main modulators of SP-B mRNA expression (6). Hence, antenatal GCs are used to induce maturation of the fetal lung, thereby reducing morbidity and mortality in neonates born $<34$ weeks gestation (20). Clinical trials show that a single course of antenatal GCs like dexamethasone (DEX) reduces the incidence of neonatal death, RDS, intraventricular haemorrhage, and necrotizing enterocolitis, as well as increases the effectiveness of postnatal surfactant therapy (20). Like antenatal GCs, which are gold standards in accelerating fetal pulmonary development $(20,26)$, postnatal caffeine administration is commonly used to treat apnea (22). Hereby it also reduces incidence of bronchopulmonary dysplasia (BPD) as defined by requirement of supplemental oxygen at 36 weeks gestation (22). Moreover, caffeine has an important clinical role in weaning infants from the ventilator (17).

The molecular basis of protective actions of caffeine in the neonatal immature lung is not well defined. Besides reducing apnea rates, caffeine seems to abate the necessity of mechanical ventilation by improving respiratory muscle strength, especially by increasing hypercapnic ventilatory response (3). In addition, also anti-inflammatory properties of caffeine have been proposed $(14,29)$. A newly described pharmacological target for caffeine and GCs is the surfactant system of the lung (10).

The aim of the present study was to investigate, if induction of SP-B mRNA and mature SP-B is facilitated by consistent, physiological caffeine doses in vitro as well as in vivo with or without DEX. For this purpose, DEX and physiological caffeine doses were applied in different combinations during cell culture experiments and in an ovine model 
of prematurity. Furthermore, another aim of this work was to reveal cellular mechanisms underlying a possible induction of mature SP-B in vitro and to characterize the influence of caffeine on lung morphology and respiratory efficiency in vivo.

\section{MATERIAL AND METHODS}

\section{Reagents}

Caffeine and DEX were purchased from Sigma-Aldrich (St. Louis, CA).

\section{Cells}

Airway epithelial cells NCl-H441 (H441) were purchased from ATCC (LGC Standards, Teddington, UK) and cultured as described (15).

\section{RNA extraction and RT-PCR}

For RNA extraction, $3 \times 10^{5} \mathrm{H} 441$ cells were seeded on six well plates (Greiner, Frickenhausen, Germany) or $1 \times 10^{6} \mathrm{H} 441$ cells were cultured in $75 \mathrm{~cm}^{2}$ flasks (Greiner) and grown at $37^{\circ} \mathrm{C}$. Cells were washed with Dulbecco's Phosphate Buffered Saline (DPBS; Sigma-Aldrich) and treated as indicated. After the appropriate time, cells were washed again and total RNA was isolated using NucleoSpin ${ }^{\circledR}$ RNA II Kit (Macherey-Nagel, Dueren, Germany) according to the manufacturer's protocol. Total RNA was eluted in $60 \mu \mathrm{L}$ nuclease-free $\mathrm{H}_{2} \mathrm{O}$ and stored at $-80^{\circ} \mathrm{C}$ until reverse transcription. For RT-PCR, $1 \mu \mathrm{g}$ of total RNA was reverse transcribed using High Capacity cDNA Reverse Transcription Kit (Applied Biosystems, Life Technologies, Carlsbad, CA) according to the manufacturer's instructions. Upon analysis, first strand cDNA was stored at $-20^{\circ} \mathrm{C}$.

\section{Quantitative real time RT-PCR ( $q P C R$ )}

Quantitative detection of human SP-B and $\beta$-actin mRNA was performed as described (10). For detection of human PGC isoform 1 (PGCiso1) and 2 (PGCiso2), CtsH, NpsA, and GAPDH mRNA, cDNA was analyzed using $12.5 \mu \mathrm{L} \mathrm{iQ}^{\mathrm{TM}} \mathrm{SYBR}^{\circledR}$ Green Supermix (Bio-Rad Laboratories, Hercules, CA), $0.5 \mu \mathrm{L}$ deionized $\mathrm{H}_{2} \mathrm{O}$, and $10 \mathrm{pmol}$ of each forward and reverse primer, respectively. Primers for PGCiso1, PGCiso2, CtsH, NpsA, and GAPDH mRNA were humPGCiso1fwd 5'-AGTATGGACAGTTTCTCGT-3', humPGCiso1rev 5'TGAGGATATAGGAGGAAGGT-3', humPGCiso2fwd 5'-TCTACCTCAGCAACCTGGTC-3', humPGCiso2rev 5'-TGAGATTGGAGACAGGTAGGG-3', humCTSHfwd 5'CATTTGCCAGCAACTGGAGGAA-3', humCTSHrev 5'-ATTGGTTCAGTGCCATTTTAAATG-3', humNAPSAfwd 5'-TACACCACCGATTTGATCCCA-3', humNAPSArev 5'- 
CACCAATAGTCAGCTTGTCCT-3', hGAPDHfwd 5'-CAAAGTTGTCATGGATGACC-3', and hGAPDHrev 5'-CCATGGAGAAGGCTGGGG-3', respectively. PCRs were performed on an ABI Prism 7500 Sequence Detection System (TaqMan ${ }^{\circledR}$ ) as described (15). In case of measurements including SYBR Green, melt curve analyses were performed to verify single PCR products. Results were normalized to $\beta$-actin or GAPDH and mean fold changes were calculated by the $\Delta \Delta C_{T}$ method (16).

\section{Immunoblotting}

Immunoblotting was performed as described (15). Blots were probed with primary antibodies to SP-B (generous gift of Dr. Jeffrey A. Whitsett, Perinatal Institute, Cincinnati Children's Hospital Medical Center, Cincinnati, OH), and $\beta$-actin (926-42212; LI-COR Inc., Lincoln, NE), followed by staining with corresponding IRDye ${ }^{\circledR}$ secondary antibodies (LICOR Inc.) for $1 \mathrm{~h}$ at RT. Specific protein bands were visualized using an ODYSSEY ${ }^{\circledR}$ Infrared Imaging System (LI-COR Inc.). Accumulated signals were quantified using Odyssey Software v2.1 (LI-COR Inc.).

\section{Animal experiments}

All studies were approved by the Animal Ethics Committee of the University of Maastricht, The Netherlands. Time-mated pregnant ewes were given 6 mg DEX intramuscularly $48 \mathrm{~h}$ before delivery. A C-section was performed at gestational age of 133/134 days. Ewes received epidural anesthesia as described (11). After lower midline incision, the fetus was extracted through incision of the uterus. The umbilical cord was carefully extracted through the incision of the uterus. Catheters were placed in the umbilical artery and in the umbilical vein. Baseline blood sampling was performed (Abbott i-STAT 1 Blood Gas Analyzer, Abbott Laboratories, Abbott Park, IL). Custom-made binasal prongs were put in the nose. After its umbilical cord was cut, the lamb was weighed and moved to an adjacent, open, heated incubator (IW930 Series CosyCot Infant Warmer, Fisher \& Paykel Healthcare, Auckland, New Zealand) maintaining normal body temperature of $38.5^{\circ} \mathrm{C}$. Nasal prongs of lambs were connected to pressure-regulated ventilation using a ventilator Babylog 8000 (Draeger, Luebeck, Germany) with initial settings as follows: $\mathrm{FiO}_{2}=1$, PEEP $6 \mathrm{~cm} \mathrm{H} \mathrm{H}_{2} \mathrm{O}$, PiP $30 \mathrm{~cm} \mathrm{H}_{2} \mathrm{O}$, frequency 60/min, I:E 1:2 (nasal intermittent positive pressure ventilation; NIPPV) with humidified gas. Caffeine citrate (20 $\mathrm{mg} / \mathrm{kg}$ ) was given intravenously. After $15 \mathrm{~min}$ of NIPPV the ventilator setting was changed to continuous positive airway pressure (CPAP, $6 \mathrm{~cm} \mathrm{H}_{2} \mathrm{O}$ ). Arterial blood gas analyses were performed at 30 and $180 \mathrm{~min}$ of age. Three hours after delivery lambs were euthanized by i.v. injection of T61 (Veterinaria AG, Zuerich, Switzerland). At autopsy, a pressure-volume curve was recorded. Individual lung lobes were prepared and weighed. Selective broncho-alveolar lavages (BAL) of each lung lobe were performed with $\mathrm{NaCl} 0.9 \%$ as described (23). 


\section{Data analysis}

All results shown are combinations of a minimum of three independent experiments. Results are given as means $\pm S D$. Data were analyzed using Student's t-test or KruskallWallis test. A $p$ value $\leq 0.05$ was considered significant. All statistical analyses were performed using Prism ${ }^{\circledR}$ version 5.00 (GraphPad Software, San Diego, CA).

\section{RESULTS}

\section{Influence of prolonged treatment with physiological caffeine doses on glucocorticoid-mediated expression of surfactant protein B mRNA}

The effect of prolonged treatment with caffeine on GC-mediated increase of SP-B mRNA and mature SP-B expression was first investigated for continuous, simultaneous induction with DEX and caffeine (Fig.1A). Our results revealed that on day 3 as well as day 6 the cellular SP-B mRNA content in cells treated with DEX and caffeine was always significantly higher than in cells treated with DEX alone ( $p<0.05$; Fig.1B). Additionally, immunoblots with corresponding samples also revealed higher mature SP-B levels of cells treated with DEX and caffeine in comparison to cells treated with DEX alone.

\section{Influence of prolonged treatment with physiological caffeine doses on expression of surfactant protein $B$ after pretreatment with dexamethasone}

Since in clinical situations preterm infants are antenatally exposed to maternal GCs and just postnatally treated with caffeine without simultaneous GC administration, we next simulated this situation by first inducing $\mathrm{H} 441$ cells with DEX for 2 days and subsequently with caffeine for up to 4 days (Fig.2A). We found that for day 1 to 4 cells pretreated with DEX and additionally exposed to caffeine expressed significant higher amounts of SP-B mRNA than cells only pretreated with DEX (Fig.2B). SP-B mRNA expression even increased one day after preincubation with $D E X$, then decreased over time but still was 6.7-fold higher on day 4 in comparison to the corresponding control. Differences to the corresponding controls for days 0-4 were always significantly higher. Also, for caffeinetreated cells which were not preincubated with DEX a lower but significantly higher SP-B mRNA expression could be detected for days 2-4 $(p<0.01)$. However, on the protein level cells pretreated with DEX and additionally treated with caffeine showed no significantly higher levels of mature SP-B compared to cells only pretreated with DEX (Fig.2CD). After day 1, mature SP-B was detectable in cells pretreated with DEX and/or additional caffeine. Detection was significant for only DEX-pretreated cells $(p<0.01$ and $p<0.05$ on days $0-1$, respectively) and cells pretreated with DEX and additionally treated with caffeine ( $p<0.05$ on days $1-2)$ in comparison to corresponding controls. 
A

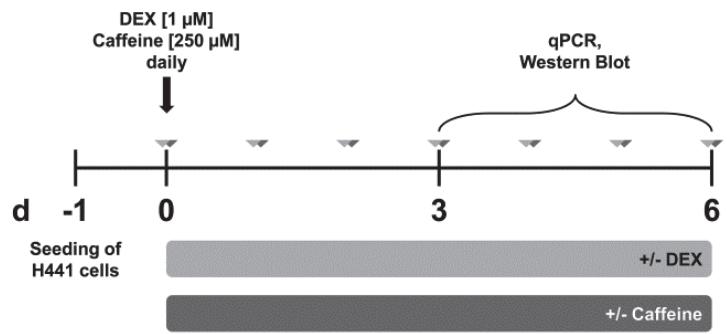

B

Day 3

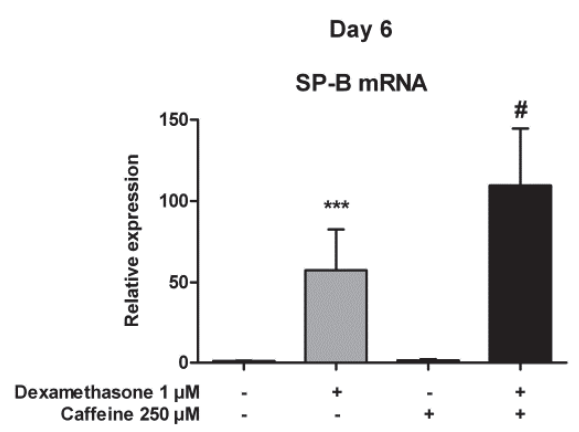

C

SP-B mRNA

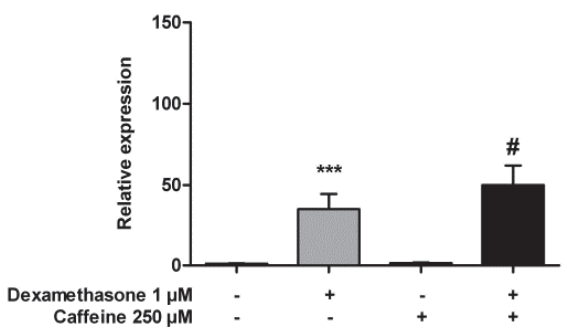

Mature SP-B
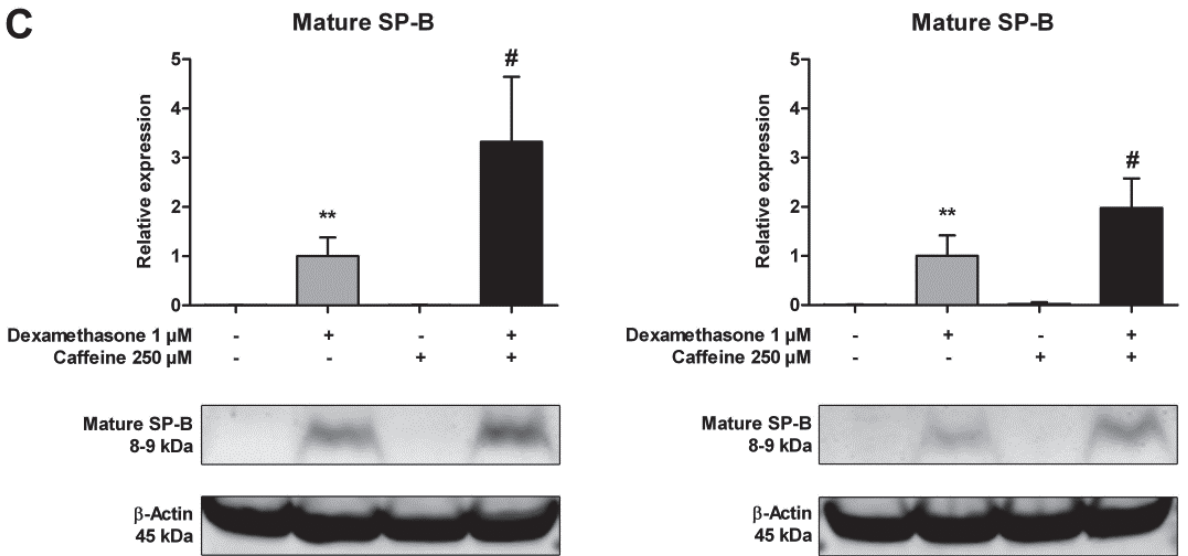

Figure 1. Influence of prolonged treatment with physiological caffeine doses during glucocorticoid-mediated expression of surfactant protein $\mathrm{B}$.

H441 cells were treated with $1 \mu \mathrm{M}$ dexamethasone (DEX) and/or $250 \mu \mathrm{M}$ caffeine for up to 6 days. During culture, medium was changed daily because of the given short stability of caffeine in aqueous solutions (A). On day 3 and 6 qPCR of SP-B mRNA was performed (B). SP-B mRNA levels were normalized to $\beta$-actin, and fold differences compared to untreated cells were calculated. (C) Additionally, on day 3 and 6 Western immunoblotting analysis against mature SP-B was performed. Relative expression levels of SP-B were calculated by normalizing signals to detected $\beta$-actin levels. Means $\pm S D$ of at least $n=3$ independent experiments are shown. In $\mathrm{C}$, representative immunoblots are shown. ${ }^{* *} \mathrm{p}<0.01$ and ${ }^{* * *} \mathrm{p}<0.001$ compared to control cells, \# $\mathrm{p}<0.05$ compared to cells treated with dexamethasone. 
A

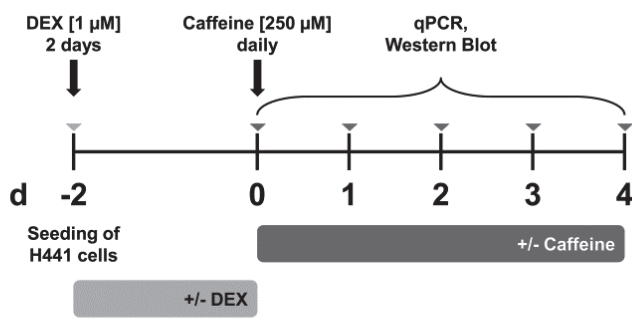

B

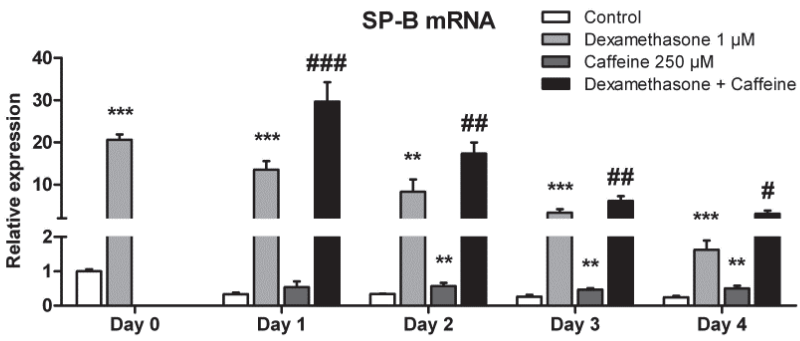

C

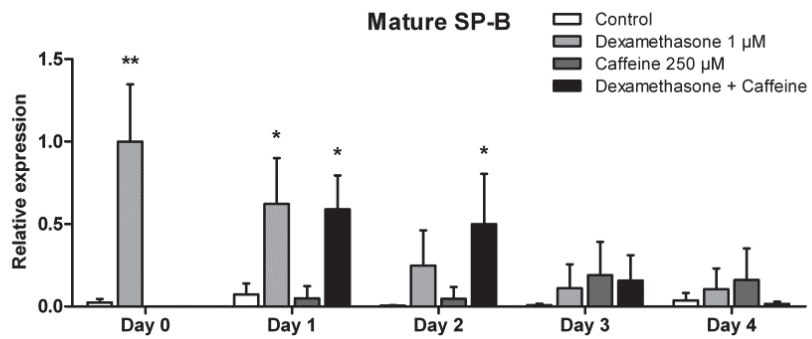

D

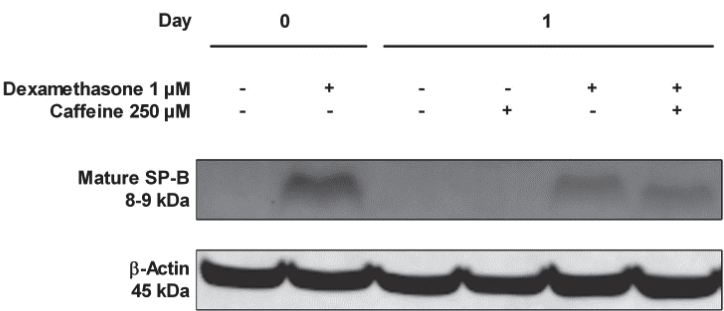

Figure 2. Influence of prolonged treatment with physiological caffeine doses on expression of surfactant protein $\mathrm{B}$ after pretreatment with dexamethasone.

H441 cells were pretreated with $1 \mu \mathrm{M}$ dexamethasone (DEX) for 2 days and subsequently with $250 \mu \mathrm{M}$ caffeine for up to 4 days (A). On days 0 to 4 qPCR of SP-B mRNA was performed (B). SP-B mRNA levels were normalized to $\beta$-actin, and fold differences compared to untreated cells were calculated for each time point. (C) Additionally, Western immunoblotting analysis against mature SP-B was performed. Relative expression levels of mature SP-B were calculated by normalizing signals to detected $\beta$-actin levels. (D) A representative immunoblot of samples from day 0 and 1 are shown. For $A-C$, means $\pm S D$ of at least $n=3$ independent experiments are shown. ${ }^{* *} p<0.01$ and $* * * p<0.001$ compared to corresponding control cells, \# $p<0.05, \# \#<<0.01$, and \#\#\# p<0.001 compared to corresponding cells treated with dexamethasone. 


\section{Expression of $m R N A$ of SP-B proteases after treatment with caffeine following dexamethasone administration}

For detection of PGCiso1, PGCiso2, CtsH, and NpsA mRNA levels the model in closer accordance to clinic situations (Fig.2A) was used. Levels of PGCiso1 mRNA were barely detectable in untreated cells, therefore these amounts could only be normalized to DEX treated cells. Levels of PGCiso1 mRNA reached highest amounts $48 \mathrm{~h}$ after induction with DEX (9.7-fold compared to day 1 ) and decreased more rapidly than SP-B mRNA levels (Fig.3A). After one day of induction with additional caffeine, PGCiso1 mRNA levels were significantly higher $(p<0.05)$ in comparison to only DEX pretreated controls. The continuous presence of caffeine in DEX untreated cells led to measurable but low levels of PGCiso1 mRNA compared to levels in DEX pretreated cells on day 1 (mean of day 1 to $4=0.13 \pm 0.03$-fold; Fig.4A). Additional experiments using high, unphysiological doses of $10 \mathrm{mM}$ caffeine in combination with $1 \mu \mathrm{M}$ DEX for $24 \mathrm{~h}$ led to even more increased PGCiso1 mRNA levels, which were significantly higher in comparison to control levels ( $p<0.01$; data not shown). PGCiso2, CtsH, and NpsA mRNAs were not significantly regulated by DEX and/or caffeine (Fig.3B-D).

\section{Levels of mature SP-B in bronchoalveolar lavage fluid of caffeine-treated preterm sheep following maternal administration with dexamethasone}

To assess, if levels of mature SP-B are altered by physiological levels of DEX and/or caffeine in vivo, we next investigated BAL of preterm sheep exposed to caffeine and/or antenatal DEX (Fig.4A). A twofold higher overall mean of mature SP-B was observed in caffeine-treated preterm lambs of DEX-exposed ewes (1116 \pm 1349 pixel/bodyweight) in comparison to completely untreated ewes and lambs ( $584 \pm 965$ pixel/bodyweight) and untreated preterm lambs of DEX-exposed ewes (524 \pm 723 pixel/bodyweight), respectively (Fig.4B-C). Mature SP-B expression of caffeine-treated preterm lambs of DEXexposed ewes was tenfold higher in comparison to caffeine-treated preterm lambs from untreated ewes $(135 \pm 279$ pixel/bodyweight $)$ and statistically significant $(p<0.01)$ (Fig.4B-C). 
A

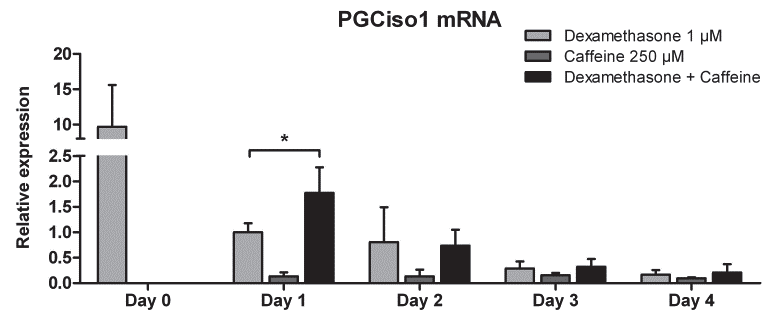

B

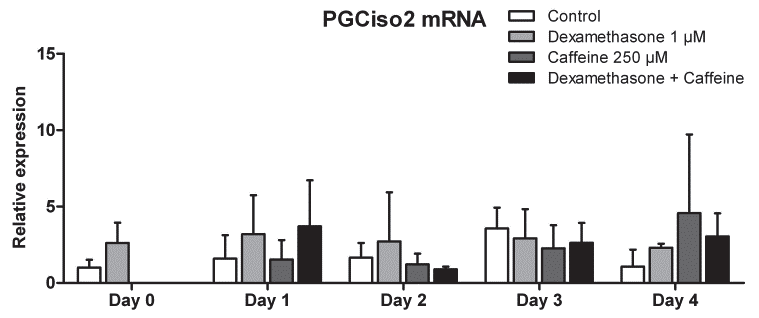

C

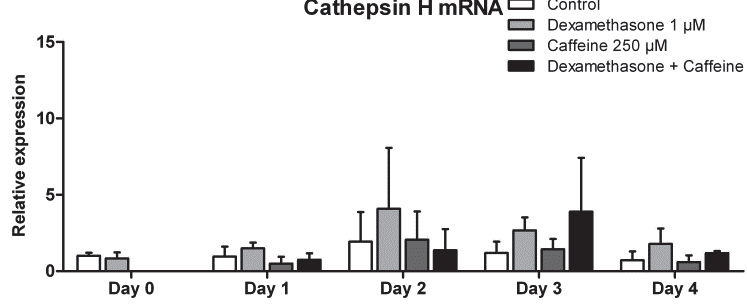

D

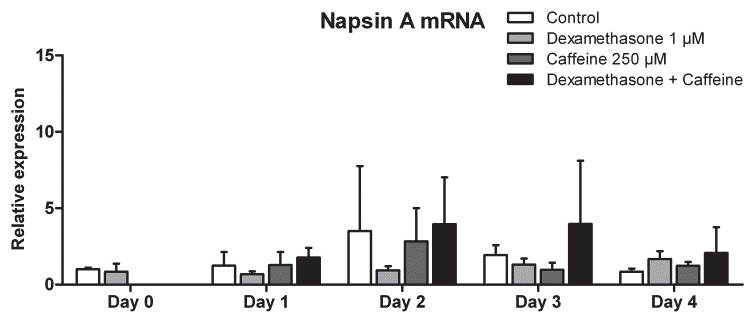

Figure 3. Expression of surfactant protein B protease mRNAs after treatment with caffeine following dexamethasone administration.

H441 cells were pretreated with $1 \mu \mathrm{M}$ dexamethasone for 2 days and subsequently with $250 \mu \mathrm{M}$ caffeine for up to 4 days. On days 0 to 4 qPCR of pepsinogen C isoform 1 (PGCiso1; A), pepsinogen C isoform 2 (PGCiso2; B), Cathepsin H (C) and Napsin A (D) mRNA was performed. Measured mRNA levels were normalized to GAPDH mRNA and fold differences compared to dexamethasone-treated cells on day $1(\mathrm{~A})$ or untreated cells on day 0 (B-D) were calculated. Means \pm SD of at least $n=3$ independent experiments are shown. ${ }^{*} p<0.05$ compared to cells treated with dexamethasone. 


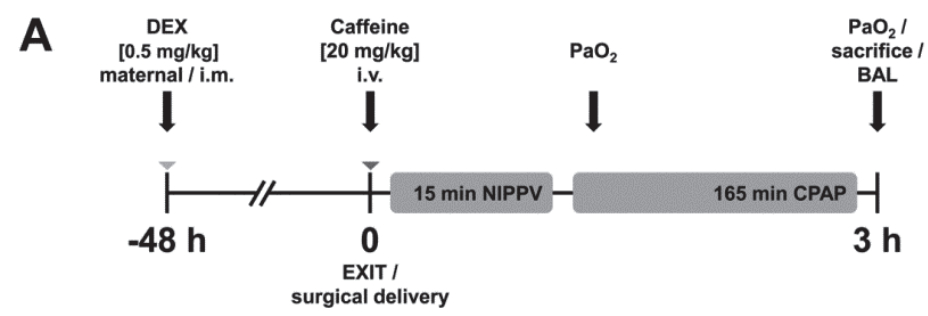

\section{+/-Caffeine}

\section{+/- DEX}

B
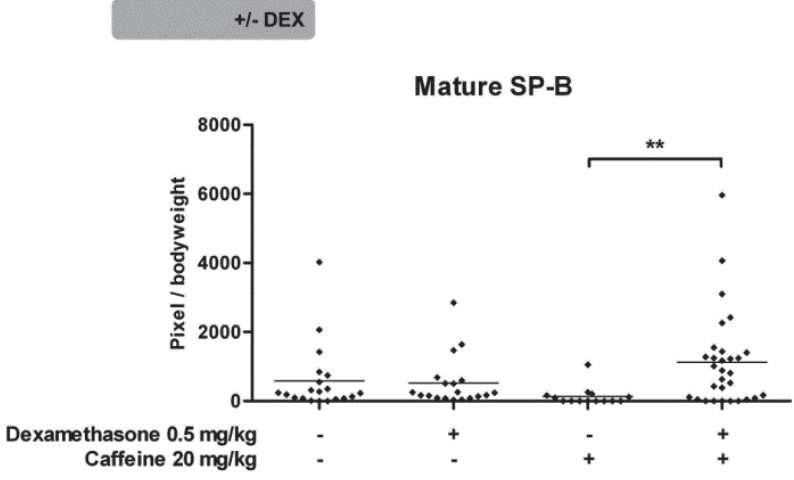

C

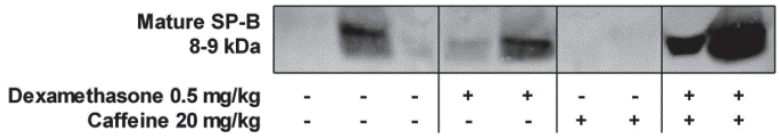

Figure 4. Increase of mature SP-B in bronchoalveolar lavage fluid of caffeine-treated preterm sheep following maternal administration with dexamethasone.

Fetal sheep were treated with $20 \mathrm{mg} / \mathrm{kg}$ caffeine following maternal administration with $6 \mathrm{mg}$ dexamethasone (DEX; A). Lung lobes were lavaged separately and mature SP-B levels in equal volumes of obtained lavage fluids were analyzed by Western immunoblotting. Relative expression levels of SP-B were calculated by normalizing signals to obtained lavage fluid, lobe-, lung-, and bodyweight of each animal (B). Mature SP-B values for all five different lobes of $n=4$ untreated lambs of untreated ewes, $n=3$ untreated lambs of dexamethasoneexposed ewes, $n=4$ caffeine-treated preterm lambs of untreated ewes, and $n=6$ caffeine-treated preterm lambs of dexamethasone-exposed ewes are shown individually. In C, a representative image of detected mature SP-B amounts in broncho-alveolar lavage of the right lower lobe is shown for at least two animals of each investigated animal-group. ${ }^{* *} p<0.01$ compared to animals treated with caffeine from untreated ewes.

\section{Arterial oxygen partial pressure $\left(\mathrm{PaO}_{2}\right)$ and carbon dioxide partial pressure $\left(\mathrm{PaCO}_{2}\right)$ of preterm sheep after treatment with caffeine following maternal administration with dexamethasone}

To study a functional lung parameter, arterial oxygen partial pressure $\left(\mathrm{PaO}_{2}\right)$ and carbon dioxide partial pressure $\left(\mathrm{PaCO}_{2}\right)$ was measured in the different animal groups. We found $\mathrm{PaO}_{2}$ to be fourfold, significantly higher in caffeine-treated preterm lambs of DEX- 
exposed ewes $(492 \pm 134 \mathrm{mmHg})$ in comparison to untreated lambs from DEX-exposed ewes $(118 \pm 40.4 \mathrm{mmHg}) 30 \mathrm{~min}$ after the administration of caffeine $(p<0.01$; Fig.5A). Differences $180 \mathrm{~min}$ after caffeine-administration were lower in general $(149 \pm 27 \mathrm{mmHg}$ and $76.3 \pm 18.9 \mathrm{mmHg}$, respectively) but still statistically significant ( $<<0.01 ;$ Fig.5B). In contrast to the $\mathrm{PaO}_{2}$ values, no significant changes were observed in the $\mathrm{PaCO}_{2}$, albeit a lower mean was observed for caffeine-treated preterm lambs of untreated ewes $(75.7 \pm 19.5 \mathrm{mmHg})$ and caffeine-treated preterm lambs of DEX-exposed ewes $(69.3 \pm 16.7 \mathrm{mmHg})$ in comparison to completely untreated ewes and lambs $(95.8 \pm 41.0$ $\mathrm{mmHg} 180 \mathrm{~min}$ after caffeine-administration.

A

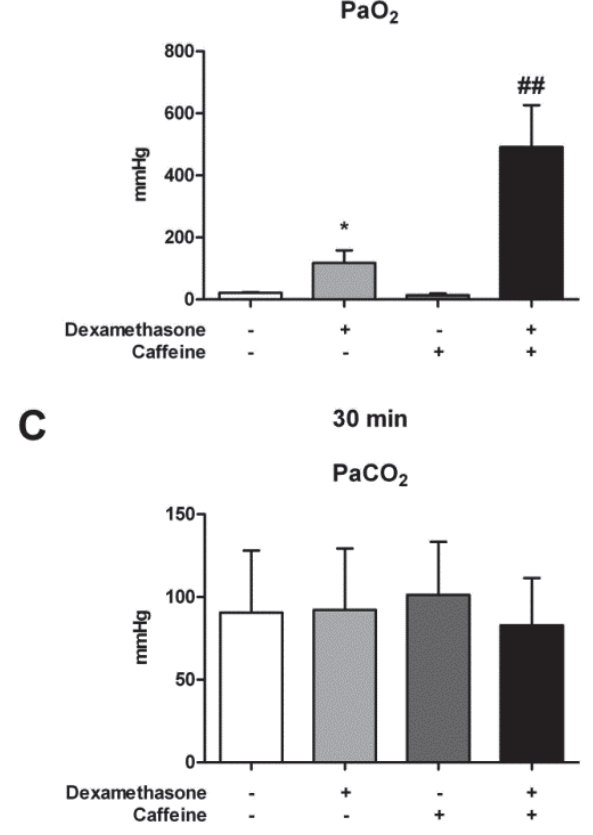

B

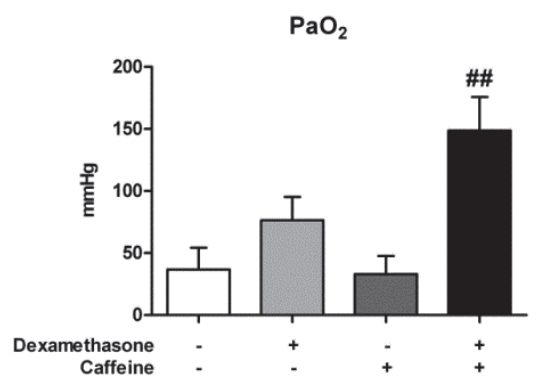

D

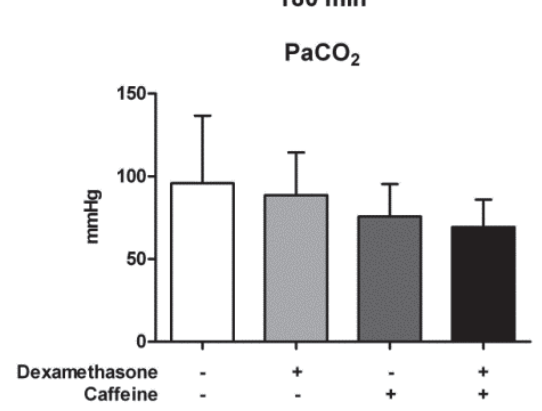

Figure 5. Arterial oxygen and carbon dioxide partial pressure of preterm sheep after treatment with caffeine following maternal administration with dexamethasone.

Arterial oxygen partial pressure $\left(\mathrm{PaO}_{2}\right)$ and carbon dioxide partial pressure $\left(\mathrm{PaCO}_{2}\right)$ of at least $n=3$ preterm lambs of every group was measured $30 \mathrm{~min}(\mathrm{~A}, \mathrm{C})$ and $180 \mathrm{~min}(\mathrm{~B}, \mathrm{D})$ after treatment of preterm lambs with caffeine, respectively. ${ }^{*} p<0.05$ compared to untreated preterm lambs of untreated ewes, \#\# $p<0.01$ compared to untreated preterm lambs of dexamethasone-exposed ewes. 


\section{DISCUSSION}

The results of our study showed that caffeine, if administered continuously and in physiological doses, is positively influencing GC-mediated effects on SP-B expression in vitro and also more importantly on $\mathrm{PaO}_{2}$ in vivo. This enhancement of GC-mediated maturation of the surfactant system and improvement of oxygenation after DEX administration to ewes reflects additional protective effects of caffeine on the neonatal lung. Other protective mechanisms of caffeine in this regard are supposed to be anti-inflammatory actions (14) which include inhibition of pro-inflammatory cytokine production $(9,29)$.

In general, a complex relationship seems to exist between dose and method of caffeine administration (single/continuous) and its biological effects. A relationship between serum caffeine levels and cytokine concentrations was already observed in tracheal aspirates and peripheral blood of preterm infants (9). For low serum caffeine levels, concentrations of pro-inflammatory cytokines TNF- $\alpha$, IL-1, and IL- 6 were reduced, but increased at higher levels, which could contribute to the severity of inflammatory conditions such as development of BPD (24). An inverse situation was observed for the anti-inflammatory cytokine IL-10 (9). In contrast to the effect of caffeine on expression of pro-inflammatory cytokines, a similar effect between high (10) and low concentrations on DEX-induced SP$\mathrm{B}$ expression in vitro was observed. However, if low caffeine doses were used its administration has to be repeated, which mimics a clinical situation.

When we further incorporated more clinical characteristics in our in vitro model, where pretreatment of H441 cells with DEX was followed by daily retreatment with low concentrations of caffeine alone, amplifying effects on SP-B expression could also be observed. This is in accordance to an already described biological residual effect observed for SP-B mRNA expression following treatment with DEX where SP-B mRNA levels are declining constantly but do not return to the same basic level as in untreated cells (27). In our case, caffeine seems to boost DEX-induced SP-B mRNA expression for several days until new basic levels are reached. Using this experimental setting however, the effect was only detected for SP-B mRNA but no longer for mature SP-B. Hence, in relation to the results of our first experimental setting using a combined treatment, the in vitro data is indicating a necessity of residing levels of DEX for full maturation of SP-B in H441 cells which is largely independent of cellular SP-B mRNA levels. The decrease of the combined effect of DEX and caffeine on SP-B expression in the second experimental setting could possibly be explained by a diminishing effect of GCs and/or the development of a caffeine-tolerance, as described for the hemodynamic and CNS effects of caffeine in humans (21). The clinical relevance of a possible tolerance to caffeine in neonatology as well as the influence of GCs on it has to be elucidated.

Since regulatory differences were found between SP-B mRNA and mature SP-B levels we speculate that additional effects of combined administration of GCs and caffeine also exist on a post-transcriptional or -translational level. For pretreatment with DEX and subsequent stimulation with caffeine we observed a significant induction of PGCi- 
so1 mRNA. This effect was even more pronounced if caffeine was increased to unphysiological doses and directly combined with DEX. These results indicate that, in contrast to the combined application of DEX and high caffeine doses, caffeine alone has no direct influence on PGC mRNA expression. Since the onset of PGC expression has been described to be induced by GCS (7) and to be more rapid than SP-B expression (12), this would explain the different mature SP-B levels detected for the combinatory or consecutive administration of DEX and caffeine. In contrast to SP-B mRNA and PGCiso1 levels, mRNAs of the proteases $\mathrm{CtsH}$ and NpsA were not found to be influenced by DEX and/or caffeine. Our results support the theory that GCs induce the final processing of pro-SP-B forms via induction of PGC which we found to be expressed only to a minor amount under normal conditions in $\mathrm{H} 441$ cells. Expression of mature SP-B therefore is likely to be rendered by GCs and in greater quantities also by the addition of caffeine in H441 cells which are not able to process pro-SP-B forms completely under normal conditions (19).

To verify our in vitro results also in vivo, we used an animal sheep model mimicking a common clinical situation, in which preterm infants have to be supported by NIPPV and/or CPAP, and treated with caffeine but lacking other pathologic factors like infection or invasive mechanical ventilation. The experiments were conducted with a set $\mathrm{FiO}_{2}$ to minimize variability and to amplify the effects of surfactant pool size on the arterial $\mathrm{PO}_{2}$. When measuring mature SP-B in vivo, in contrast to our expectations only a higher overall mean by trend was detected in BAL of caffeine-treated preterm lambs of DEXexposed ewes after caffeine exposure in comparison to all other groups. These results indicate that caffeine is possibly able to modify mature SP-B levels not only in vitro but also in vivo, albeit in a different manner at the investigated time point. Measuring $\mathrm{PaO}_{2}$ as a first functional parameter showed an improved gas exchange in animals treated with dexamethasone, and this effect was amplified by postnatal caffeine administration. Because this improvement emerged already 30 min after the application of caffeine, the additive effect of caffeine and dexamethasone on SP-B mRNA expression described in vitro seems, however, not be the main responsible factor for this effect in vivo. De novo synthesis and posttranslational processing of SP-B, and other surfactant proteins as well, would require several hours. A proposed direct effect of caffeine as a respiratory stimulant enhancing respiratory drive $(1,4,5)$ seems to be no explanation, since animals from untreated ewes exposed to caffeine showed no improvement of oxygenation at all. Our results prove that such a short-term improvement of oxygenation by caffeine seems to depend on the presence of dexamethasone. Therefore one might speculate that antenatal application of dexamethasone induces intracellular maturation of SP-B precursors and enhances SP-B secretion. This last step, the release of SP-B reservoirs from lamellar bodies, could than likely be potentiated by caffeine potentially through modification of intracellular $\mathrm{Ca}^{2+}$ or protein kinases (2), explaining the observed early improvement after 30 minutes in the double-treated group. The trend of higher mature SP-B content in BAL of caffeine treated lambs from dexamethasone exposed ewes after $180 \mathrm{~min}$ is in concordance with this proposed mechanism, but at this later time point 
the described in vitro-effect could also be involved. Unfortunately, we had no possibility to measure the SP-B content in BAL 30 min after caffeine exposure which could confirm our hypothesis. Measuring $\mathrm{PaCO}_{2}$ as a second functional parameter showed no improved $\mathrm{CO}_{2}$ exchange after 30 min but a trend for improvement in the caffeine- and double-treated group after $180 \mathrm{~min}$. Our findings may therefore indicate that the main effect of GC treatment resulted from changes in surfactant production, maturation, or release, which was amplified by the presence of caffeine.

Nevertheless, the kinetics of the lung in the whole body to intravenous caffeine and to an individual cell line and type in culture media are very difficult to evaluate and to compare. We have therefore assessed the kinetics of caffeine in vitro over a long time period. The in vivo approach was based on the immediate administration of caffeine to provide enough time for the direct and indirect effects on the oxygenation of spontaneously breathing preterm lambs. Possible impacts of a long-term treatment with physiological doses of caffeine on SP synthesis and respiratory drive/oxygenation following maternal treatment with glucocorticoids have to be elucidated.

Together with our previous findings (10) the effect of caffeine applied continuously for several days and at physiological doses in vitro and in vivo described here further underlines its clinical relevance.

\section{Conclusion}

We conclude that the continuous presence of physiological levels of caffeine in vitro is amplifying the stimulatory property of DEX on SP-B mRNA expression and full maturation of SP-B. Our results suggest that DEX is necessary to induce maturation of pro-SP-B via $P G C$ and that this process can be amplified by caffeine. Beside this and the already described inhibitory effect on pro-inflammatory cytokine production, the here described short-term enhancement of GC-mediated improvement of the surfactant system in vivo, which is possibly due to changes in surfactant release, reflects a complementary protective effect of caffeine on the neonatal lung.

\section{ACKNOWLEDGEMENTS}

We thank Barbara Ottensmeier and Silvia Seidenspinner for excellent technical assistance. We also gratefully acknowledge the generous financial support of this project by Mr. Georg Bierich, Duesseldorf, Germany. 


\section{REFERENCES}

1. Adén U. Methylxanthines during pregnancy and early postnatal life. Handb Exp Pharmacol 373-389, 2011.

2. Andreeva AV, Kutuzov MA, and Voyno-Yasenetskaya TA. Regulation of surfactant secretion in alveolar type II cells. Am J Physiol Lung Cell Mol Physiol 293: L259-L271, 2007.

3. Aranda JV, Beharry K, Valencia GB, Natarajan G, and Davis J. Caffeine impact on neonatal morbidities. J Matern Fetal Neonatal Med 23 Suppl 3: 20-23, 2010.

4. Aranda JV, Turmen T, Davis J, Trippenbach T, Grondin D, Zinman R, and Watters G. Effect of caffeine on control of breathing in infantile apnea. J Pediatr 103: 975-978, 1983.

5. Bairam A, Blanchard PW, Bureau MA, Laudignon N, Cote A, and Aranda JV. Interactive ventilatory effects of two respiratory stimulants, caffeine and doxapram, in newborn lambs. Biol Neonate 61: 201-208, 1992.

6. Ballard PL, Ertsey R, Gonzales LW, and Gonzales J. Transcriptional regulation of human pulmonary surfactant proteins SP-B and SP-C by glucocorticoids. Am J Respir Cell Mol Biol 14: 599-607, 1996.

7. Ballard PL, Lee JW, Fang X, Chapin C, Allen L, Segal MR, Fischer H, Illek B, Gonzales LW, Kolla V, and Matthay MA. Regulated gene expression in cultured type II cells of adult human lung. Am J Physiol Lung Cell Mol Physiol 299: L36-L50, 2010.

8. Bersani I, Kunzmann S, and Speer CP. Immunomodulatory properties of surfactant preparations. Expert Rev Anti Infect Ther 11: 99-110, 2013.

9. Chavez-Valdez R, Ahlawat R, Wills-Karp M, Nathan A, Ezell T, and Gauda EB. Correlation between serum caffeine levels and changes in cytokine profile in a cohort of preterm infants. J Pediatr 158: 57-64, 64.e51, 2011.

10. Fehrholz M, Bersani I, Kramer BW, Speer CP, and Kunzmann S. Synergistic effect of caffeine and glucocorticoids on expression of surfactant protein B (SP-B) mRNA. PLoS One 7: e51575, 2012.

11. Gavilanes AW, Gantert M, Strackx E, Zimmermann LJ, Seeldrayers S, Vles JS, and Kramer BW. Increased EEG delta frequency corresponds to chorioamnionitis-related brain injury. Front Biosci 2: 432-438, 2010.

12. Gerson KD, Foster CD, Zhang P, Zhang Z, Rosenblatt MM, and Guttentag SH. Pepsinogen C proteolytic processing of surfactant protein B. J Biol Chem 283: 10330-10338, 2008.

13. Guttentag S. Posttranslational regulation of surfactant protein B expression. Semin Perinatol 32: 367-370, 2008.

14. Horrigan LA, Kelly JP, and Connor TJ. Immunomodulatory effects of caffeine: friend or foe? Pharmacol Ther 111: 877-892, 2006.

15. Ladenburger A, Seehase M, Kramer BW, Thomas W, Wirbelauer J, Speer CP, and Kunzmann S. Glucocorticoids potentiate IL-6-induced SP-B expression in H441 cells by enhancing the JAK-STAT signaling pathway. Am J Physiol Lung Cell Mol Physiol 299: L578-L584, 2010.

16. Livak KJ, and Schmittgen TD. Analysis of relative gene expression data using real-time quantitative PCR and the 2(-Delta Delta C(T)) Method. Methods 25: 402-408, 2001.

17. Martin RJ, Abu-Shaweesh JM, and Baird TM. Apnoea of prematurity. Paediatr Respir Rev 5 Suppl A: S377S382, 2004.

18. Nogee LM, Garnier G, Dietz HC, Singer L, Murphy AM, deMello DE, and Colten HR. A mutation in the surfactant protein $B$ gene responsible for fatal neonatal respiratory disease in multiple kindreds. J Clin Invest 93: 1860-1863, 1994.

19. Perez-Gil Js, and Weaver TE. Pulmonary surfactant pathophysiology: current models and open questions. Physiology (Bethesda) 25: 132-141, 2010.

20. Roberts $D$, and Dalziel $S$. Antenatal corticosteroids for accelerating fetal lung maturation for women at risk of preterm birth. Cochrane Database Syst Rev CD004454, 2006.

21. Robertson D, Wade D, Workman R, Woosley RL, and Oates JA. Tolerance to the humoral and hemodynamic effects of caffeine in man. J Clin Invest 67: 1111-1117, 1981.

22. Schmidt B, Roberts R, Millar D, and Kirpalani H. Evidence-based neonatal drug therapy for prevention of bronchopulmonary dysplasia in very-low-birth-weight infants. Neonatology 93: 284-287, 2008. 
23. Seehase M, Collins JJP, Kuypers E, Jellema RK, Ophelders DRMG, Ospina OL, Perez-Gil J, Bianco F, Garzia R, Razzetti R, and Kramer BW. New Surfactant with SP-B and C Analogs Gives Survival Benefit after Inactivation in Preterm Lambs. PLoS One 7: e47631, 2012.

24. Speer CP. Inflammation and bronchopulmonary dysplasia: a continuing story. Semin Fetal Neonatal Med 11: 354-362, 2006

25. Speer CP, Robertson B, Curstedt T, Halliday HL, Compagnone D, Gefeller O, Harms K, Herting E, McClure G, Reid M, and et al. Randomized European multicenter trial of surfactant replacement therapy for severe neonatal respiratory distress syndrome: single versus multiple doses of Curosurf. Pediatrics 89: 13-20, 1992.

26. Sweet DG, Carnielli V, Greisen G, Hallman M, Ozek E, Plavka R, Saugstad OD, Simeoni U, Speer CP, Halliday $\mathrm{HL}$, and of Perinatal Medicine EA. European consensus guidelines on the management of neonatal respiratory distress syndrome in preterm infants - 2010 update. Neonatology 97: 402-417, 2010.

27. Vidaeff AC, Ramin SM, Gilstrap LC, and Alcorn JL. In vitro quantification of dexamethasone-induced surfactant protein B expression in human lung cells. J Matern Fetal Neonatal Med 15: 155-159, 2004.

28. Weaver TE, and Conkright JJ. Function of surfactant proteins B and C. Annu Rev Physiol 63: 555-578, 2001.

29. Weichelt U, Cay R, Schmitz T, Strauss E, Sifringer M, Bührer C, and Endesfelder S. Prevention of hyperoxiamediated pulmonary inflammation in neonatal rats by caffeine. Eur Respir J 41: 966-973, 2013.

30. Whitsett JA, and Glasser SW. Regulation of surfactant protein gene transcription. Biochim Biophys Acta 1408: 303-311, 1998.

31. Yang L, Johansson J, Ridsdale R, Willander H, Fitzen M, Akinbi HT, and Weaver TE. Surfactant protein B propeptide contains a saposin-like protein domain with antimicrobial activity at low $\mathrm{pH}$. J Immunol 184: 975-983, 2010. 



\section{Chapter}

\section{Short term effects of endotracheally vs. intravenously administered nano-encapsuled, water-soluble vitamin $A$ in preterm lambs}

Wahl HB*, Hütten MC*, Monz D, Tutdibi E, Ophelders D, Nikiforou M, Tschernig T, Gortner L, Nohr D, Biesalski HK, Kramer BW

*contributed equally

submitted 


\section{ABSTRACT}

Background: Vitamin A (VA) is a fat-soluble vitamin and transcription factor which is of importance for human health due to its effects on development and regeneration of various tissues including the lungs. The term VA describes a number of different chemical substances, such as retinol, retinoic acid or retinyl esters, e.g. retinyl palmitate, and is crucial for prenatal lung maturation and postnatal growth and differentiation of the mucous membranes of the lungs. Premature infants may have inadequate VA pulmonary stores, which is associated with a significant risk of developing bronchopulmonary dysplasia (BPD), a disorder of lung maturation and function. Intramuscular VA supplementation in preterm neonates has been shown to prevent BPD and to improve longterm pulmonary outcome. However, despite longstanding research efforts, there is still no consensus with regard to the optimal supplementation regime, since the best substrate, method and dose of administration remains to be elucidated.

Objectives: This feasibility study was designed to evaluate a new substance and route of VA application for use in the preterm population: a water-soluble, nano-encapsulated retinyl palmitate mono-preparation.

Methods: We used a well-established animal model of preterm lambs to study VA distribution and the induction of early genetic expression of two retinoid homeostatic genes: lecithin:retinol acyltransferase (LRAT) and cytochrome P $26 B 1$ (CYP26B1), comparing intravenous and endotracheal VA administration.

Results: We found significant increases in retinol and retinyl palmitate in serum, lung and liver after intravenous and endotracheal retinylester administration as well as changes in the genetic expression of LRAT and CYP26B1.

Conclusion: Our data indicate the feasibility of the tested substance for supplementation in the neonatal cohort using either the intravenous or endotracheal route. Further studies are warranted to explore this substance's safety profile, short- and long-term effects, and practicalities with regard to dose, mode of application and its influence on $\mathrm{BPD}$ in the preterm neonatal population. 


\section{INTRODUCTION}

Bronchopulmonary dysplasia (BPD) is the most common complication in premature infants [1, 2]. BPD affects up to $40 \%$ of survivors of preterm birth below 29 weeks of gestation [3]. Therefore, the prevention of BPD in at-risk infants is one of the most important aspects of early neonatal care. Bronchopulmonary dysplasia is characterized by chronic inflammation, impaired alveolarization and vascularization which results in chronic lung damage with significant short and long term mortality and morbidity [4]. Vitamin A (VA), an umbrella term for different chemical substances such as retinol $(\mathrm{ROH})$, retinyl ester (RE) or retinoic acid (RA) [5], is a prerequisite for the adequate preand postnatal development of lung tissue $[6,7]$. The availability of VA is crucial for the maturation and function of the respiratory system as well as for embryonic lung development and maturation, the growth and differentiation of respiratory epithelium, alveologenesis and septation of alveoli in utero, postnatal and after lung injury [8-13]. Premature infants have a lower availability of VA compared to full-term neonates, as shown by lower serum ROH and retinol-binding protein (RBP) levels. VA stores are crucially important in the last trimester and are utilised for lung maturation at the time of term birth [14]. As a result of preterm birth, low ROH blood levels have been associated with BPD development and long-term respiratory morbidity $[15,16]$. Therefore VA supplementation in very low birth weight infants is considered a promising pharmacological option in BPD prevention $[2,8,17]$. Clinical studies of VA supplementation as retinyl ester preparations for BPD prevention have previously been conducted in the ELBW cohort [18-22]. A meta-analysis of clinical studies has shown a reduction in deaths or oxygen requirement at one month of age in infants treated with retinyl ester preparations [23].

A common route for additional VA supplementation for the prevention of BPD is intramuscular injection since there are no VA monopreparations available for additional intravenous use. Additional oral supplementation of VA, an alternative currently investigated in a multicenter study [24], has not shown any beneficial treatment effects in a previous study [18]. Intramuscular administration, however, is not widely accepted, mainly due to the associated pain $[25,26]$. Consequently a direct delivery of RE to the lung might be an alternative and promising approach. Nearly twenty years ago, Biesalski et al. investigated endotracheally administered VA in rodents with promising results [27]. Subsequent clinical studies using aerosolized VA preparations already demonstrated clinical benefits in preschool children and adults $[28,29]$.

The availability of a commercially sold, nano-encapsuled, water-soluble RE monopreparation, containing retinyl palmitate (RP) and intended for use in nutritional supplementation (NovaSOL ${ }^{\circ}$ A) but, due to its composition, principally usable as parenteral substrate, led us to explore the efficacy of this substance in an translational study. We employed a well-established animal model by using preterm lambs [30]. The pre-clinical 
lamb model allowed the use of neonatal equipment in realistic conditions and has been shown to be an adequate model for translation into clinical practice [31].

The aim of our study was therefore twofold: first, to test the feasibility of intravenous and endotracheal application of the described nano-encapsuled vitamin A preparation using a dose which is consistent with currently available clinical data [18, 19, 21 , 24] and second, to study VA distribution in serum, lungs and liver tissue. Further, we explored the mRNA levels of early homeostatic genes related to retinol uptake (STRA6), esterification (LRAT), and catabolism (CYP26B1) in the lungs [32, 33].

\section{MATERIALS AND METHODS}

\section{Dose preparation}

Retinol (retinyl palmitate [RP], [CAS-Nr.: 79-81-2)]) was provided by AquaNova (NovaSOL ${ }^{\circledR}$ A 10\% [RETI20010], AquaNova , Darmstadt, Germany). The product is a solubilisate, which means that a liposoluble product (VA) was made water soluble through encapsulation in a micellar structure of the size less than $10 \mathrm{~nm}$, a molar mass distributed between $2 \mathrm{e}+5$ and $6 \mathrm{e}+5 \mathrm{~g} / \mathrm{mol}$ and that contains at least $170.000 \mathrm{IU} / \mathrm{g} \mathrm{VA}$. For treatment, $1 \mathrm{~mL}$ of the original solution was solved in $33 \mathrm{~mL}$ saline (i.e. $5000 \mathrm{IU} / \mathrm{mL}$ ), protected from light and warmed to body temperature $\left(37^{\circ} \mathrm{C}\right)$ before application.

\section{Animals and experimental design}

Animal experiments were approved by the Institutional Animal Ethics Committee of Maastricht University. Ten lambs of time-mated Texel ewes were operatively delivered at a gestational age of 128-133 days (term $\sim 150$ days), at which lung maturation resembles about 30 weeks of gestation in humans [34]. One day before the experiment, the ewe received an intra-muscular injection with betamethasone $\left(12 \mathrm{mg}\right.$, Celestone ${ }^{\circledR}$, ScheringPlough, North Ryde, New South Wales, Australia) to induce foetal lung maturation [35]. Caesarean section was performed in a modified EXIT procedure, including placement of an arterial and a venous catheter (Argyle ${ }^{\circledR}, 3.5$ Fr., Covidien, Tullamore, Ireland) in the umbilical vessels and subsequent oral intubation (Microcuff ${ }^{\circledR} 4.5 \mathrm{~mm}$, Kimberly-Clarke, Zaventem, Belgium) [30]. After the cord was clamped, lambs were weighed and brought to an open, heated incubator (IW930 Series CosyCot ${ }^{\mathrm{TM}}$ Infant Warmer, Fisher \& Paykel Healthcare, Auckland, New Zealand), maintaining the physiologic body temperature of $38{ }^{\circ} \mathrm{C}$. Body temperature was monitored by placing a rectal temperature probe. Lambs were continuously sedated with intravenous midazolam and ketamine, and were provided with parenteral nutrition (1:1 mix of Glucose $20 \%$ and Ringer's solution, B. Braun Medical B.V. Oss, The Netherlands, 3,4 mL/kg body weight per hour). The tube was connected to intermittent positive pressure ventilation (IPPV) using an infant ventilator 
(Babylog 8000, Draeger, Luebeck, Germany). Initial settings were as follows: $\mathrm{FiO}_{2}=1$, PEEP $8 \mathrm{~cm} \mathrm{H}_{2} \mathrm{O}$, PIP $30 \mathrm{~cm} \mathrm{H}_{2} \mathrm{O}$, frequency $60 /$ min, relation of inspiratory to expiratory time (I:E) 1:2. Blood pressure and heart rate were measured via the arterial catheter, and frequent blood gas analysis was performed for ventilation control.

\section{Retinyl palmitate delivery}

At 0.5 hours of life, lambs randomly received $5000 \mathrm{IU} / \mathrm{kg}$ body weight of retinyl palmitate diluted in saline $(5000 \mathrm{IU} / \mathrm{mL})$ either intravenously via the umbilical venous catheter ("i.v.") or endotracheally ("e.t.") via a gastric tube (6 Fr., Vygon, Ecouen, France) placed within the tube directly after an endotracheal surfactant bolus (Poractant alfa $100 \mathrm{mg} / \mathrm{kg}$, generous gift of Chiesi Pharmaceuticals, Parma, Italy). Untreated animals served as control group.

\section{Tissue collection}

Blood for serum $\mathrm{ROH}$ and RP analysis was taken immediately prior to treatment (pretreatment value) and at $0.5 \mathrm{~h}, 1 \mathrm{~h}, 1.5 \mathrm{~h}, 2 \mathrm{~h}, 2.5 \mathrm{~h}$ and at the end of the experiment. Unfortunately, for technical reasons, in one of the three control animals no serum was available for data analysis. Blood samples were taken in $1.1 \mathrm{ml}$ tubes (Microtube, Serum Gel with Clotting Activator, Sarstedt, Nümbrecht, Germany), wrapped in aluminium foil and kept on ice. After the experiment, blood samples were centrifuged for 10 minutes at $1300 \times$ g to obtain serum that was immediately frozen at -80 degrees Celsius. The lambs were euthanized with an overdose of pentobarbital after $3.5+/-0.5 \mathrm{~h}$ for necropsy. We further sampled solid organs (lung, liver, kidney) and urine, which were immediately snap frozen. All samples were shielded from light.

\section{Vitamin A analysis}

All preparation steps were performed on ice and under yellow light, and the samples were stored in light-tight boxes.

\section{Serum and urine}

Frozen serum was warmed to $20^{\circ} \mathrm{C}$. $200 \mu \mathrm{L}$ were transferred to a reaction vial containing $200 \mu \mathrm{L}$ ethanol. After mixing, $500 \mu \mathrm{L} \mathrm{N}$-hexane were added and the sample was mixed again, followed by a centrifugation step ( $1 \mathrm{~min}, \mathrm{RT}, 16000 \mathrm{xg}$ ). The hexane phase was removed, extraction repeated and both hexane phases pooled and dried in a speed-vac concentrator. Dried samples were resuspended in $200 \mu \mathrm{L}$ HPLC buffer, centrifuged (1 min, RT, $16000 \mathrm{xg}$ ) and supernatant transferred to an HPLC vial for analysis. Urine samples were treated accordingly. 


\section{Organ samples:}

For extraction, the antioxidant (BHT) was added to either $\mathrm{N}$-hexane (100 ppm) or ethanol (10 ppm), samples of 100-500 mg were put into a $15 \mathrm{~mL}$ Falcon tube filled with $2 \mathrm{~mL}$ PBS and $2 \mathrm{~mL}$ ethanol. After mixing, samples were homogenized with an Ultra-Turrax. For extraction, $5 \mathrm{~mL} \mathrm{~N}$-hexane were added, mixed and shaken on a roller-shaker for 10 min. Samples were centrifuged ( $2 \mathrm{~min}, 10{ }^{\circ} \mathrm{C}, 4500 \mathrm{xg}$ ) and the supernatant hexane phase transferred into a $50 \mathrm{~mL}$ round bottom flask. Pooled hexane phases from three extractions were dried in a rotating evaporator at a water temperature $<25{ }^{\circ} \mathrm{C}$. Samples were then transferred to HPLC-buffer (80\% acetonitrile, $20 \%$ Tetrahydrofuran (THF) as 2 aliquots, one of which was analyzed immediately, the other one stored at $-80{ }^{\circ} \mathrm{C}$ as backup.

\section{HPLC}

We used the Shimadzu Prominence gradient system with 2 pumps (LC20AT), autosampler (Sil-20AC) cooled to $4{ }^{\circ} \mathrm{C}$ and a diode-array detector (SPD-M20A) set to $325 \mathrm{~nm}$. The column used was a Nucleosil 5C18 (300mm $\times 4 \mathrm{~mm}, 3 \mu \mathrm{m})$ from Trentec (Gerlingen, Germany). The used HPLC buffer was acetonitrile (80\%), (THF, 12\%), methanol solution (0,1M ammoniumacetat in methanol, $8 \%)$, flow rate $1.6 \mathrm{ml} / \mathrm{min}$.

\section{RNA isolation and gene expression analysis}

Expression analysis was performed by applying the MIQE guidelines [36]. Total RNA was extracted from lung tissue using the NucleoSpin ${ }^{\circledR}$ RNA kit (Macherey-Nagel GmbH \& Co KG, Düren, Germany) according to the manufacturer's instructions and converted to cDNA using the High-Capacity cDNA Reverse Transcription Kit by Applied Biosystems (Life Technologies $\mathrm{GmbH}$, Darmstadt, Germany). Prior to reverse transcription, it was confirmed that the PCR results were not influenced by contaminating DNA in the samples. Quantitative real time PCR was performed in triplicates with 10 ng cDNA per reaction using Custom TaqMan Gene Expression Assays from Applied Biosystems on an Applied Biosystems 7500 Fast Real-Time PCR system . Beta Actin served as endogenous control. Primer and Probe combinations were as follows: OVIS_STRA6_F: 5'-GCTGCTAGTGGGTGTGGTA-3' (forward), 5'-GGAGACGTCCGTGGTGATC-3' (reverse), 5'-CCGCCCTCACCTTC-3' (probe) OVIS_LRAT_F: 5'-TCAAGAAGAAGGCACTGCTCAA-3' (forward), 5'GTGCCCAGCAGCTTCTCT3' (reverse), 5'-CTGTGCCACCTCTTCG-3' (probe) OVIS_CYP26B1_F: 5'CGCAGGGCAAGGACTACT-3' (forward), 5'-CTCCTTGCTGCTCTCGATGAG-3' (reverse), 5'CAGACGCGCTGGACAT-3' (probe) OVIS_ACTB_F: 5'-CTTCCTTCCTGGGCATGGA-3' (forward), 5'-ACGTCACACTTCATGATGGAATTGA-3' (reverse), 5'-CTGCGGCATTCACG-3' (probe). 
Relative quantification to the untreated control and normalization to the endogenous control were performed using Data Assist ${ }^{\mathrm{TM}}$ Software v3.0 (Applied Biosystems, Life Technologies $\mathrm{GmbH}$, Darmstadt, Germany) according to the Comparative CT (ddCT) method.

\section{Statistical analysis}

IBM SPSS Version 20 (IBM, Armink, NY) was used for statistical analysis. Animal characteristics and RP and $\mathrm{ROH}$ tissue levels were compared using non-parametric testing (Kruskal-Wallis $\mathrm{H}$ test). Groups of interest were compared by the Mann-Whitney $\mathrm{U}$ test. Data from RP and $\mathrm{ROH}$ serum level measurements were compared by the Friedman test. Comparative assessment of PCR data was done by the Student t-test. Significance was accepted at p-values <0.05. Graphs were drawn with GraphPad Prism v5.0 (GraphPad Software, San Diego, CA).

\section{RESULTS}

\section{Animal characteristics}

Ten animals were randomly assigned to three different groups. Treatment was performed at $30+/-5$ min of age. Three animals received no vitamin A treatment (control), three animals received vitamin A intravenously (i.v.), and four animals received vitamin A endotracheally (e.t.). There were no statistical significant differences with regard to animal characteristics, organ weight and physiological variables (Table 1).

Table 1: Animal characteristics

\begin{tabular}{lllll}
\hline & control & i.v. & e.t. & \\
$\mathrm{n}=$ & 3 & 3 & 4 & $\mathrm{p}=$ \\
\hline gestational age (days) & $131 \pm 1.5$ & $131 \pm 1$ & $130 \pm 1$ & 0.62 \\
birth weight (kg) & $2.6 \pm 0.5$ & $2.3 \pm 0.3$ & $2.4 \pm 0.3$ & 0.94 \\
left lung weight (g) & $32.1 \pm 9.5$ & $27.3 \pm 6.9$ & $33.9 \pm 5.6$ & 0.74 \\
right lung weigth (g) & $21.7 \pm 6.5$ & $21.7 \pm 2.3$ & $23.3 \pm 1.7$ & 0.96 \\
liver weight (g) & $39.6 \pm 7.1$ & $59.3 \pm 15.1$ & $68.1 \pm 19.6$ & 0.41 \\
left kidney (g) & $7.7 \pm 1.7$ & $7.5 \pm 1.4$ & $8.5 \pm 1.1$ & 0.88 \\
start of treatment & & & & 0.08 \\
$\mathrm{pH}$ & $7.12 \pm 0.10$ & $7.25 \pm 0.05$ & $7.00 \pm 0.08$ & 0.08 \\
$\mathrm{pCO}_{2}$ (mmHg) & $68 \pm 26$ & $38 \pm 6$ & $86 \pm 18$ & 0.82 \\
$\mathrm{pO}_{2}$ (mmHg) & $136 \pm 101$ & $95 \pm 49$ & $125 \pm 61$ & \\
end of experiment & & & & 0.29 \\
$\mathrm{pH}$ & $7.26 \pm 0.02$ & $7.18 \pm 0.04$ & $7.09 \pm 0.08$ & 0.76 \\
$\mathrm{pCO}_{2}$ (mmHg) & $54 \pm 2$ & $57 \pm 8$ & $64 \pm 9$ & 0.10 \\
$\mathrm{pO}_{2}$ (mmHg) & $29 \pm 1$ & $54 \pm 15$ & $57 \pm 6$ & \\
\hline
\end{tabular}

Data given as mean $\pm \mathrm{SEM}$. $\mathrm{pO}_{2}$ partial pressure of oxygen, $\mathrm{pCO}_{2}$ partial pressure of carbondioxide. 


\section{Serum analysis of $R O H$ and $R P$}

Serum ROH and RP analysis during all selected points in time in untreated control animals revealed a narrow distribution of $\mathrm{ROH}$ values between $99 \mathrm{nM}$ (minimum) and 284 $\mathrm{nM}$ (maximum), and pre-treatment $\mathrm{ROH}$ and RP results in i.v. and e.t. treated animals were similar to those measured in untreated controls $(p=0.61$ and $p=1.00)$. Following intervention, ROH (Figure 1a) and RP (Figure 1b) increased significantly in i.v. and e.t. treated animals ( $p<0.017$ and $p<0.018$ compared to controls).
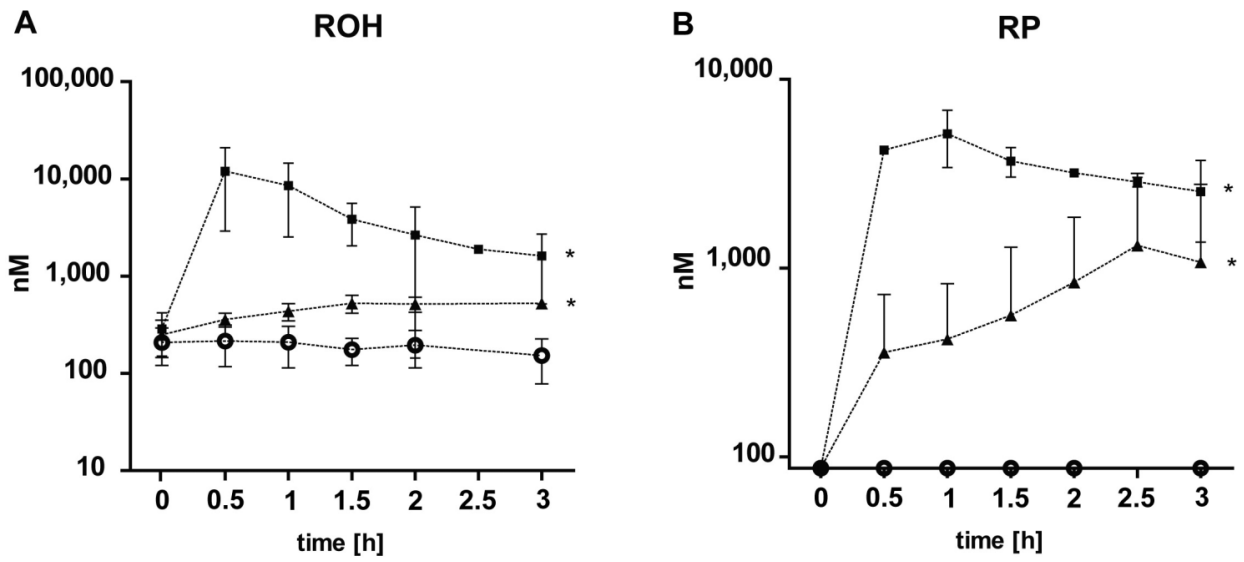

Figure $1 \mathrm{~A}$ and $\mathrm{B}$ : Pre-treatment (A) serum $\mathrm{ROH}$ and (B) serum RP in i.v. (square) and e.t. (triangle) treated animals were similar to those measured in untreated controls (circle), and increased significantly in both groups after treatment ( ${ }^{*} p<0.05$ compared to control).

\section{Tissue analysis of ROH and RP - Lung tissue}

Retinol and RP analysis in control animals revealed $\mathrm{ROH}$ and RP values just at or below the detection limit (mean $( \pm S D) 17.3( \pm 13.0 \mathrm{ng} / \mathrm{g})$ ). After intravenous and endotracheal application of retinyl palmitate, concentrations of $\mathrm{ROH}$ ( $p=0.001$ [i.v.] and $p<0.001$ [e.t.]) and $\operatorname{RP}(p<0.001$ [i.v.] and $p<0.001$ [e.t.]) increased at a statistically significant rate within lung tissue in both groups when compared to controls (Figure $2 \mathrm{a}+\mathrm{b}$ ) .

When comparing the distribution of vitamin A within the lung in different treatment groups, no statistically significant difference was found in i.v. treated ( $\mathrm{ROH}$ lung apex $42.6 \% \pm 11.5 \%$, lung hilus $17.4 \% \pm 13.6 \%$ and lung base $40.0 \% \pm 3.7 \%$; RP $33.2 \% \pm 17.8 \%$, $23.8 \% \pm 21.7 \%$ and $43.0 \% \pm 6.2 \%$, respectively) and e.t. treated animals ( $\mathrm{ROH}$ $16.1 \% \pm 10.2 \%, \quad 37.7 \% \pm 34.2 \%$ and $46.2 \pm 17.9 \%$, respectively; RP $14.4 \% \pm 16.7 \%$, $49.1 \% \pm 30.6 \%$ and $36.5 \% \pm 38.2 \%$, respectively, $p=0.097$ to $p=1.0$ ). 


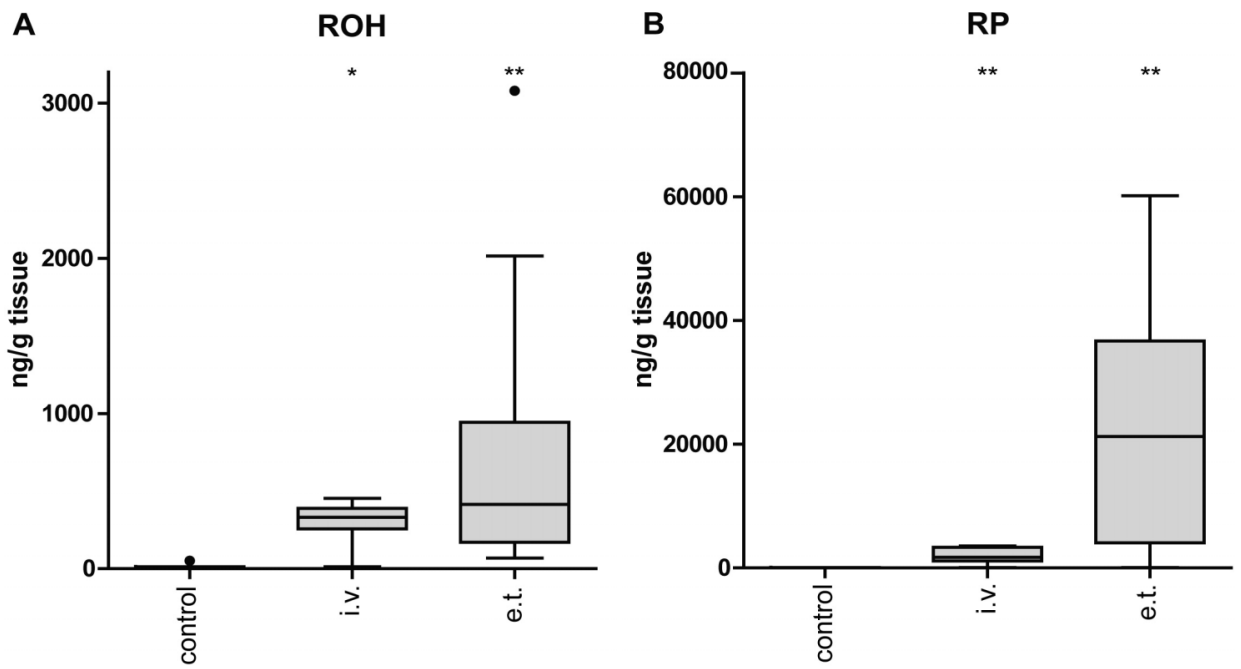

Figure $2 \mathrm{~A}$ and $\mathrm{B}$ : In the lung of control animals, we found (A) ROH and (B) RP levels just at or below the detection limit. Both i.v. and e.t. treated animals showed statistically significant increase of lung tissue concentrations of ROH and RP at autopsy $\left({ }^{*} p=0.001\right.$ and ${ }^{* *} p<0.001$ vs. control).

\section{Tissue analysis of ROH and RP - Liver tissue}

After intravenous application, $\mathrm{ROH}$ and RP levels were increased at a statistically significant rate in the liver $(p=0.05[R O H]$ and $p<0.05[R P])$. However, vitamin A increase in the liver after e.t. administration missed statistical significance (Mann-Whitney-Test; $p=0.08$ $[\mathrm{ROH}]$ and $\mathrm{p}=0.14[\mathrm{RP}]$.
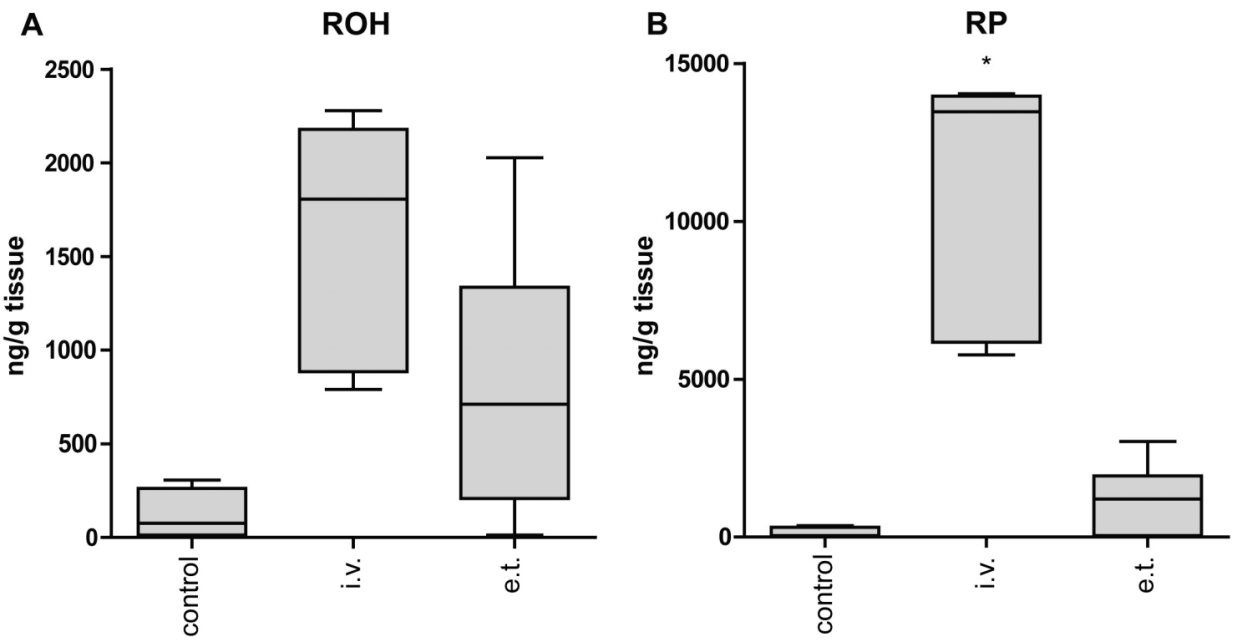

Figure $3 \mathrm{~A}$ and $\mathrm{B}$ : In the liver, (A) ROH and (B) RP levels increased after intravenous application $(p=0.05[\mathrm{ROH}]$ and $\left.{ }^{*} p<0.05[R P]\right)$. However, vitamin $A$ increase in the liver after e.t. administration missed statistical significance $(p=0.08[R O H]$ and $p=0.14[R P])$. 


\section{Tissue analysis of ROH and RP - Kidney and urine}

Although we used a water soluble vitamin A preparation, $\mathrm{ROH}$ levels were below detection limits in the urine of all animals and RP was below detection limits in the urine of all but one animal, in which RP concentration was very low (12 nM). Kidney levels of ROH did not differ significantly between groups (control $635 \pm 328 \mathrm{ng} / \mathrm{g}$, IV $943 \pm 42 \mathrm{ng} / \mathrm{g}$, ET $686 \pm 112 \mathrm{ng} / \mathrm{g}$ tissue, respectively, $\mathrm{p}=0.333$ ). Although RP levels where highest in the i.v. group, differences were not statistically significance (control $206 \pm 206 \mathrm{ng} / \mathrm{g}$, IV $1284 \pm 338 \mathrm{ng} / \mathrm{g}$, ET $128 \pm 48 \mathrm{ng} / \mathrm{g}$ tissue, respectively; $\mathrm{p}=0.109$ ).

\section{Molecular analysis of mRNA levels}

After intravenous application of VA, we saw increased mRNA levels of CYP26B1 $(p=0.029)$ in lung tissue when compared to controls. No changes were seen for LRAT or STRA6 mRNA levels when comparing i.v. to controls (Fig. 4). After endotracheal application of RP, LRAT showed significantly reduced mRNA levels when compared to controls $(p=0.0399)$. Neither CYP26B1 nor STRA6 showed a change in expression following e.t. treatment compared to control (Fig. 4).

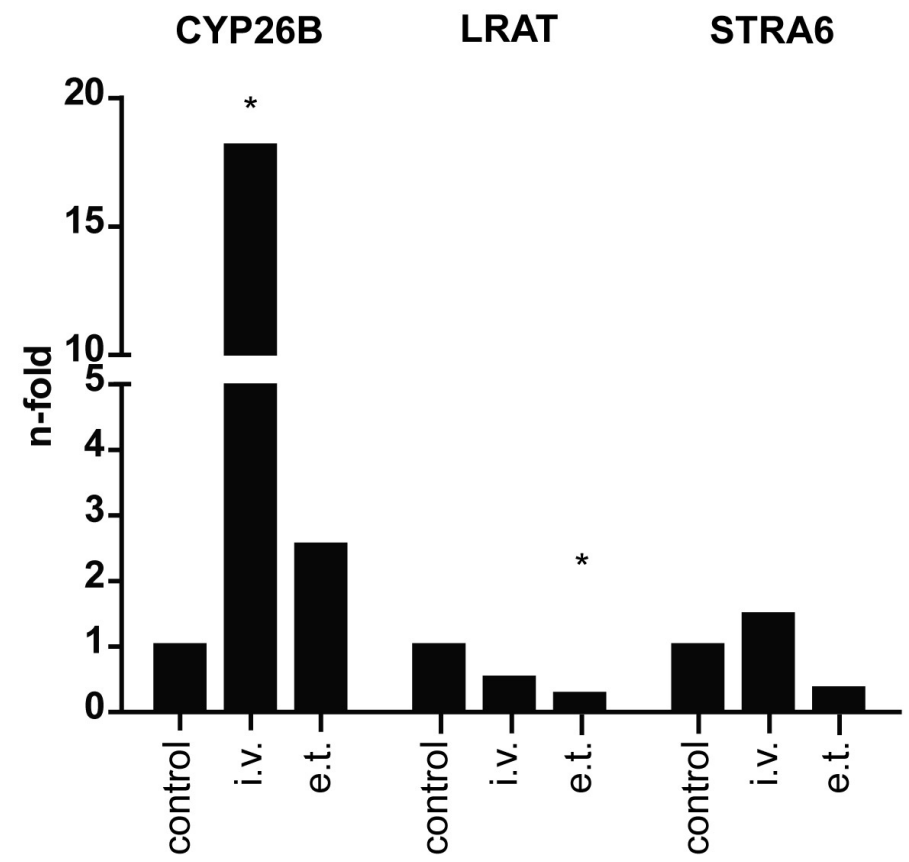

Figure 4: Molecular analysis of enzymes of vitamin A metabolism showed a significant increase in CYP26B mRNA levels in the i.v. group and a significant decrease in LRAT mRNA levels in the e.t. group $\left({ }^{*} p<0.05\right.$ vs. control). 


\section{DISCUSSION}

Our results show that both i.v. and e.t. supplementation of RP increases ROH and RP levels in serum and target organs (liver and lungs) significantly, hereby confirming those routes as potential routes for VA delivery. Current supplementation regimes do not sufficiently correct VA deficiency in the ELBW cohort [37], and it is therefore important to explore alternative preparations which allow for exact weight-targeted dosing and for usage via alternative routes of delivery. Biesalski et al. demonstrated that topical application of REs was able to increase intracellular REs and ROH in buccal epithelial cells $[38,39]$. Further, it has been shown that retinyl palmitate supplementation by inhalation of an aerosol establishes an intracellular pool of retinol, improves VA status and is feasible as a treatment option [27-29]. The obvious advantage of the endotracheal application is its delivery in close proximity to the target organ and its possible potential to increase the VA supply where it is needed most: at the alveolar septum. This is important as VA supplementation has been shown to revert the epithelial changes associated with BPD [40]. VA reaching lung epithelial cells from the airway side instead of from the capillaries led to sufficient tissue concentrations [27, 28]. In our study, VA levels increased in lung tissue after both i.v. and e.t. application.

In contrast, only i.v. application was shown to also increase liver concentrations significantly. This may have significant implications: on the one hand and although VA, in particular RE is generally considered nontoxic [41, 42] at recommended dose [43-47], toxic effects of long-term use of high doses of natural Vitamin A (not RA) can result in RE accumulation with subsequent liver dysfunction and at least cirrhosis. In particular, in preterm neonates the metabolic capacity of the liver is still immature and may be further compromised by various other drugs commonly used in this cohort such as antibiotics. An effective application route that bypasses the liver metabolism but still results in the desired clinical effect within the main target organ may therefore be advantageous.

On the other hand, the liver serves as the main VA storage side. Increasing those stores, as long as no toxic effects are observed, may have long-term advantages. So far, and in favour of this argument, unphysiological formation of RA after RE supplementation does not seem possible due to the strictly controlled metabolism [6]. Hence supplementation of RE compared to supplementation of RA is thought to be more advantageous in view of its physiological properties. The lungs accumulate REs in the $3^{\text {rd }}$ trimester and those stores are being depleted immediately prior to term birth $[14,48]$ in order to provide RA which in turn induces lung maturation [49]. The sufficient repletion of VA storing cells in the developing lung is seen as an important factor for long-term lung health $[6,50,51]$. However, any direct supplementation with RA may only provide short-term effects, and these effects may additionally be diminished by up-regulation of RA inhibiting enzymes such as CRABP or CYP26 system $[52,53]$. 
Interestingly, although we tested a water-soluble vitamin A preparation, no significant amounts of ROH and RP were found in the urine and kidneys of treated animals, indicating that the substance was not rapidly lost via diuresis but stored.

The determination of the expression of early molecular markers as an indication of an early VA effect has been of interest for several working groups in various animal models. In line with those previous studies we explored the mRNA levels of STRA6, LRAT and CYP26B1 $[32,54]$. It is known that RA regulates several important genes in VA homeostasis. Among those, STRA6, a transmembrane receptor for RBP, mediates retinol uptake through retinol binding protein from plasma and extracellular fluid into cells [33]. Retinoic acid further regulates the expression of LRAT and RA hydroxylases of the CYP26 family of cytochrome P450 genes [55]. Those enzymes and proteins are variably expressed with VA status and seem to exert tight control over intracellular VA status [56]. If RA is available, which is an indication for a sufficient VA status, the expression of LRAT is maintained [56]. Conversely, LRAT is down-regulated during VA deficiency [57]. CYP26B1 also increases with a rise in the concentration of RA [58] and is thought to be the cell's response for detoxification of RA [59]. CYP26B1 is maintained at very low levels in VA deficiency $[60,61]$.

In our study, we did not find increased levels in lung tissue of STRA6. This might document that the applied retinyl esters were directly absorbed into cells after i.v. and e.t. application, bypassing the well-known pathway using RBP. Indeed direct uptake of RE into different tissues has been documented previously [62].

A statistically significant reduction of the mRNA levels of LRAT was seen after e.t. treatment, although no effect was seen after i.v. treatment. This result shows that esterification may not be needed because the retinyl ester can be absorbed by the lung cells without prior cleavage to retinol, a delivery route which has been shown using non-physiological fatty acids for retinol esterification (retinyl margarinate) [62].

In rodents and following oral supplementation, it was previously shown that both lung RE concentrations and LRAT expression increased significantly after 6 hours following oral supplementation [32]. Our findings suggest down-regulation of LRAT due to the direct uptake of RE into the cells. Cellular response may depend on the route of administration and the substrate (ROH or RE) and may be noticeably different when using different application methods. Given the short time-period, the results in this study may be quite promising in indicating that the build-up of VA stores, the substrate for the biologically more active forms, may already have induced a cellular response.

The third metabolic enzyme investigated, CYP26B1, catalyses the oxidation of RA to non-toxic metabolites and appears to play a major role in VA detoxification and catabolism [32]. It increases in several tissues when the concentration of RA rises [58]. Our results showed an early increase of CYP26B1 in lung tissue in the i.v. group. This increase was not seen in the e.t. group. Although RA is the desired metabolic active form of VA, early expression of CYP26B1 may indicate high influx of potentially toxic RA. The differences in expression using different routes of administration plays an important 
role with regard to the safety profile of the substrate and should be investigated in further studies.

\section{Study limitations}

This study is limited by the small sample size and the short duration of the study protocol, which in particular does not allow for any conclusions on long-term or diseasemodifying aspects of the preparation. Further, ongoing investigations regarding safety are necessary. We saw pulmonary complications in one animal in the e.t. group. Although individual risk factors seemed to play an important role in this animal, which was unusually small for gestational age and required higher positive inspiratory pressures during ventilation in contrast to all other trial animals, further testing of endotracheal dosing is needed. This should also include pharmacological interactions between VA preparations and surfactant, although in previous studies with lavaged piglets endotracheal vitamin A supplementation did not influence therapeutic effects of surfactant administration [63].

\section{Conclusion}

In conclusion, we could show that the newly tested, water-soluble, nano-encapsuled VA mono-preparation (as RP) is feasible for both intravenous and endotracheal VA supplementation in preterm lambs. Our results are in line with previous studies in demonstrating a rise of systemic and tissue bond VA levels and early changes in mRNA levels of VA metabolic markers. Our results contribute to the ongoing research for the optimal supplementation regime by adding a potentially new substance allowing for weighttargeted supplementation via either the i.v. or e.t. routes. Ultimately, the best route of administration will depend on biological effects. The promising results of endotracheal VA administration in previous clinical and translational trials [27-29] and results from current trials using less invasive surfactant application (LISA) and surfactant nebulization in our animal model $[64,65]$ bear the potential of vitamin A supplementation via the endotracheal route in a non-invasive manner. Translational trials will enable us to further improve means of vitamin A administration, while clinical trials and safety studies are warranted to help to investigate biological and clinical effects.

\section{ACKNOWLEDGEMENT:}

The authors are grateful for the support of the DFG (Deutsche Forschungsgemeinschaft; ME 3827/1-1) and Stichting Kindergeneeskunde (Maastricht, The Netherlands). The authors further thank A. Koza, E. Maurer, Ingrid Lang, EMD, and Nico Kloosterboer for excellent technical assistance, analyses and sample management. 


\section{REFERENCES}

1. Coalson, J.J., Pathology of new bronchopulmonary dysplasia. Semin Neonatol, 2003. 8(1): p. 73-81.

2. Tropea, K. and H. Christou, Current pharmacologic approaches for prevention and treatment of bronchopulmonary dysplasia. Int J Pediatr, 2012. 2012: p. 598606.

3. Jobe, A.H., What is BPD in 2012 and what will BPD become? Early human development, 2012. 88 Suppl 2: p. S27-8.

4. Kinsella, J.P., A. Greenough, and S.H. Abman, Bronchopulmonary dysplasia. Lancet, 2006. 367(9520): p. 1421-31.

5. Underwood, B.A., Vitamin A in animal and human nutrition., in The retinoids, M.B. Sporn, A.B. Roberts, and D.S. Goodman, Editors. 1984, Academic Press: Orlando, FL. p. 282-392.

6. Biesalski H.K., The importance of vitamin A for the development and function of lungs in newborns. Sight and Life, 2011. 25: p. 16-29.

7. Mactier, H., Vitamin A for preterm infants; where are we now? Semin Fetal Neonatal Med, 2013.

8. Massaro, D. and G.D. Massaro, Retinoids, alveolus formation, and alveolar deficiency: clinical implications. Am J Respir Cell Mol Biol, 2003. 28(3): p. 271-4.

9. Massaro, D. and G.D. Massaro, Invited Review: pulmonary alveoli: formation, the "call for oxygen," and other regulators. Am J Physiol Lung Cell Mol Physiol, 2002. 282(3): p. L345-58.

10. Roth-Kleiner, M. and M. Post, Similarities and dissimilarities of branching and septation during lung development. Pediatr Pulmonol, 2005. 40(2): p. 113-34.

11. Shoseyov, D., et al., Repeated allergen challenge in rats increases vitamin A consumption. Chest, 2002. 122(4): p. 1407-11.

12. Biesalski, H.K. and D. Nohr, Importance of vitamin-A for lung function and development. Mol Aspects Med, 2003. 24(6): p. 431-40.

13. Maden, M. and M. Hind, Retinoic acid in alveolar development, maintenance and regeneration. Philos Trans R Soc Lond B Biol Sci, 2004. 359(1445): p. 799-808.

14. Masuyama, H., Y. Hiramatsu, and T. Kudo, Effect of Retinoids on Fetal Lung Development in the Rat. Neonatology, 1995. 67(4): p. 264-273.

15. Spears, K., C. Cheney, and J. Zerzan, Low plasma retinol concentrations increase the risk of developing bronchopulmonary dysplasia and long-term respiratory disability in very-low-birth-weight infants. Am J Clin Nutr, 2004. 80(6): p. 1589-94.

16. Shenai, J.P., F. Chytil, and M.T. Stahlman, Vitamin A status of neonates with bronchopulmonary dysplasia. Pediatr Res, 1985. 19(2): p. 185-8.

17. Massaro, D. and G.D. Massaro, Toward therapeutic pulmonary alveolar regeneration in humans. Proc Am Thorac Soc, 2006. 3(8): p. 709-12.

18. Wardle, S.P., et al., Randomised controlled trial of oral vitamin A supplementation in preterm infants to prevent chronic lung disease. Arch Dis Child Fetal Neonatal Ed, 2001. 84(1): p. F9-F13.

19. Ambalavanan, N., et al., A comparison of three vitamin A dosing regimens in extremely-low-birth-weight infants. J Pediatr, 2003. 142(6): p. 656-61.

20. Shenai, J.P., et al., Clinical trial of vitamin A supplementation in infants susceptible to bronchopulmonary dysplasia. J Pediatr, 1987. 111(2): p. 269-77.

21. Tyson, J.E., et al., Vitamin A supplementation for extremely-low-birth-weight infants. National Institute of Child Health and Human Development Neonatal Research Network. N Engl J Med, 1999. 340(25): p. 1962-8.

22. Werkman, S.H., et al., Effect of vitamin A supplementation of intravenous lipids on early vitamin A intake and status of premature infants. Am J Clin Nutr, 1994. 59(3): p. 586-92.

23. Darlow, B.A. and P.J. Graham, Vitamin A supplementation to prevent mortality and short- and long-term morbidity in very low birthweight infants. Cochrane Database Syst Rev, 2011(10): p. Cd000501.

24. Meyer, S., L. Gortner, and A.T.I. NeoVita, Early postnatal additional high-dose oral vitamin A supplementation versus placebo for 28 days for preventing bronchopulmonary dysplasia or death in extremely low birth weight infants. Neonatology, 2014. 105(3): p. 182-8. 
25. Kaplan, H.C., et al., Understanding variation in vitamin A supplementation among NICUs. Pediatrics, 2010. 126(2): p. e367-73.

26. Ambalavanan, N., et al., Survey of vitamin A supplementation for extremely-low-birth-weight infants: is clinical practice consistent with the evidence? J Pediatr, 2004. 145(3): p. 304-7.

27. Biesalski, H.K., Effects of intra-tracheal application of vitamin A on concentrations of retinol derivatives in plasma, lungs and selected tissues of rats. Int J Vitam Nutr Res, 1996. 66(2): p. 106-12.

28. Kohlhaufl, M., et al., Inhalation of aerosolized vitamin a: reversibility of metaplasia and dysplasia of human respiratory epithelia -- a prospective pilot study. Eur J Med Res, 2002. 7(2): p. 72-8.

29. Biesalski, H., et al., Retinyl palmitate supplementation by inhalation of an aerosol improves vitamin $A$ status of preschool children in Gondar (Ethiopia). Br J Nutr, 1999. 82(3): p. 179-82.

30. Seehase, M., et al., New surfactant with SP-B and $C$ analogs gives survival benefit after inactivation in preterm lambs. PLoS One, 2012. 7(10): p. e47631.

31. Kramer, B.W., Antenatal inflammation and lung injury: prenatal origin of neonatal disease. J Perinatol, 2008. 28 Suppl 1: p. S21-7.

32. Wu, L. and A.C. Ross, Acidic retinoids synergize with vitamin A to enhance retinol uptake and STRA6, LRAT, and CYP26B1 expression in neonatal lung. J Lipid Res, 2010. 51(2): p. 378-87.

33. Kawaguchi, R., et al., A membrane receptor for retinol binding protein mediates cellular uptake of vitamin A. Science, 2007. 315(5813): p. 820-5.

34. Kramer, B.W., Antenatal inflammation and lung injury: prenatal origin of neonatal disease. Journal of perinatology : official journal of the California Perinatal Association, 2008. 28 Suppl 1: p. S21-7.

35. Jobe, A.H., et al., Betamethasone for lung maturation: testing dose and formulation in fetal sheep. American journal of obstetrics and gynecology, 2007. 197(5): p. 523 e1-6.

36. Bustin, S.A., et al., The MIQE guidelines: minimum information for publication of quantitative real-time PCR experiments. Clin Chem, 2009. 55(4): p. 611-22.

37. Mactier, H., et al., Vitamin A provision for preterm infants: are we meeting current guidelines? Arch Dis Child Fetal Neonatal Ed, 2011. 96(4): p. F286-9.

38. Sobeck, U., A. Fischer, and H.K. Biesalski, Uptake of vitamin A in buccal mucosal cells after topical application of retinyl palmitate: a randomised, placebo-controlled and double-blind trial. Br J Nutr, 2003. 90(1): p. 69-74.

39. Biesalski, H.K. and D. Nohr, New aspects in vitamin a metabolism: the role of retinyl esters as systemic and local sources for retinol in mucous epithelia. J Nutr, 2004. 134(12 Suppl): p. 3453S-3457S.

40. Chytil, F., Retinoids in lung development. FASEB J, 1996. 10(9): p. 986-92.

41. Ulbricht, C., et al., An evidence-based systematic review of vitamin A by the natural standard research collaboration. J Diet Suppl, 2012. 9(4): p. 299-416.

42. Van Eyken, P., et al., Hepatic injury to the newborn liver due to drugs. Curr Pharm Des, 2012. 18(21): p. 3050-60.

43. Agostoni, C., et al., Enteral nutrient supply for preterm infants: commentary from the European Society of Paediatric Gastroenterology, Hepatology and Nutrition Committee on Nutrition. J Pediatr Gastroenterol Nutr, 2010. 50(1): p. 85-91.

44. European Food Safety Authority (EFSA), Tolerable upper intake levels for vitamins and minerals, 2006, European Food Safety Authority, http://www.efsa.europa.eu/en/ndatopics/docs/ndatolerableuil.pdf: Parma.

45. Koletzko, B., et al., 1. Guidelines on Paediatric Parenteral Nutrition of the European Society of Paediatric Gastroenterology, Hepatology and Nutrition (ESPGHAN) and the European Society for Clinical Nutrition and Metabolism (ESPEN), Supported by the European Society of Paediatric Research (ESPR). J Pediatr Gastroenterol Nutr, 2005. 41 Suppl 2: p. S1-87.

46. Mirtallo, J., et al., Safe practices for parenteral nutrition. JPEN J Parenter Enteral Nutr, 2004. 28(6): p. S39-70.

47. Institute of Medicine. Food and Nutrition Board, Dietary Reference Intakes for Vitamin A, Vitamin K, Arsenic, Boron, Chromium, Copper, lodine, Iron, Manganese, Molybdenum, Nickel, Silicon, Vanadium, and Zinc, 2001, National Academy Press: Washington, DC. 


\section{Chapter 5}

48. Geevarghese, S.K. and F. Chytil, Depletion of retinyl esters in the lungs coincides with lung prenatal morphological maturation. Biochem Biophys Res Commun, 1994. 200(1): p. 529-35.

49. Hind, M., J. Corcoran, and M. Maden, Alveolar proliferation, retinoid synthesizing enzymes, and endogenous retinoids in the postnatal mouse lung. Different roles for Aldh-1 and Raldh-2. Am J Respir Cell Mol Biol, 2002. 26(1): p. 67-73.

50. Shenai, J.P. and F. Chytil, Vitamin A storage in lungs during perinatal development in the rat. Biol Neonate, 1990. 57(2): p. 126-32.

51. Dirami, G., et al., Lung retinol storing cells synthesize and secrete retinoic acid, an inducer of alveolus formation. Am J Physiol Lung Cell Mol Physiol, 2004. 286(2): p. L249-56.

52. McGowan, S.E., C.S. Harvey, and S.K. Jackson, Retinoids, retinoic acid receptors, and cytoplasmic retinoid binding proteins in perinatal rat lung fibroblasts. Am J Physiol, 1995. 269(4 Pt 1): p. L463-72.

53. Luu, L., et al., Regulation of retinoic acid metabolism. Adv Enzyme Regul, 2001. 41: p. 159-75.

54. Schaffer, M.W., et al., Uptake of all-trans retinoic acid-containing aerosol by inhalation to lungs in a guinea pig model system--a pilot study. Exp Lung Res, 2010. 36(10): p. 593-601.

55. Ross, A.C., R. Zolfaghari, and J. Weisz, Vitamin A: recent advances in the biotransformation, transport, and metabolism of retinoids. Curr Opin Gastroenterol, 2001. 17(2): p. 184-192.

56. Ross, A.C., Retinoid production and catabolism: role of diet in regulating retinol esterification and retinoic Acid oxidation. J Nutr, 2003. 133(1): p. 291S-296S.

57. Randolph, R.K. and A.C. Ross, Vitamin A status regulates hepatic lecithin: retinol acyltransferase activity in rats. J Biol Chem, 1991. 266(25): p. 16453-7.

58. Petkovich, P.M., Retinoic acid metabolism. J Am Acad Dermatol, 2001. 45(5): p. S136-42.

59. Das, B.C., et al., Retinoic acid signaling pathways in development and diseases. Bioorg Med Chem, 2014. 22(2): p. 673-83.

60. Yamamoto, Y., R. Zolfaghari, and A.C. Ross, Regulation of CYP26 (cytochrome P450RAI) mRNA expression and retinoic acid metabolism by retinoids and dietary vitamin A in liver of mice and rats. FASEB J, 2000. 14(13): p. 2119-27.

61. Wang, Y., R. Zolfaghari, and A.C. Ross, Cloning of rat cytochrome P450RAI (CYP26) CDNA and regulation of its gene expression by all-trans-retinoic acid in vivo. Arch Biochem Biophys, 2002. 401(2): p. 235-43.

62. Gerlach, T., et al., Vitamin A in parenteral nutrition: uptake and distribution of retinyl esters after intravenous application. Am J Clin Nutr, 1989. 50(5): p. 1029-38.

63. Singh, A.J., et al., Vitamin $A$ is systemically bioavailable after intratracheal administration with surfactant in an animal model of newborn respiratory distress. Pediatr Res, 2010. 67(6): p. 619-23.

64. Niemarkt, H.J., et al., Effects of less-invasive surfactant administration on oxygenation, pulmonary surfactant distribution, and lung compliance in spontaneously breathing preterm lambs. Pediatric research, 2014. 76(2): p. 166-70.

65. Hutten, M.C., et al., Nebulization of Poractant alfa via a vibrating membrane nebulizer in spontaneously breathing preterm lambs with binasal continuous positive pressure ventilation. Pediatric research, 2015. 78(6): p. 664-9. 


\section{Chapter}

\section{Discussion}

Based in parts on Hutten, M.C., T.G. Wolfs, and B.W. Kramer, Can the preterm lung recover from perinatal stress? Molecular and cellular pediatrics, 2016. 3(1): p. 15 [1] 


\section{KEEPING THE BALANCE: LONG-TERM EFFECTS OF IMPROVED RESPIRATORY MANAGEMENT IN PRETERM INFANTS}

Improved management of RDS in prematurely born infants has been a success story in neonatology for more than 50 years. Milestones of respiratory management contributed remarkably to increased preterm survival. Until today, mortality of infants born very prematurely is constantly decreasing [2]. Along with the increased survival of these infants, a decrease in survivable gestational age could be observed. However, the lower the gestational age the more susceptible prematurely born infants are to complications during their hospital stay, but also to impaired long-term outcome. Postnatal fetal lung development is affected by pulmonary responses to postnatal interventions such as mechanical ventilation, oxygen exposure, pharmaceutical interventions including antiinflammatory substances like corticosteroids and substances directly interacting with lung development like vitamin A [1]. The different effects of antenatal and postnatal insults and interventions are summarized in figure 1.

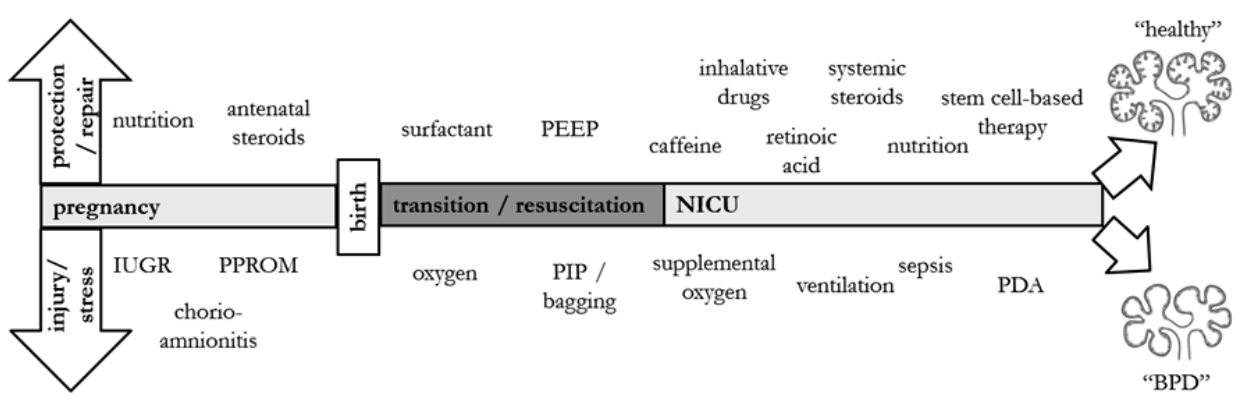

Figure 1: Multiple factors influence lung development in preterm infants. Postnatally, both potentially protective and injurious factors are mainly associated with therapeutic means (IUGR intra-uterine growth restriction, PPROM preterm premature rupture of membranes, PIP positive inspiratory pressure, PEEP positive endexpiratory pressure, PDA persistent ductus arteriosus, NICU neonatal intensive care unit). From [1]

There is a growing body of evidence that delivery room interventions may initiate lung injury [3]. Careful respiratory management including CPAP for avoidance of barotrauma by mechanical ventilation, avoidance of hyperoxia, and timely administration of surfactant to spontaneously breathing infants has been proposed to improve long-term pulmonary outcome by preventing lung injury already from transition onwards [4-7]. For example, routine use of CPAP at delivery has been shown to be effective in decreasing BPD or death in preterm infants [6], [7].

However, BPD is a multifactorial disease, and the onset of lung injury might be initiated in utero after intraamniotic infection [8]. Although exposure to chorioamnionitis might protect preterm infants from RDS [9], growing evidence suggests an important role of intrauterine inflammation as contributing factor to the development of BPD [10- 
12]. Exposure to chorioamnionitis has also been shown to increase the risk of BPD development derived from mechanical ventilation [11]. Therefore, postnatal respiratory management may need to be adjusted to prenatal risk factors in order to counteract BPD development at an early stage.

BPD is of such high importance since it exerts lifelong consequences on lung health of survivors of preterm birth. Low gestational age has been shown to be a risk factor for any obstructive airway disease in later life $[13,14]$. Lung function impairment of former very low birth weight infants with BPD can be found until adulthood [15], and survivors of prematurity have higher risks for developing asthma when they were diagnosed with BPD [16]. Moreover, BPD as an independent risk factor for impaired neurocognitive outcome in children born very prematurely [17].

Therefore, reduction of exposure towards potentially hazardous interventions already in the delivery room is of clinical, socioeconomic and scientific interest. Avoidance of oxygen overexposure by automated $\mathrm{FiO}_{2}$ control (chapter 3), the use of gentle approaches of surfactant replacement therapy helping to enhance the success of noninvasive respiratory support (chapter 2), and the understanding of beneficial effects of early pharmacological interventions (chapter 4,5 ) bear the potential to improve the health of preterm babies beyond the neonatal period.

\section{AUTOMATIZATION IN THE DELIVERY ROOM - THE TIME IS NOW?}

Oxygenation after birth is a gradual process [18]. The fetus develops in a low oxygen environment, and the arterial partial pressure of oxygen $\left(\mathrm{PaO}_{2}\right)$ physiologically rises directly after birth [19]. This abrupt change in oxygen content of blood and tissue may induce physiological maturation of metabolic processes after birth [20]. However, an excess supply of oxygen resulting in hyperoxia might have detrimental effects on infants born prematurely. Oxygen supplementation is one of the most common therapeutic interventions in resuscitation of newborns [21]. However, its historically generous use in the delivery room has been abandoned in the last years due to new evidence from clinical studies [22]. In preterm infants, current guidelines advocate the use of a mixture of air and oxygen according to the infants' oxygen saturation $\left(\mathrm{SpO}_{2}\right)$. A recent metaanalysis of studies comparing different initial fractions of oxygen $\left(\mathrm{FiO}_{2}\right)$ in delivery room stabilization and resuscitation of preterm infants $\leq 32$ weeks showed a trend towards a lower mortality when the initial $\mathrm{FiO}_{2}$ was $0.21-0.30$ [23]. Two studies found a significant increase of markers of oxidative stress in preterm infants resuscitated with $90-100 \%$ oxygen compared to $21 \%$ or $30 \%[4,24]$. Therefore, current guidelines recommend using an initial $\mathrm{FiO}_{2}$ of $0,21-0,30$, and to subsequently titrate $\mathrm{FiO}_{2}$ according to the infant's $\mathrm{SpO}_{2}$ measured by pulse oximetry in order to avoid hyperoxia [25-27]. Oxygen overexposure is a potential source of oxidative stress. Infants born at a very low birth weight are especially susceptible to oxidative stress, as their antioxidant enzyme activity 
is low. Tissue damage by oxidative stress might have lasting effects, and BPD is considered by some authors as an oxygen-radical disease of the preterm [28].

Although experimental and clinical data indicate the importance of avoiding oxygen overexposure in preterm infants, it is very difficult to stick with $\mathrm{SpO}_{2}$ target values in the delivery room. Large deviations from the varying $\mathrm{SpO}_{2}$ target range during resuscitation of preterm infants have been observed in clinical studies [29], suggesting that manual $\mathrm{FiO}_{2}$ control in the delivery room is inadequate. Therefore, automatization of $\mathrm{FiO}_{2}$ control offers a possible solution for this problem. Automated $\mathrm{FiO}_{2}$ control has not yet been tested in the delivery room setting in clinical trials [30]. However, the use of automated closed loop $\mathrm{FiO}_{2}$ control has been proven to efficiently keep infants within a predefined $\mathrm{SpO}_{2}$ target in the NICU, using various modes of ventilation, and using different algorithms (as reviewed in [31]). We could show in a lamb model of preterm respiratory distress syndrome that automated $\mathrm{FiO}_{2}$ control using a closed-loop is feasible during the transition after birth and during surfactant replacement therapy (chapter 3). Moreover, we could show in our model that automated $\mathrm{FiO}_{2}$ control during transition in the first 15 minutes of life resulted in less hyperoxia (chapter 3 ).

Therefore, avoidance of oxygen overexposure by using automated systems might help to improve pulmonary outcome of preterm infants, and clinical studies are on the way. Still, oxygenation after birth does not only depend on $\mathrm{FiO}_{2}$, but therapeutic interventions in the delivery room have to be adapted to a multitude of parameters [32].

Rapid establishment and maintenance of an adequate functional residual capacity (FRC) is one important factor [33]. FRC can effectively be established using sustained inflation (SI). SI is performed by administration of a high peak inspiratory pressure (20$25 \mathrm{~cm} \mathrm{H} \mathrm{H}_{2} \mathrm{O}$ ) for 10-15 seconds by a face mask or nasopharyngeal tube [34]. In animal studies, respiratory and cardiovascular transition after birth was facilitated by an early FRC and uniform aeriation when SI was applied $[35,36]$. Clinical data suggests that SI improved short-term respiratory outcome in preterm infants, although BPD and/or death were not reduced [37]. Adequate FRC is further maintained by applying positive end-expiratory pressure (PEEP). In a model of prematurely delivered lambs, oxygenation increased with increasing PEEP [38]. When in this model PEEP was increased stepwise within the first minutes of life, gas exchange was improved compared to a group receiving SI [39].

Beside different ventilatory manoeuvres, oxygenation is also influenced by perinatal procedures like delayed cord clamping (DCC). DCC is performed in order to reduce neonatal anaemia, and is considered to be safe and to have no negative effects on adaptation of preterm infants [40]. However, clinical data suggests a small but significant decrease in $\mathrm{SpO}_{2}$ measured by blood gas analysis from the umbilical cord [41]. In addition, decrease in $\mathrm{SpO}_{2}$ can be a symptom of a pathological condition such as pneumothorax or ventilation related complication, e.g. tube dislocation. Therefore, the complex task of oxygen therapy in the delivery room can so far not be managed by automated systems 
alone, but the results of our study suggest that automated devices can help and support the delivery room team in the initial management of preterm babies.

\section{CAFFEINE - THE HIDDEN DR CHAMPION?}

In the last three decades, methylxanthines such as caffeine have successfully been used as pharmacological treatment for apnea of prematurity [42]. Caffeine is administered both prophylactically and therapeutically, and a third indication is weaning from mechanical ventilation [43]. Although earlier trials had raised concerns about unwanted side effects like increased oxygen consumption and impaired weight gain [44], recent clinical trials showed impressive short-term and long-term beneficial effects of caffeine treatment in preterm infants [45]. In the Caffeine for Apnea of Prematurity (CAP) trial, the duration of positive pressure ventilation was shortened and supplemental oxygen could be stopped earlier in VLBW infants receiving caffeine instead of placebo as secondary outcome [43]. In the caffeine group, removal of endotracheal tube was possible at an earlier gestational age, and the need for postnatal steroids was significantly lower [43]. In line with these findings, a Cochrane review described less failure of extubation in infants receiving prophylactic methylxanthines [46]. As long-term outcome, the CAP trial could show that caffeine reduced BPD, defined as need for supplemental oxygen at 36 weeks corrected gestational age, from $47 \%$ to $36 \%$ [43]. This effect was presumably linked to the shortened duration of positive pressure respiratory support.

However, the positive effects of caffeine on development of BPD might result from unevaluated benefits of this drug. A recent retrospective study revealed a strong correlation between high serum levels of caffeine and a decreased incidence of BPD in infants born $\leq 29$ weeks GA [47]. Caffeine is a known unspecific inhibitor of phosphodiesterase (PDE), and the consecutive bronchodilation by an increase of cyclic AMP might support the infants' respiration [3]. In addition, our data suggest that caffeine amplifies the positive effect of prenatal glucocorticosteroids on surfactant-protein $B$ expression, indicating a maturational effect of caffeine on the preterm lung (chapter 4). In vitro, an additive effect on both transcription and translation of SP-B was shown [48]. Furthermore, in vitro studies indicated that unspecific PDE inhibition by caffeine also interferes with airway remodelling [49]. In this study, caffeine downregulated TGF- $\beta$ induced connective tissue growth factor (CTGF) expression in lung epithelial cells, most likely by PDE-4 inhibition [49]. Inhibition of specific PDE-isoenzymes could therefore bear the potential to reduce lung remodelling in the context of BPD. In rodent models, a protective effect of PDE-4 inhibitors on BPD development has already been demonstrated [50-52]. This protective effect was not only attributed to reversal of aberrant remodelling, but also through anti-inflammatory action [50,52]. Modulation of inflammation in preterm infants has also been described for caffeine in a recent clinical study [53]. In this study, therapeutic levels of caffeine correlated with a decrease of proin- 
flammatory and an increase of anti-inflammatory cytokines, whereas caffeine levels above the therapeutic range were associated with a proinflammatory cytokine profile [53]. In a rodent model, caffeine was found to promote anti-inflammatory effects in the immature lung when rat pups were prenatally exposed to lipopolysaccharide (LPS) [54]. However, if immune-modulatory effects of caffeine are influenced by prenatal corticosteroids, as we could describe for SP-B maturation, is still unclear.

Moreover, data from both the CAP trial and from retrospective cohort studies indicate how important timing of the start of caffeine therapy might be. In a subgroup analysis of the CAP trial, infants in whom caffeine therapy was initiated early, i.e. $<3$ days of age, had a significantly lower postmenstrual age at last endotracheal intubation and last positive pressure ventilation [55]. This suggests a possible mechanism for the decrease in BPD rates in infants receiving caffeine $<3$ days of age in previous retrospective studies $[45,56,57]$. Early caffeine in the delivery room has also been used as co-intervention when surfactant was administered by LISA [58]. However, in order to develop future recommendations, earlier initiation of therapy within the first hours of life or even in the delivery room need to be evaluated by currently ongoing clinical trials [59].

\section{VITAMIN A - AN OLD DRUG REVISITED}

Drugs for postnatal modulation of lung injury have been extensively studied in the past. One of the most promising substances is vitamin A. Vitamin A is crucial for fetal lung development and maturation, and prerequisite for adequate lung development $[60,61]$. Retinol and retinoic acid act like steroid hormones, controlling gene expression by binding to nuclear proteins [62]. In preterm infants, vitamin A availability is lower than in term neonates [63]. Low plasma concentrations of retinol in preterm infants are attributed to inadequate transplacental transport, inadequate storage and increased tissue utilization [62]. Clinically, vitamin A supplementation reduces mortality and oxygen requirement at 36 weeks, and is therefore considered as a promising pharmacological intervention in BPD prevention [64]. However, the number needed to treat in the reviewed clinical studies is considerably high (mortality or oxygen requirement at 28 days of age: number needed to treat (NNT) 20, oxygen at 36 weeks: NNT 13). In addition, vitamin $\mathrm{A}$ is mainly administered via intramuscular administration, and the associated pain is another reason why vitamin A supplementation is not widely accepted amongst clinicians $[65,66]$. A less invasive mode of delivery is therefore a promising treatment option (chapter 5). Our results showed that vitamin A administered endotracheally to ventilated lambs increased serum levels and lung tissue concentrations (chapter 5). We also found a trend towards higher vitamin A levels in the liver of animals treated with endotracheal vitamin A. The "direct route" to the lung might therefore be an interesting option for premature infants. 
In our study, vitamin A was given as bolus directly after surfactant replacement therapy. Surfactant has already been tested as carrier for intra-pulmonary delivery of antibiotics [67] and corticosteroids [68, 69]. Another option might be inhalation of nebulized vitamin A. Inhaled vitamin A has already been successfully tested for supplementation in preschool children in Ethiopia [70]. In a neonatal setting, administration of drugs via the airways became more available [71]. We could show feasibility of surfactant nebulization in our lamb model (chapter 3). Although our data indicated that at last some of the nebulized surfactant does not reach the lung, but is "lost" in the upper airways or swallowed to the stomach (chapter 3), vitamin A uptake after nebulization might be more effective due to the ability of epithelial cells to take up vitamin A [72], and the uptake of swallowed vitamin A in the gastrointestinal tract [73]. Endotracheal or nebulized vitamin $A$ in combination with a suitable surfactant preparation might therefore not only increase acceptance of vitamin A therapy for preterm infants, but also include physiological advantages.

\section{CONCLUSION AND OUTLOOK: HOW PRECLINICAL MODELS SUPPORT THERAPEUTIC INTERVENTIONS}

The developing lung of the preterm infant is pre-, peri- and postnatally exposed to different stress factors (Figure 1). Their impact on lung development also depends on interaction between different insults and interventions. In this thesis, different approaches to optimization of neonatal respiratory care have successfully been tested in a preclinical animal model (chapter 2-5). Preclinical testing can increase safety before new therapeutic interventions are tested in premature babies. Furthermore, the strictly defined circumstances in a preclinical model allow the concise testing of an intervention and in parallel avoid interference by controlling additional parameters which potentially influence outcome measures. In the preterm lung, clinical data indicates that different pre- and postnatal insults interact. For example, surfactant replacement therapy has been shown to be less effective in preterm infants who were exposed to chorioamnionitis and developed a fetal inflammatory response [74]. Exploring the pathophysiological background of the interactions of two or more hits is not possible without translational models, which e.g. allowed testing a synthetic surfactant in an in vivo model of surfactant inactivation [75].

In this thesis, we could show that the effects of maternal steroid therapy interact with postnatal caffeine therapy in a synergistic manner (chapter 4). Vitamin A is another example how therapeutic interventions depend on prenatal conditions. In a rodent model, intrauterine vitamin A deficiency resulted in an abnormal airway smooth muscle phenotype, which persisted postnatally regardless of the adult vitamin A status [76]. In a sheep model, intraamniotic exposure to inflammation reduced vitamin $A$ in the lung [77], indicating that therapeutic benefit also depends on the presence or absence of 
prenatal inflammation. Translational studies can not only help to improve modes of administration of vitamin A (chapter 5), but can aim to test the efficacy of prenatal vitamin A, e.g. in a context of chorioamnionitis. In our lamb model, it could also be shown that chorioamnionitis interferes with prenatal glucocorticosteroid therapy. This experimental data revealed that the combined effects of prenatal exposure to chorioamnionitis and glucocorticosteroids are variable and do not simply "add up". Inhibition or even prevention of impaired structural pulmonary development after exposure to intraamniotic lipopolysaccharide depended on the timing of administration of maternal steroids [78, 79].

In the future, investigation on these combined effects might be the key to individualize therapeutic interventions in the preterm child. Hypotheses of how different exposures and interventions interact will be generated based on knowledge gained from large epidemiological trials. Therapeutic interventions tested in preclinical models in the context of perinatal insults will then help to optimize neonatal care. Experimental knowledge will form the background for randomized, controlled clinical trials, which can be planned according to the pre- and postnatal factors with the highest impact on the preterm lung. Consequently, postnatal interventions will be tailored individually to help the lung recover from early stress without causing more interventional stress than absolutely necessary, based on biology and increasing clinical evidence. 


\section{REFERENCES}

1. Hutten, M.C., T.G. Wolfs, and B.W. Kramer, Can the preterm lung recover from perinatal stress? Molecular and cellular pediatrics, 2016. 3(1): p. 15.

2. Stoll, B.J., et al., Trends in Care Practices, Morbidity, and Mortality of Extremely Preterm Neonates, 19932012. JAMA : the journal of the American Medical Association, 2015. 314(10): p. 1039-51.

3. Martin, R.J. and A.A. Fanaroff, The preterm lung and airway: past, present, and future. Pediatrics and neonatology, 2013. 54(4): p. 228-34.

4. Vento, M., et al., Preterm resuscitation with low oxygen causes less oxidative stress, inflammation, and chronic lung disease. Pediatrics, 2009. 124(3): p. e439-49.

5. Kribs, A., How best to administer surfactant to VLBW infants? Archives of disease in childhood. Fetal and neonatal edition, 2011. 96(4): p. F238-40.

6. Schmolzer, G.M., et al., Non-invasive versus invasive respiratory support in preterm infants at birth: systematic review and meta-analysis. BMJ, 2013. 347: p. 15980.

7. Fischer, H.S. and C. Buhrer, Avoiding endotracheal ventilation to prevent bronchopulmonary dysplasia: a meta-analysis. Pediatrics, 2013. 132(5): p. e1351-60.

8. Kramer, B.W., Antenatal inflammation and lung injury: prenatal origin of neonatal disease. Journal of perinatology : official journal of the California Perinatal Association, 2008. 28 Suppl 1: p. S21-7.

9. Lahra, M.M., P.J. Beeby, and H.E. Jeffery, Maternal versus fetal inflammation and respiratory distress syndrome: a 10-year hospital cohort study. Archives of disease in childhood. Fetal and neonatal edition, 2009. 94(1): p. F13-6.

10. Watterberg, K.L., et al., Chorioamnionitis and early lung inflammation in infants in whom bronchopulmonary dysplasia develops. Pediatrics, 1996. 97(2): p. 210-5.

11. Van Marter, L.J., et al., Chorioamnionitis, mechanical ventilation, and postnatal sepsis as modulators of chronic lung disease in preterm infants. The Journal of pediatrics, 2002. 140(2): p. 171-6.

12. Been, J.V. and L.J. Zimmermann, Histological chorioamnionitis and respiratory outcome in preterm infants. Archives of disease in childhood. Fetal and neonatal edition, 2009. 94(3): p. F218-25.

13. Brostrom, E.B., et al., Obstructive pulmonary disease in old age among individuals born preterm. European journal of epidemiology, 2013. 28(1): p. 79-85.

14. Been, J.V., et al., Preterm birth and childhood wheezing disorders: a systematic review and meta-analysis. PLoS medicine, 2014. 11(1): p. e1001596.

15. Saarenpaa, H.K., et al., Lung Function in Very Low Birth Weight Adults. Pediatrics, 2015. 136(4): p. 642-50.

16. Fawke, J., et al., Lung function and respiratory symptoms at 11 years in children born extremely preterm: the EPICure study. American journal of respiratory and critical care medicine, 2010. 182(2): p. 237-45.

17. Potharst, E.S., et al., Perinatal risk factors for neurocognitive impairments in preschool children born very preterm. Developmental medicine and child neurology, 2013. 55(2): p. 178-84.

18. Dawson, J.A., et al., Defining the reference range for oxygen saturation for infants after birth. Pediatrics, 2010. 125(6): p. e1340-7.

19. Maltepe, E. and O.D. Saugstad, Oxygen in health and disease: regulation of oxygen homeostasis--clinical implications. Pediatric research, 2009. 65(3): p. 261-8.

20. Friel, J.K., et al., Evidence of oxidative stress in full-term healthy infants. Pediatric research, 2004. 56(6): p. 878-82.

21. Finer, N. and W. Rich, Neonatal resuscitation for the preterm infant: evidence versus practice. Journal of perinatology : official journal of the California Perinatal Association, 2010. 30 Suppl: p. S57-66.

22. Obladen, M., History of neonatal resuscitation. Part 2: oxygen and other drugs. Neonatology, 2009. 95(1): p. 91-6.

23. Saugstad, O.D., et al., Systematic review and meta-analysis of optimal initial fraction of oxygen levels in the delivery room at </=32 weeks. Acta paediatrica, 2014. 103(7): p. 744-51.

24. Kapadia, V.S., et al., Resuscitation of preterm neonates with limited versus high oxygen strategy. Pediatrics, 2013. 132(6): p. e1488-96. 


\section{Chapter 6}

25. Vento, M., et al., Oxygen saturation targets for preterm infants in the delivery room. The journal of maternal-fetal \& neonatal medicine : the official journal of the European Association of Perinatal Medicine, the Federation of Asia and Oceania Perinatal Societies, the International Society of Perinatal Obstetricians, 2012. 25 Suppl 1: p. 45-6.

26. Vento, M., Oxygen supplementation in the neonatal period: changing the paradigm. Neonatology, 2014. 105(4): p. 323-31.

27. Wyllie, J., et al., Part 7: Neonatal resuscitation: 2015 International Consensus on Cardiopulmonary Resuscitation and Emergency Cardiovascular Care Science with Treatment Recommendations. Resuscitation, 2015. 95: p. e169-201.

28. Saugstad, O.D., Update on oxygen radical disease in neonatology. Current opinion in obstetrics \& gynecology, 2001. 13(2): p. 147-53.

29. Goos, T.G., et al., Observing the resuscitation of very preterm infants: are we able to follow the oxygen saturation targets? Resuscitation, 2013. 84(8): p. 1108-13.

30. Hummler, H., H. Fuchs, and M. Schmid, Automated Adjustments of Inspired Fraction of Oxygen to Avoid Hypoxemia and Hyperoxemia in Neonates - A Systematic Review on Clinical Studies. Klinische Padiatrie, 2014. 226(4): p. 204-210.

31. Claure, N. and E. Bancalari, Closed-loop control of inspired oxygen in premature infants. Seminars in fetal \& neonatal medicine, 2015. 20(3): p. 198-204.

32. Rich, W.D., T. Leone, and N.N. Finer, Delivery room intervention: improving the outcome. Clinics in perinatology, 2010. 37(1): p. 189-202.

33. Hooper, S.B. and R. Harding, Role of aeration in the physiological adaptation of the lung to air-breathing at birth. Curr. Resp. Med. Rev. , 2005(1): p. 185-195.

34. Lista, G., P.A. La Verde, and F. Castoldi, Sustained Inflation and Its Role in the Delivery Room Management of Preterm Infants. Neonatology, 2016. 109(4): p. 366-8.

35. te Pas, A.B., et al., Effect of sustained inflation length on establishing functional residual capacity at birth in ventilated premature rabbits. Pediatric research, 2009. 66(3): p. 295-300.

36. Sobotka, K.S., et al., An initial sustained inflation improves the respiratory and cardiovascular transition at birth in preterm lambs. Pediatric research, 2011. 70(1): p. 56-60.

37. Schmolzer, G.M., et al., Sustained inflation versus positive pressure ventilation at birth: a systematic review and meta-analysis. Archives of disease in childhood. Fetal and neonatal edition, 2015. 100(4): p. F361-8.

38. Polglase, G.R., et al., Positive end-expiratory pressure differentially alters pulmonary hemodynamics and oxygenation in ventilated, very premature lambs. Journal of applied physiology, 2005. 99(4): p. 1453-61.

39. Tingay, D.G., et al., Effect of sustained inflation vs. stepwise PEEP strategy at birth on gas exchange and lung mechanics in preterm lambs. Pediatric research, 2014. 75(2): p. 288-94.

40. Rabe, H., G. Reynolds, and J. Diaz-Rossello, A systematic review and meta-analysis of a brief delay in clamping the umbilical cord of preterm infants. Neonatology, 2008. 93(2): p. 138-44.

41. Valero, J., et al., Effect of delayed umbilical cord clamping on blood gas analysis. European journal of obstetrics, gynecology, and reproductive biology, 2012. 162(1): p. 21-3.

42. Aranda, J.V., et al., Caffeine impact on neonatal morbidities. The journal of maternal-fetal \& neonatal medicine : the official journal of the European Association of Perinatal Medicine, the Federation of Asia and Oceania Perinatal Societies, the International Society of Perinatal Obstetricians, 2010. 23 Suppl 3: p. 20-3.

43. Schmidt, B., et al., Caffeine therapy for apnea of prematurity. The New England journal of medicine, 2006. 354(20): p. 2112-21.

44. Bauer, J., et al., Effect of caffeine on oxygen consumption and metabolic rate in very low birth weight infants with idiopathic apnea. Pediatrics, 2001. 107(4): p. 660-3.

45. Dobson, N.R., et al., Trends in caffeine use and association between clinical outcomes and timing of therapy in very low birth weight infants. The Journal of pediatrics, 2014. 164(5): p. 992-998 e3.

46. Henderson-Smart, D.J. and P.G. Davis, Prophylactic methylxanthines for endotracheal extubation in preterm infants. The Cochrane database of systematic reviews, 2010(12): p. CD000139. 
47. Alur, P., et al., Serum caffeine concentrations and short-term outcomes in premature infants of 29 weeks of gestation. Journal of perinatology : official journal of the California Perinatal Association, 2015. 35(6): p. 434-8.

48. Fehrholz, M., et al., Synergistic effect of caffeine and glucocorticoids on expression of surfactant protein $B$ (SP-B) mRNA. PloS one, 2012. 7(12): p. e51575.

49. Fehrholz, M., C.P. Speer, and S. Kunzmann, Caffeine and rolipram affect Smad signalling and TGF-beta1 stimulated CTGF and transgelin expression in lung epithelial cells. PloS one, 2014. 9(5): p. e97357.

50. de Visser, Y.P., et al., Phosphodiesterase-4 inhibition attenuates pulmonary inflammation in neonatal lung injury. The European respiratory journal, 2008. 31(3): p. 633-44.

51. de Visser, Y.P., et al., Phosphodiesterase 4 inhibition attenuates persistent heart and lung injury by neonatal hyperoxia in rats. American journal of physiology. Lung cellular and molecular physiology, 2012. 302(1): p. L56-67.

52. Woyda, K., et al., Inhibition of phosphodiesterase 4 enhances lung alveolarisation in neonatal mice exposed to hyperoxia. The European respiratory journal, 2009. 33(4): p. 861-70.

53. Chavez Valdez, R., et al., Correlation between serum caffeine levels and changes in cytokine profile in a cohort of preterm infants. The Journal of pediatrics, 2011. 158(1): p. 57-64, 64 e1.

54. Koroglu, O.A., et al., Anti-inflammatory effect of caffeine is associated with improved lung function after lipopolysaccharide-induced amnionitis. Neonatology, 2014. 106(3): p. 235-40.

55. Davis, P.G., et al., Caffeine for Apnea of Prematurity trial: benefits may vary in subgroups. The Journal of pediatrics, 2010. 156(3): p. 382-7.

56. Patel, R.M., et al., Early caffeine therapy and clinical outcomes in extremely preterm infants. Journal of perinatology : official journal of the California Perinatal Association, 2013. 33(2): p. 134-40.

57. Lodha, A., et al., Association of early caffeine administration and neonatal outcomes in very preterm neonates. JAMA pediatrics, 2015. 169(1): p. 33-8.

58. Kribs, A. and H. Hummler, Ancillary therapies to enhance success of non-invasive modes of respiratory support - Approaches to delivery room use of surfactant and caffeine? Seminars in fetal \& neonatal medicine, 2016.

59. Katheria, A.C., et al., A Pilot Randomized Controlled Trial of Early versus Routine Caffeine in Extremely Premature Infants. American journal of perinatology, 2015. 32(9): p. 879-86.

60. Massaro, D. and G.D. Massaro, Retinoids, alveolus formation, and alveolar deficiency: clinical implications. American journal of respiratory cell and molecular biology, 2003. 28(3): p. 271-4.

61. Biesalski, H.K., The significance of vitamin A for the development and function of the lung. Forum of nutrition, 2003. 56: p. 37-40.

62. Guimaraes, H., et al., Vitamin A in prevention of bronchopulmonary dysplasia. Current pharmaceutical design, 2012. 18(21): p. 3101-13.

63. Ambalavanan, N., et al., A comparison of three vitamin A dosing regimens in extremely-low-birth-weight infants. The Journal of pediatrics, 2003. 142(6): p. 656-61.

64. Darlow, B.A. and P.J. Graham, Vitamin A supplementation to prevent mortality and short- and long-term morbidity in very low birthweight infants. The Cochrane database of systematic reviews, 2011(10): p. CD000501.

65. Kaplan, H.C., et al., Understanding variation in vitamin A supplementation among NICUs. Pediatrics, 2010. 126(2): p. e367-73.

66. Ambalavanan, N., et al., Survey of vitamin A supplementation for extremely-low-birth-weight infants: is clinical practice consistent with the evidence? J Pediatr, 2004. 145(3): p. 304-7.

67. Stichtenoth, G., et al., Prophylactic intratracheal polymyxin B/surfactant prevents bacterial growth in neonatal Escherichia coli pneumonia of rabbits. Pediatric research, 2010. 67(4): p. 369-74.

68. Yeh, T.F., et al., Early intratracheal instillation of budesonide using surfactant as a vehicle to prevent chronic lung disease in preterm infants: a pilot study. Pediatrics, 2008. 121(5): p. e1310-8.

69. Yeh, T.F., et al., Intratracheal Administration of Budesonide/Surfactant to Prevent Bronchopulmonary Dysplasia. American journal of respiratory and critical care medicine, 2016. 193(1): p. 86-95. 


\section{Chapter 6}

70. Biesalski, H., et al., Retinyl palmitate supplementation by inhalation of an aerosol improves vitamin $A$ status of preschool children in Gondar (Ethiopia). The British journal of nutrition, 1999. 82(3): p. 179-82.

71. Shinwell, E.S., Optimization of airway medications in the infant. Neonatology, 2013. 103(4): p. 331-4.

72. Kohlhaufl, M., et al., Inhalation of aerosolized vitamin a: reversibility of metaplasia and dysplasia of human respiratory epithelia -- a prospective pilot study. European journal of medical research, 2002. 7(2): p. $72-8$.

73. Meyer, S. and L. Gortner, Early postnatal additional high-dose oral vitamin A supplementation versus placebo for 28 days for preventing bronchopulmonary dysplasia or death in extremely low birth weight infants. Neonatology, 2014. 105(3): p. 182-8.

74. Been, J.V., et al., Chorioamnionitis alters the response to surfactant in preterm infants. The Journal of pediatrics, 2010. 156(1): p. 10-15 e1.

75. Seehase, M., et al., New surfactant with SP-B and $C$ analogs gives survival benefit after inactivation in preterm lambs. PloS one, 2012. 7(10): p. e47631.

76. Chen, F., et al., Prenatal retinoid deficiency leads to airway hyperresponsiveness in adult mice. The Journal of clinical investigation, 2014. 124(2): p. 801-11.

77. Kramer, B.W., et al., All-trans retinoic acid and intra-amniotic endotoxin-mediated effects on fetal sheep lung. Anatomical record, 2008. 291(10): p. 1271-7.

78. Collins, J.J., et al., LPS-induced chorioamnionitis and antenatal corticosteroids modulate Shh signaling in the ovine fetal lung. American journal of physiology. Lung cellular and molecular physiology, 2012. 303(9): p. L778-87.

79. Kuypers, E., et al., Intra-amniotic LPS and antenatal betamethasone: inflammation and maturation in preterm lamb lungs. American journal of physiology. Lung cellular and molecular physiology, 2012. 302(4): p. L380-9. 
Chapter

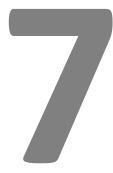

Summaries 



\section{NEDERLANDSE SAMENVATTING}

Vroeggeboorte wordt gedefinieerd als geboorte voor een zwangerschapsduur van 37 weken en de incidentie van vroeggeboorte stijgt wereldwijd. Vroeggeboorte is de belangrijkste doodsoorzaak onder pasgeborenen wat neerkomt op bijna één miljoen doden wereldwijd in 2013. Vanwege het steeds beter worden van de neonatale zorg zijn in de afgelopen 40 jaar de overlevingskansen van vroeggeborenen enorm toegenomen, en in het bijzonder van kinderen geboren voor de 28 weken zwangerschap. De voornaamste reden hiervoor is het ontstaan van nieuwe behandelingsopties ter ondersteuning van de longfunctie van deze te vroeg geboren baby's. De bekendste voorbeelden hiervan zijn maternale steroïden ter stimulatie van de longrijping in utero, het toedienen van surfactant - wat ervoor zorgt dat de longen open blijven tijdens het ademen - direct in de longen, en verbeterde niet invasieve beademing.

Echter, de premature long is erg kwetsbaar. Behandelingen die na de geboorte nodig zijn om de long goed te laten functioneren en daarmee voldoende zuurstof op te kunnen nemen kunnen ook nadelige effecten op de longontwikkeling hebben en longschade veroorzaken. Deze longschade kan persisteren en vooral de extreem vroeg geboren kinderen (tussen 22 en 28 weken) hebben een groot risico op het ontwikkelen van een chronische longziekte, ook wel bronchopulmonary dysplasia (BPD) genoemd. Op latere leeftijd kan zich dit uiten door een verslechterde longfunctie en door een groter risico op astma. Echter, de profylaxe en behandeling van chronische longschade is zeer complex.

In dit proefschrift worden verschillende methoden onderzocht om longschade in een zo vroeg mogelijk stadium te verminderen, namelijk direct na de geboorte. Voor dit onderzoek hebben wij een uniek prematuur schaap model gebruikt waarin behandelingsopties werden geoptimaliseerd. Allereerst hebben wij onderzocht hoe door een vernieuwde geautomatiseerde techniek de zuurstoftoediening tijdens de beademing geoptimaliseerd kan worden. Dit onderzoek toont aan dat een computer algoritme kan helpen om zuurstoftoediening te verbeteren door onder andere te voorkomen dat teveel zuurstof wordt gegeven. Daarnaast hebben we een nieuwe manier van surfactant toediening getest door gebruik te maken van een vernevelaar waarbij surfactant direct in de longen terecht komt. Hierbij werden ook factoren geïdentificeerd die het succes van de behandeling kunnen beïnvloeden. Bovendien hebben we onderzocht hoe het geven van glucocorticoïden tijdens de zwangerschap en caffeïne na de geboorte elkaar beïnvloeden. Deze studie laat zien dat de combinatie van beide medicijnen een positief effect heeft op de endogene surfactant productie van de long wat mogelijk leidt tot het afnemen van meer invasieve manieren om te beademen. Ten slotte hebben we aangetoond dat het geven van vitamine $\mathrm{A}$ in combinatie met surfactant direct in de longen een potentiele behandelingsoptie is voor longschade. Vitamine A is een belangrijke factor voor de ontwikkeling en regeneratie van de longen bij te vroeg geboren kinderen. 
Chapter 7

Samengevat, de bevindingen in dit proefschrift dragen bij aan het optimaliseren van de behandeling van vroeggeboren kinderen en daarmee het verminderen van longschade en het voorkomen van levenslange longproblemen in te vroeg geboren kinderen. 


\section{ENGLISH SUMMARY}

Preterm birth is defined as birth before 37 weeks of gestation, and the rate of preterm birth is rising worldwide. Preterm birth is the most important single cause of death in the first month of life, with almost a million deaths related to prematurity worldwide in 2013. However, due to advances in neonatal medicine, survival rates increased dramatically in the past 40 years, especially in infants born very prematurely (i.e. birth before 28 weeks of gestation). This was achieved mainly by new therapies which support the lung function of these very immature babies. Well known examples for these therapies are maternal steroid therapy before birth which matures the lung in utero already, administering surfactant in the lung, a substance which is important to keep the lung open while breathing, and ventilation or ventilatory support.

However, the preterm lung is very vulnerable. Postnatal therapy of breathing problems is necessary to guarantee that the lung functions and oxygen reaches the organs. But therapeutic interventions can also induce lung injury and interfere with lung development. Finally, lung injury can persist and preterm babies can develop a chronic lung disease called bronchopulmonary dysplasia (BPD), which is a common diagnosis in children born extreme prematurely between 22-28 weeks gestational age. Preterm lung injury can therefore have consequences which can last the whole life, e.g. by worsening lung function even until adulthood, or by increasing the risk to develop asthma. However, prophylaxis and therapy of chronic lung injury is very difficult.

In this thesis, different ways are explored in order to decrease lung injury at a very early stage: directly after birth. We used a unique model of prematurely born lambs to investigate optimal therapy. This was done by testing innovative automated techniques for oxygen therapy in the delivery room, and we could show that a computer algorithm can help to reach this goal by e.g. avoiding that too much oxygen is given. We further tested an innovative way to give surfactant into the lung by using a nebulizer, and could identify how success of this therapy is influenced by different treatment protocols. Furthermore, we investigated how a combination of glucocorticoids and caffeine supports the preterm lung's own surfactant production. Finally, we tested a new way to give vitamin A, a substance which helps the lung to develop and to regenerate, directly where it is most needed: into the lung.

These results can help to find optimal treatment protocols for preterm infants, and hopefully to reduce lung injury and to avoid lifelong lung problems in former preterm babies. 



\section{DEUTSCHE ZUSAMMENFASSUNG}

Frühgeburt ist definiert als Geburt vor der 37. Schwangerschaftswoche. Die Frühgeburtenrate nimmt zu, und Frühgeburtlichkeit ist die häufigste Todesursache bei Neugeborenen. Allein 2013 sind weltweit fast 1 Million Kinder aufgrund ihrer Frühgeburtlichkeit verstorben. Durch große Fortschritte in der medizinischen Versorgung hat die Sterblichkeit von Frühgeborenen in den letzten 40 Jahren stetig abgenommen, insbesondere bei sehr frühgeborenen Kindern unter der 28. Schwangerschaftswoche. Die größten Erfolge wurden hierbei durch Therapien erzielt, die die Atmung der Frühgeborenen unterstützen. Hierzu zählen die Lungenreifebehandlung durch Kortikosteroidgabe an die Mutter, die Gabe von Surfactant - einer Substanz, die die Lungenbläschen beim Atmen offenhält - direkt in die Lunge, und verbesserte Beatmung bzw. Atemunterstützung.

Allerdings ist die Lunge des frühgeborenen Kindes sehr verletzlich. Therapien, die nach der Geburt die Atmung und damit die Aufnahme von Sauerstoff erleichtern oder sogar erst ermöglichen, können unter Umständen auch schädliche Wirkungen auf die sich entwickelnde Lunge haben. Lungenschädigungen in so einer frühen Phase des Lebens können bleibend sein, und insbesondere sehr kleine Frühgeborene haben ein großes Risiko, eine chronische Lungenkrankheit zu entwickeln, die bronchopulmonale Dysplasie (BPD). In der späteren Kindheit und selbst im Erwachsenenalter können sich bei ehemaligen Frühgeborene noch Veränderungen der Lungenfunktion finden, und das Asthmarisiko ist erhöht. Sowohl die Prophylaxe als auch die Therapie der chronischen Lungenschädigung sind allerdings sehr schwierig.

In dieser Arbeit wurden daher Ansätze untersucht, die helfen sollen, eine Lungenschädigung so früh wie möglich zu vermindern: direkt nach der Geburt. In einem einzigartigen Modell wurden an frühgeborenen Lämmern verschiedene Wege untersucht, wie die Behandlung im Kreißsaal optimiert werden kann. Es wurde zum Beispiel untersucht, inwieweit mit einem computergestützten Algorithmus, der auf Frühgeborenenintensivstationen zur Steuerung der Sauerstoffkonzentration bei der Beatmung benutzt wird, bereits im Kreißsaal die Sauerstoffgabe optimiert werden kann. Diese Arbeit konnte zeigen, dass eine solche automatische Steuerung hilfreich ist und z.B. eine Überversorgung mit Sauerstoff hilft zu verhindern. Auch wurde eine Technik untersucht, mit deren Hilfe der o.g. Surfactant mittels Vernebelung in die Lunge Frühgeborener eingebracht werden kann. In dieser Arbeit wurden dabei Faktoren identifiziert, die den Therapieerfolg einer Surfactantvernebelung beeinflussen können. Des Weiteren wurde untersucht, wie die Gabe von Kortikosteroiden vor der Geburt und die Gabe von Koffein nach der Geburt einander beeinflussen. Ein wichtiges Ergebnis war hier, dass die Kombination beider Therapien eine positive Einfluss auf die Reifung der lungeneigenen Surfactantproduktion hat, was möglicherweise hilft, invasive Beatmung weniger notwendig zu machen. Schließlich wurde in dieser Arbeit gezeigt, dass in Kombination mit Surfactant auch die Gabe von Vitamin A direkt in die Lunge eine mögliche Therapieoption zur Be- 


\section{Chapter 7}

handlung von Lungenschäden ist. Vitamin A ist ein wichtiger Faktor bei der Entwicklung und auch der Regeneration der Lunge Frühgeborener.

Zusammenfassend können die Ergebnisse dieser Arbeit dazu beitragen, die Behandlung von frühgeborenen Kindern weiter zu optimieren, um hoffentlich frühestmöglich eine Lungenschädigung zu verhindern. 
Valorization 



\section{RELEVANCE}

My research concentrates on how the transition after birth of infants born prematurely (i.e. birth before 37 weeks of gestation) can be improved. Worldwide, the overall rate of preterm birth is rising. Due to advances in neonatal medicine, survival rates increased dramatically in the past 40 years, especially in infants born very prematurely (i.e. birth before 28 weeks of gestation). Nevertheless, preterm birth is still the most important single cause for mortality in the neonatal period, with almost a million deaths related to prematurity worldwide in 2013.

The improvement in survival was achieved mainly by implementing therapeutic interventions supporting the lung function of these very immature children. Adequate pulmonary function is necessary for gas exchange and is a prerequisite for survival of preterm infants. Major milestones in neonatal medicine include antenatal maternal steroid therapy to induce lung maturation in utero, exogenous surfactant administration as replacement therapy for the insufficient endogenous surfactant production in the preterm lung, and the appliance of continuous positive airway pressure (CPAP) helping to keep the premature airways open and to reduce postnatal lung injury.

After birth, the preterm lung is very susceptible to injury. Although postnatal therapeutic interventions are necessary to establish and maintain pulmonary function, these interventions can induce lung injury and interfere with lung development, resulting in structural and functional impairment of the lung. Finally, lung injury can persist and contribute to chronic lung disease of preterm children, bronchopulmonary dysplasia (BPD). BPD is the most common diagnosis in children born extreme prematurely between 22-28 weeks gestational age, with incidences reported from approximately $40 \%$ to $70 \%$. Recent data from the U.S. suggests that the incidence of BPD is rising in this group of extremely preterm babies, while mortality decreases. In addition, direct costs for extreme premature infants increase by more than $31,000 \$$ per child if BPD is present.

The consequences of preterm lung injury can however last the whole life: Survivors of prematurity have per se a higher risk for long-term impairment of lung function pulmonary morbidities like asthma, and this risk is markedly pronounced in preterm infants diagnosed with BPD. Lung function impairment of former very low birth weight infants with BPD can be found until adulthood. In addition, BPD is an important independent risk factor for an impaired neurocognitive outcome in preterm infants. Therefore, longterm impairment of quality of life, but also lifelong health care costs put a high burden on both the individual and society, reaching far beyond the neonatal period.

Despite advances in neonatal therapy, prophylactic and therapeutic means for management of BPD are scarce. Therefore, there is an urgent need to explore new therapeutic options, but also to adjust known therapeutic concepts in order to reduce pulmonary impairment in these vulnerable patients. 


\section{INNOVATION}

The results described in this thesis all bear the potential to improve pulmonary function of preterm infants by optimizing delivery room interventions leading to reduced lung injury. We have tested different innovative approaches to achieve this goal by

- testing technology to improve pharmacological therapy,

- applying existing procedures in a new environment to a new patient population,

- combining existing drug therapies to understand synergistic mechanisms, and

- testing an established pharmacological intervention in a new form of administration.

Using a unique translational large-animal model, this research paves the way to bring these approaches to the patient.

The results presented in this thesis are of interest for different groups. Patients and their parents will profit from improved short- and long-term outcome after premature birth. Survivors of preterm birth carry a lifelong health burden. Reducing lung injury can help to avoid pulmonary diseases in later childhood and adulthood associated with BPD, such as asthma or emphysema, and to avoid morbidities associated with BPD such as impaired neurocognitive development. In summary, BPD is associated with impaired quality of life, but also with a high socioeconomic burden. Research helping to improve the preterm lung has therefore positive effects for both the individual patient and for society.

However, a single gold standard strategy does not exist. A combination of pharmacological and technical interventions can be the key to solve this problem. Our results are therefore of interest for doctors and caretakers engaged in neonatal intensive care, by providing important information about how therapeutic strategies interact or can be combined in order to provide best possible care not only with respect to the acute effects, but also in the context of long-term morbidities of survivors of premature birth.

Furthermore, these results are of interest for developers of technical equipment and infrastructure, but also for pharmaceutical research and pharmaceutical companies. We expect that our results regarding different therapeutic strategies help to develop innovative, clinically applicable products already within the next years.

Our results regarding nebulization of surfactant further show that a close collaboration between pharmaceutical researchers and developers of technical equipment is a prerequisite for successful development of an innovative therapeutic strategy. Both surfactant replacement and nebulization per se are techniques established in the past decades. However, merging these two interventions depends on a variety of factors, as we could show in our experiments. Before nebulized surfactant can become a standard clinical application, translational research as performed in our model will help to identify factors interacting with treatment results and lead to optimized treatment protocols. Knowledge derived from our experiments forms the basis for clinical tests and helps to 
establish clinical protocols. As we used commercially available surfactant and technical equipment, a clinical protocol can be expected in the near future.

Our results regarding endotracheal administration of vitamin A are also promising regarding its clinical application. Our results identified the endotracheal route as a possible way to administer an innovative vitamin A preparation in parallel to surfactant replacement therapy. The obvious advantage of the endotracheal application is its delivery in close proximity to the target organ and its possible potential to increase the VA supply where it is needed most: at the alveolar septum. Our results contribute to the ongoing research for the optimal supplementation regime by adding a potentially new substance allowing for weight-targeted supplementation. In the context of our results regarding surfactant nebulization, our results bear the potential of vitamin A supplementation via the endotracheal route in a non-invasive manner. Further translational trials will enable us to improve means of vitamin A administration, while clinical trials and safety studies are warranted to help to investigate biological and clinical effects.

Our research also helps to extend the use of newly emerging techniques like closedloop ventilation in neonatal care. First, our results showed safety and feasibility of closed loop oxygen control in a delivery room setting. Second, we obtained data about how biological parameters such as oxygen saturation are influenced by applying technical solutions. These findings are also a prerequisite for clinical application, and are especially important for caretakers on the neonatal intensive care unit. Meeting oxygen saturation $\left(\mathrm{SpO}_{2}\right)$ targets by manually controlling the inspired fraction of oxygen is a difficult and time-consuming task. During routine $\mathrm{NICU}$ care, $\mathrm{SpO}_{2}$ target ranges are met during $50 \%$ of the time. Meeting $\mathrm{SpO}_{2}$ targets affects morbidity and mortality, depending on the target range chosen. Several clinical trials with different devices already have proven feasibility of automated closed loop $\mathrm{FiO}_{2}$ control in the $\mathrm{NICU}$ for various modes of ventilation, mixed populations, and by using different algorithms. In addition, an overall reduction of manual interventions during automated control was found in these studies, indicating facilitation of caretakers and nursing staff in clinical routine. The delivery of oxygen is also crucial in the delivery room setting. In this thesis, we could show that automated $\mathrm{FiO}_{2}$ control during mechanical ventilation was feasible in the delivery room setting with rapidly changing physiology of fetal transition to extrauterine life and during surfactant replacement therapy, and helped to avoid hyperoxia. In conclusion, a closed-loop device for control of inspired oxygen can be tailored to meet the patient's needs directly after birth and to support the caretakers in the delivery room the best possible way. The use of a commercially available device will allow easily the next step by launching a clinical trial. 

Acknowledgements 

It has been a long, challenging, but also inspiring way to finalize my thesis. However, it would not have been possible to achieve this goal without the people who guided, accompanied and supported this voyage. I want to cordially thank every one of you!

My particular gratitude goes to my promotors, Prof. Boris Kramer, Prof. Thorsten Orlikowsky, Prof. Steffen Kunzmann, and my co-promotor Dr. Tim Wolfs:

Dear Boris, I am still impressed how - already after our first meeting - you integrated me in your team without reservation or hesitation. You opened the world of research to an interested but cautious pediatrician, and inspired the idea of pursuing an academic career in neonatology. Your personal interest and the trust you set in me honours me. I am looking forward to our collaboration in the years to come.

Dear Thorsten, you offered me the opportunity to become a fellow neonatologist under your supervision, starting the most "intensive" time of my career at KIO8, the combined neonatal and pediatric intensive care unit. You supported my growing research interest and - by starting the research collaboration with Maastricht - gave me the unique chance to follow this interest.

Dear Steffen, our collaboration was always inspiring, and I remember a lot of good discussions, but also a great time testing Franconian or Scandinavian specialties. Thank you for entrusting your innovative ventilation project to me, which we will launch within a short time.

Dear Tim, you never hesitated to share your knowledge, your advice and your contacts to help me with my projects. Working with you combines seriousness whenever necessary - and great fun whenever possible.

I also want to thank the members of the reading commitee, Prof. Luc Zimmermann, Prof. Sidarto Bambang-Oetomo, Prof. Christoph Bührer, Prof. Edward Dompeling and Prof. Mark Spaanderman, for investing your time and your expertise in judging my thesis.

I thank my paranimfen, Frank Brinkmann and Daan Ophelders, not only for beeing here today, but also for beeing there beforehand: Frank, my best friend and brother-inarms, for always reassuring and supporting me; and Daan, my partner in crime, for your invaluable support during my projects.

This research would not have been possible without the help and support from a great research group in Maastricht: my co-PhD students Reint Jellema, Maria Nikiforou, Ruth Gussenhoven, Elke Kuypers, Monique Willems and Jip Beugels, your enthusiasm was inspiring, your support was priceless - I had a great time with you both during discussions and coffee break. Nico Kloosterboer, Lilian Kessels, Leon Jansen - the unbeatable lab team: thanks for always having a solution at hand!

I also thank all the people at Centrale Proefdier Voorziening in Maastricht: Joyce, Sanne, Petra and Huub, without your hard work, none of these projects would have ever been possible. And Saskia: thanks for your open door.

However, substantial part of this study could not have been performed without collaboration with some outstanding specialists in their field: Tom Goos, Rotterdam: testing your algorithm, "your baby" in our model was the beginning of a great and fruitful 
cooperation. Thanks for introducing me to the pleasure of IPA. I hope for new opportunities to work together. Holger Wahl, Homburg: your dedication is without example. Thank you for the invaluable discussions we had from the very first contact, about research - and about life as a neonatologist. Markus Fehrholz, Würzburg: thank you for the good and reliable collaboration. Peter Andriessen, Thilo Mohns and Hendrik Niemarkt, Veldhoven, and Prof. Irwin Reiss, Rotterdam, thank you for your valuable input.

I would not have been here without my former colleagues from Aachen, who taught me so much about neonatology and intensive care: Mark Schoberer, Sonja TrepelsKottek, Konrad Heimann, Peter Vaessen, Wolfgang Wicher. I also want to thank the team of KIO8 and all my other former colleagues at the Pediatrics department in Aachen: it has always been a pleasure, even when times were rough.

Special thanks to Hagen Ott: you paved my way into Pediatrics, and you were the first to spark my research interest.

And special thanks to Uli Pecks for our obstetrics-neonatology collaboration.

I also thank my new colleagues in Maastricht: Prof. Luc Zimmermann as head of department for offering me the opportunity to become a member of your team, and my fellow neonatologists Eduardo Villamor, Danilo Gavilanes, Twan Mulder, Pieter Degraeuwe, and Mark van der Hoeven, for welcoming me and supporting my first steps in an all new environment.

Finally, I am grateful to my family in friends:

Ich danke meiner Mutter für deine fortwährende liebevolle Unterstützung, meinem Vater, der mich in Gedanken immer leitet, und meiner Schwester Stefanie für deine Verlässlichkeit.

Ich danke allen meinen Freunden, die ich viel zu oft vernachlässige; dafür, dass ihr da seid, dass ihr ein offenes Ohr für mich habt, und dass ihr wisst wie es mir geht ohne zu fragen.

Meiner Frau Ira danke ich für alles! Besonders danke ich dir für deine Unterstützung, deine Geduld und deine Zuversicht. Was wäre ich ohne dich? 
Curriculum vitae 

Matthias Christian Hütten was born on 17th December 1976 in Düren, Germany, with a gestational age of 38 weeks and 4 days by an emergency C-section because of fetal distress.

He graduated from school, obtaining his "Abitur" from Burgau Gymnasium Düren in 1996. After accomplishing his military service as a medic, he started his studies in medicine in 1997 at the RWTH Aachen, Germany. After an elective in surgery and pediatric surgery at Glasgow University in 2003, he obtained his medical degree in summer 2004. The same year, he started his internship at the Department of Pediatrics at University Hospital Aachen, where he also had spent an elective term before. He received a broad pediatric training, including general pediatrics, oncology, neonatal and pediatric intensive care, and pediatric cardiology. During his training, he engaged in interdisciplinary consultation hours in Pediatric Dermatology.

In parallel, he obtained his medical doctorate (Dr. med.) at the Radiology Department in 2006 on the subject "Categorization of vascular endoprotheses by quantitative signal and artefact studies in vitro - potential of contrast-enhanced 3D magnetic resonance angiography in comparison with computed tomography". At the same time, he took his first steps in pediatric research, and published his first case reports.

After finishing his residency as pediatrician, he started his fellowship in neonatology at the Neonatal and Pediatric Intensive Care Unit at University Hospital Aachen. He extended his research interest by amongst others becoming the local investigator for the German Neonatal Network. He completed his fellowship in 2012 and registered as neonatologist. The same year, he successfully applied for a 2 year research grant from the medical faculty ("Rotationsprogramm"), which led him to the perinatal research group in Maastricht where he started as external PhD candidate. After returning to Aachen in 2014, he continued working as a neonatologist and in parallel finished his PhD studies. Since 2016, he fulfils a combined position as a neonatologist and researcher at Maastricht University Medical Center in a joint collaboration with the Pediatrics Department of Würzburg University, granted by Deutsche Forschungsgemeinschaft.

Today, he lives in Aachen together with his wife Ira whom he married in 2009. 

Publications 

Hütten MC, Wolfs TG, Kramer BW. Can the preterm lung recover from perinatal stress? Mol Cell Pediatr. 2016 Dec;3(1):15.

Hütten MC, Kuypers E, Ophelders DR, Nikiforou M, Jellema RK, Niemarkt HJ, Fuchs C, Tservistas M, Razetti R, Bianco F, Kramer BW. Nebulization of Poractant alfa via a vibrating membrane nebulizer in spontaneously breathing preterm lambs with binasal continuous positive pressure ventilation. Pediatr Res. 2015 Dec;78(6):664-9.

Hütten MC, Goos TG, Ophelders D, Nikiforou M, Kuypers E, Willems M, Niemarkt HJ, Dankelman J, Andriessen P, Mohns T, Reiss IK, Kramer BW. Fully automated predictive intelligent control of oxygenation (PRICO) in resuscitation and ventilation of preterm lambs. Pediatr Res. 2015 Dec;78(6):657-63.

Hütten MC, Kramer BW. Patterns and ethology of acute and chronic lung injury: insights from experimental evidence. Chin J Contemp Ped. 2014 May;16(5):448-59.

Fehrholz M, Hütten M, Kramer BW, Speer CP, Kunzmann S. Amplification of steroidmediated SP-B expression by physiological levels of caffeine. Am J Physiol Lung Cell Mol Physiol. 2014 Jan 1;306(1):L101-9.

Niemarkt HJ, Kuypers E, Jellema R, Ophelders D, Hütten M, Nikiforou M, Kribs A, Kramer BW. Effects of less-invasive surfactant administration on oxygenation, pulmonary surfactant distribution, and lung compliance in spontaneously breathing preterm lambs. Pediatr Res. 2014 Aug;76(2):166-70.

Vlassaks E, Nikiforou M, Strackx E, Hütten M, Bekers O, Gazzolo D, Li Volti G, MartinezMartinez P, Kramer BW, Gavilanes AW. Acute and chronic immunomodulatory changes in rat liver after fetal and perinatal asphyxia. J Dev Orig Health Dis. 2014 Apr;5(2):98-108.

Pecks U, Mohaupt MG, Hütten MC, Maass N, Rath W, Escher G. Cholesterol acceptor capacity is preserved by different mechanisms in preterm and term fetuses. Biochim Biophys Acta. 2014 Feb;1841(2):251-8.

Hütten MC, Heimann K, Schoberer M, Brintrup J, Wintgens J, Orlikowsky TW, Kohne E. Impaired point-of-care blood testing by photometry in a neonate with congenital cyanosis and haemoglobin F-M-Osaka. Cure\&Care Neonatal Intensive Care 2014; Feb 19

Hütten M, Kohne E, Yagmur E, Schaible T, Wenzl TG, Wagner N, Heimann K. Persisting cyanosis in a 4 month old infant with severe pneumonia and haemoglobin $M$. Klinische Pädiatrie 2009; 221:302-4

Hütten M, Heimann K, Baron JM, Wenzl TG, Merk HF, Ott H. Staphylococcal Scalded Skin Syndrome as a Harbinger of Late-onset Staphylococcal Septicaemia in a Premature Infant of Very Low Birth Weight. Acta Derm Venereol 2008 July;88(4):416-417 
Hütten M, Lassay L, Sachs B, Deutz P, Mertens R, Baron JM, Merk HF, Ott H. Successful topical treatment of Sorafenib-induced hand-foot skin reaction in a child with hepatocellular carcinoma. Pediatr Dermatol. 2009 May-Jun;26(3):349-50

Ott H, Hütten M, Baron JM, Merk HF, Fölster-Holst R. Neonatal and infantile erythrodermas. JDDG 2008;6:1070-1086

Hütten M, Baron JM, Ott H. Systemic retinoid therapy for severe acne infantum. Hautarzt 2008 Jun;59(6):454-7

Ott H, Hütten M, Häusler M, Megahed M, Baron JM. Collodium baby: nonbullous congenital ichthyosiform erythroderma. Hautarzt 2007 May; 58(5): 380, 382-3

Ott H, Lassay L, Hütten M, Megahed M, Merk H, Baron J. Phakomatosis pigmentovascularis Typ I/ a (Phakomatosis cesioflammea). Hautarzt 2006, 57:439-440 


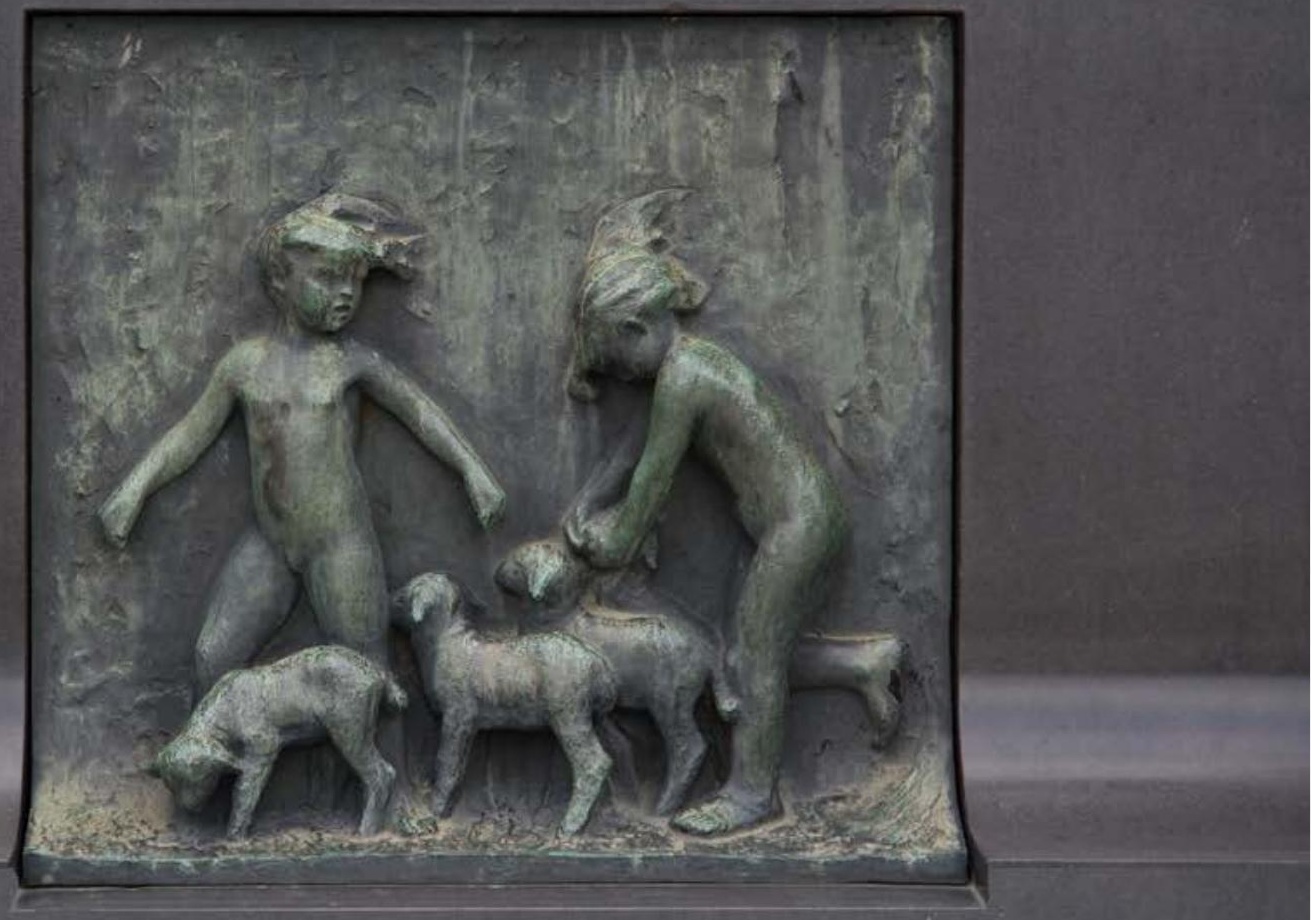

